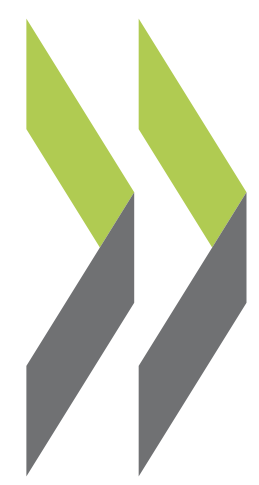

OECD Economics Department Working Papers No. 1049

Measuring Total Factor Productivity at the Firm Peter N. Gal Level using OECD-ORBIS 


\section{Unclassified}

ECO/WKP(2013)41

Organisation de Coopération et de Développement Économiques

Organisation for Economic Co-operation and Development

21-May-2013

ECONOMICS DEPARTMENT

English - Or. English

MEASURING TOTAL FACTOR PRODUCTIVITY AT THE FIRM LEVEL USING OECD-ORBIS

ECONOMICS DEPARTMENT WORKING PAPERS No. 1049

By Peter N. Gal

Complete document available in pdf format only.

All Economics Department Working Papers are available through OECD's Internet website at www.oecd.org/eco/Workingpapers

JT03339822

Complete document available on OLIS in its original format

This document and any map included herein are without prejudice to the status of or sovereignty over any territory, to the delimitation of international frontiers and boundaries and to the name of any territory, city or area. 


\section{ABSTRACT/RÉSUMÉ}

\section{Measuring Total Factor Productivity at the Firm Level using OECD-ORBIS}

Recent OECD research has utilised harmonised cross-country firm level data to explore the contribution of public policies to cross-country differences in productivity, innovation and resource allocation. This paper describes the steps taken to and the trade-offs involved in constructing firm-level total factor productivity (TFP) measures using ORBIS, a cross-country longitudinal firm-level database available from Bureau van Dijk, an electronic publishing firm. First, it shows that not all productivity measures can be calculated using readily available variables for all countries, and presents possible solutions to this problem by using imputations for certain variables. Second, it assesses the accuracy of these imputations on a set of countries where the available data in ORBIS provides a good coverage, for a wide range of TFP measures. Indeed, an extensive comparison of the actual and the imputed values of TFP for those countries suggests that TFP measures using imputations provide a reasonable approximation for the "true" values. Furthermore, to improve representativeness, resampling weights are constructed - which help correcting for the underrepresentation of small firms - while for the sake of international comparability, industry-level PPP conversions are also applied. Finally, as a plausibility check and to illustrate the potential of the database, the paper explores the country-composition of the globally most productive firms, the forces of convergence to the productivity frontier and the impact of regulation on productivity growth, in a sample of 18 OECD countries.

JEL classification codes: D24, O47, D22

Keywords: Productivity measurement; firm-level data; cross-country analysis

\section{$* * * * * * * * * * * *$ \\ Mesurer la productivité totale des facteurs au niveau de l'entreprise à l'aide de la base de données OCDE-ORBIS}

Des travaux récents de l'OCDE ont utilisé des données harmonisées d'entreprises des pays de l'OCDE afin d'étudier la contribution des politiques publiques aux différences entre pays dans la productivité, l'innovation et l'allocation des ressources. Ce document décrit les mesures prises pour et les compromis impliqués dans la construction des séries au niveau de l'entreprise, de la productivité totale des facteurs (PTF) à l'aide d'ORBIS, une base de données d'entreprises longitudinale mises à disposition par le Bureau van Dijk, une maison d'édition électronique. D'abord, il montre que toutes les mesures de la productivité ne peuvent être calculées à l'aide de variables facilement disponibles dans tous les pays, et présente d'éventuelles solutions à ce problème en utilisant des imputations pour certaines variables. Deuxièmement, il évalue l'exactitude de ces imputations sur un ensemble de pays où les données, disponibles dans ORBIS, offrent une bonne couverture pour un large éventail de mesures de la PTF. En effet, une comparaison approfondie des valeurs réelles et imputées des PTF pour ces pays suggère que les mesures de la PTF, utilisant des imputations, constituent une approximation raisonnable des valeurs «réelles». En outre, afin d'améliorer la représentativité, des poids de rééchantillonnage ont été construits - afin d'aider à corriger la sous-représentativité des petites entreprises - pour des raisons de comparabilité internationale, des conversions en PPP ont également été appliquées au niveau des industries. Enfin, comme contrôle de plausibilité et pour illustrer le potentiel de la base de données, ce document examine la composition pays des entreprises les plus productives au niveau mondial, les forces de convergence vers la frontière de la productivité et l'impact de la réglementation sur la croissance de la productivité, dans un échantillon de 18 pays de l'OCDE.

Codes JEL : D24, O47, D22

Mots clés : mesure de la productivité ; données sur les entreprises ; analyses comparatives entre pays

C) OECD (2013)

You can copy, download or print OECD content for your own use, and you can include excerpts from OECD publications, databases and multimedia products in your own documents, presentations, blogs, websites and teaching materials, provided that suitable acknowledgment of OECD as source and copyright owner is given. All requests for commercial use and translation rights should be submitted to rights@oecd.org. 


\section{Table of Contents}

1 Introduction $\quad 5$

2 Preparing ORBIS for TFP Measurement $\quad 7$

2.1 Detailed Outline and Key Concepts . . . . . . . . . . . . . . . . . . . 7

2.2 Coverage of ORBIS . . . . . . . . . . . . . . . . . . . . . 7

2.3 Extending the Coverage: Using Imputations . . . . . . . . . . . . . . . . . . . 9

2.4 Improving Representativeness . . . . . . . . . . . . . . . . . . . . . . . . . 10

2.5 Deflation and Internationally Comparable Price Levels ～. . . . . . . . . . . . . . . . . . 15

3 Productivity Measures and the Resulting TFP-Database 16

3.1 Details of the Resulting TFP Database . . . . . . . . . . . . . . . . . . . . . 18

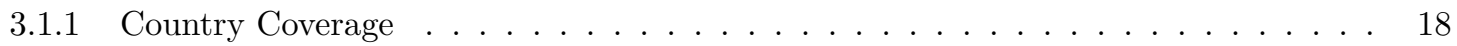

3.1 .2 Sectoral Coverage . . . . . . . . . . . . . . . . . . 20

3.1 .3 Industry Breakdown . . . . . . . . . . . . . . . . . . . . 20

3.1 .4 Filtering for Outliers . . . . . . . . . . . . . . . . . 20

3.1.5 Further Criteria for TFP Estimates . . . . . . . . . . . . . . . . 20

3.2 Qualifications and Limitations with TFP Measures from ORBIS . . . . . . . . . . . 21

4 Comparison of Productivity Measures $\quad 22$

4.1 Quality of Imputations for TFP Measures . . . . . . . . . . . . . . . . . . . . . . . 22

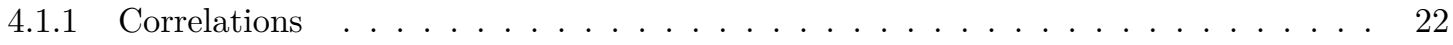

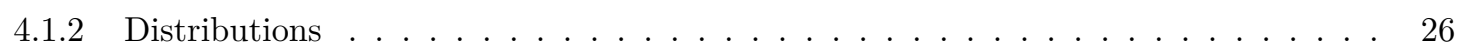

4.1 .3 Dispersion by Industry . . . . . . . . . . . . . . . . . . . . . . . . 29

4.2 Comparing Different Methodologies . . . . . . . . . . . . . . . . . . . . . . . 32

5 Empirical Illustrations $\quad 34$

5.1 Which Countries Make it to the Global Frontier? . . . . . . . . . . . . . . . . . . . . . 34

5.2 The Impact of Product Market Regulations on Productivity Growth . . . . . . . . . . . . 34

$\begin{array}{llr}6 & \text { Conclusions } & 37\end{array}$

A Estimating Capital Stock at the Firm Level $\quad 39$

B Deflation and Construction of Internationally Comparable Price Levels 39

B.1 Deflation - Price Indices over Time . . . . . . . . . . . . . . . . . . . . . . . . 39

B.2 Price-level Corrections across Countries . . . . . . . . . . . . . . . . . . 40

B.3 Combining Deflation over Time and across Countries . . . . . . . . . . . . . . . . . 40

$\begin{array}{ll}\text { C Balancing the SDBS Database } & 41\end{array}$

D Comparing Production Function Parameters $\quad 42$

$\begin{array}{ll}\text { E Additional Tables } & 43\end{array}$ 
ECO/WKP(2013)41

$\begin{array}{ll}\text { F Structure of the Resulting ORBIS-TFP Database } & 48\end{array}$

F.1 The File Structure $\ldots \ldots \ldots \ldots \ldots \ldots \ldots \ldots$

F.2 Variables in the Productivity Data Files . . . . . . . . . . . . . . 50

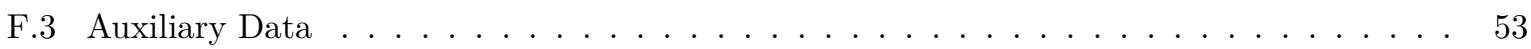

The statistical data for Israel are supplied by and under the responsibility of the relevant Israeli authorities. The use of such data by the OECD is without prejudice to the status of the Golan Heights, East Jerusalem and Israeli settlements in the West Bank under the terms of international law. 
$\mathrm{ECO} / \mathrm{WKP}(2013) 41$

\title{
Measuring Total Factor Productivity at the Firm Level using OECD-ORBIS
}

\author{
Peter N. Gal*
}

17th May 2013

\section{Introduction}

Important questions regarding the determinants of firm-level productivity, reallocation and firm dynamics can only be answered if one uses firm-level data. ${ }^{1}$ Similarly, analyses based on firm-level data have the potential to more credibly identify the effects of certain policies than studies using only aggregate (country or industry-level) data, and also to describe the mechanisms behind the policy effect in more detail. Accordingly, accessing high-quality data at the firm-level is a priority for many researchers in the field of firm behavior and productivity. While the most comprehensive firm-level data sources are usually held by national statistical agencies or tax offices (e.g. business registers, production surveys, tax returns), data access restrictions due to confidentiality concerns are key barriers in cross-country research. ${ }^{2}$ Reflecting these constraints, researchers often turn to commercial data sets, such as ORBIS, which contain more timely cross-country firm-level information and are more easily accessible than official, statistical sources. $^{3}$

Recent OECD research has utilized harmonized cross-country firm level data from ORBIS to explore the contribution of public policies to cross-country differences in productivity, innovation and resource allocation (see Andrews and Cingano, 2012; Andrews et al., 2013; Andrews and Criscuolo, 2013). Before this research was undertaken, however, considerable effort was put into improving the reliability and international comparability of these firm level data, and to address a number of complicated methodological issues - outlined below - that are posed by the design of the database. Against this backdrop, this paper describes these efforts as well as the specific trade-offs involved when using ORBIS for productivity

*OECD, Directorate for Science, Technology and Industry, Structural Policy Division (STI/SPD), Tinbergen Institute and VU University Amsterdam. E-mail: peter.gal@oecd.org or p.gal@vu.nl. This work was prepared during my stay at the OECD's Economics Department, at its Structural Policy Analysis Division (ECO/SPAD), and originated from discussions with Dan Andrews, Alain de Serres and Giuseppe Nicoletti. I thank them for the arrangements during my stay at $\mathrm{ECO} / \mathrm{SPAD}$, and also for detailed comments on drafts of the working paper. Further, I wish to thank also Benoit Arnaud, Jens Arnold, Chiara Criscuolo, Carlo Menon, Alexandros Ragoussis, Gueram Sargysan, Jean-Luc Schneider, Annamaria Tuske, Colin Webb and Zoltan Wolf for their help and suggestions. All remaining errors are my own. The views expressed here do not necessarily reflect those of the OECD or any of its member countries.

${ }^{1}$ For surveys on heterogeneity of productivity across firms and within sectors, see Bartelsman and Doms (2000) and Syverson (2011). For the aggregate productivity effects of the allocation of resources, see Hsieh and Klenow (2009) and Bartelsman et al. (2009). For a related literature on adjustment costs, see Hamermesh and Pfann (1996).

${ }^{2} \mathrm{~A}$ possible workaround to this problem is distributed microdata analysis, developed by Eric Bartelsman (see Bartelsman et al. (2005, 2009), among others) and has been also used by the studies in the OECD (Bartelsman et al., 2003 and more recently Biosca et al. (2012)). It involves a decentralized analysis by collecting micro-aggregated data (e.g. by industry, firm size, age, etc.) on a set of economic variables from official, national firm-level data sources, which are produced by standard program codes sent to local experts. Despite its main advantage of using the widest possible coverage and best data quality, its drawbacks, such as the inability to pool together the data set and run cross-country firm-level regressions in one site, the time-consuming nature of the procedure and publication lags, may make it a less attractive choice in some cases than using commercial data such as ORBIS.

3 The ORBIS version used in this report is the one downloaded by the OECD from the data vendor Bureau van Dijk in June 2011. For more details, see Section 2 and Gonnard and Ragoussis (2013). 
analysis. It builds on earlier work done by the OECD on the ownership structure and on cross-country harmonization (see Gonnard and Ragoussis, 2013), with a more specific focus on productivity measurement and on further improvements of international comparability (e.g. resampling and PPP-conversion). Moreover, it carries out a wide range of quality and robustness checks of the measures obtained, also highlighting various potential uses of the data. As such, it aims to serve as a reference for current and future firm-level analyses utilizing ORBIS either within or outside the OECD.

ORBIS brings together firm-level data from many countries, thus enabling firm-level cross-country analysis. Research using Amadeus, the earlier, "European-version" of ORBIS, has explored the effects of entry regulations on business dynamics (Klapper et al., 2006), product market regulations on productivity growth (Arnold et al., 2008) and corporate taxes on investment (Schwellnus and Arnold, 2008). In addition to the European countries included in Amadeus, ORBIS covers other, non-European countries, notably the United States, Japan and Korea, and some important emerging countries like Brazil, China and Russia. Despite this potential to extend firm-level analysis into a global context, ORBIS does not cover all variables equally well in all countries. Hence there is a trade-off between coverage (i.e. the set of firms and countries included in the analysis) and the type of analysis one can carry out. For instance, there are some limitations regarding data from the United States in ORBIS, but it is important - from the perspective of productivity analysis - that these issues are addressed, since firms from the United States are likely to be at the technological frontier in many industries.

More specifically, the key obstacle to including a wider coverage of countries in the analysis is the lack of availability of certain variables (value added and intermediate inputs) required for measuring total factor productivity (TFP). Hence, this paper - continuing along the lines of Gonnard and Ragoussis (2013) - examines the scope for imputing these variables, using both available information in ORBIS and from industry-level data sources (such as the STructural ANalysis Database of the OECD, or STAN). To assess the appropriateness of imputations, the paper compares TFP measures using imputed and non-imputed variables for those countries with the most comprehensive data coverage.

Across a variety of TFP measures, reasonably high correlations, in the range of 0.7-0.95, are observed between the measures based on actual values and on imputed values, for levels as well as growth rates. Thus, for instances where imputations are required (e.g. the United States), TFPs based on imputed values may serve as a reasonable approximation for the true unobserved values. This results in an increase in the cross country sample by about $60 \% .^{4}$

In order to correct for the underrepresentation of small firms, resampling weights are also constructed using the total number of employees for each country, industry, year and size-class from the OECD Structural and Demographic Business Statistics (SDBS). Moreover, for the sake of international comparability, industry-level PPP conversions are applied.

A final database of 24 countries results, once these procedures have been implemented. As a plausibility check and to illustrate the potential uses of the final database, the paper explores which countries are most successful in reaching the global productivity frontier, the forces of convergence to the frontier and the impact of product market regulation in upstream sectors on productivity growth.

Section 2 gives a detailed outline and defines key concepts, and explores (i) data coverage issues; (ii) the potential use of imputations to enhance coverage; (iii) the construction of resampling weights and (iv) price indices. Section 3 discusses measurement and estimation of TFP at the firm-level and a set of general practical issues for users of the data. Section 4 assesses the reliability of TFP measures based on imputed data. Using the constructed data set, Section 5 presents a few cross-country applications, and Section 6 offers some conclusive thoughts.

\footnotetext{
${ }^{4}$ For some countries (Japan and Korea, Norway, Switzerland and the United States), there are some qualifications, see Table 5 .
} 


\section{Preparing ORBIS for TFP Measurement}

\subsection{Detailed Outline and Key Concepts}

A harmonized cross-country database on firm-level TFP, inputs and output is a useful tool for analysing a range of policy questions related to productivity, and since TFP controls for both capital and labor (and possibly intermediate inputs), it has the potential to more accurately describe the efficiency with which resource are used than labor productivity. However, there is no single best measure for TFP, some variants may be better suited for certain purposes than others (see Section 3 and the Box therein on productivity measurement). Bearing in mind these differences, the paper takes four approaches to calculate TFP: the simplest Solow residual (least demanding in terms of data availability and quality), the superlative index (best suited for level comparisons), OLS-residuals (benchmark for production function based methods) and the recent Wooldridge (2009) method (most sophisticated but most demanding in terms of data).

Numerous steps are initially taken in order to enhance the international comparability of the measurement. First, to increase the country coverage as well as the number of firms within countries, imputation methods are introduced for certain variables (value added and intermediate inputs). Next, in order to correct for the typical under-representation of small firms, resampling weights are constructed using administrative sources. As final steps in the data preparation, to ensure comparability of productivity levels across countries and over time, currency conversion based on PPPs and deflation are discussed, and capital stocks are also constructed. The imputation methods and the resampling weights build on and refine earlier work by Gonnard and Ragoussis (2013).

In the next step, the actual estimation of TFP is carried out, for the 4 types of measures mentioned above, and labor productivity is also calculated as a benchmark. The details of these various measures and a general background on productivity measurement is given in Section 3, while the characteristics of the resulting database (country and industry coverage) as well as its limitations are also discussed. ${ }^{5}$ In turn, in order to test the quality of the imputations, detailed comparisons for productivity levels, growth rates and their within-industry distributions are carried out for the set of observations where non-imputed and imputed estimates are both available, for all the productivity measures considered (Section 4). To give a sense of the similarities and differences between the various productivity measurement approaches, they are also compared using non-imputed data.

Section 5 highlights some illustrations for the uses of the data, exploiting the wide cross-country coverage (up to 24 countries) and the enhanced international comparability both in terms of a more balanced coverage (by using resampling weights) and in productivity levels (by using industry level PPPs).

\subsection{Coverage of ORBIS}

For some countries in ORBIS, firm-level TFP measures can only be calculated if one is prepared to use additional information, i.e. imputations, for value added and in some cases, intermediate inputs (see Section 2.3 below for details on imputation methods). To illustrate the problem, Table 1 presents the number of available observations per country where labour productivity (using turnover as a measure of output) and the TFP measures can be constructed, for a selected group of countries. ${ }^{6}$ The table ranks countries according to the ratio of the number of observations where TFP can be measured and

\footnotetext{
${ }^{5}$ The data behind all the tables and calculations below concentrates on the market sector (NACE Rev 1.1 codes 15-74, i.e. all industries except agriculture, mining and public services) for the years 1999-2009, if not stated otherwise, and is derived from filtering out accounts referring to less than complete calendar years and consolidated accounts, using indicator variables prepared Gonnard and Ragoussis (2013).

${ }^{6}$ See Table E. 1 in the Appendix for the same table with all countries and with more sophisticated TFP measures, and also for 2002 in Table E.2.
} 
Table 1: Comparing the availability of variables for productivity measures for selected countries Number of observations by country and by productivity measures, for the years 1999-2009

\begin{tabular}{lrrrrrrr} 
Country & $\begin{array}{c}\text { Labor Prod. } \\
\text { using } \\
\text { Turnover }\end{array}$ & $\begin{array}{c}\text { TFP, non } \\
\text { imputed }\end{array}$ & $\begin{array}{c}\text { Non-imputed } \\
\text { TFP / } \\
\text { Labor } \\
\text { productivity }\end{array}$ & $\begin{array}{c}\text { TFP, internally } \\
\text { imputed }\end{array}$ & $\begin{array}{c}\text { Internally } \\
\text { imputed TFP / } \\
\text { Labor } \\
\text { productivity }\end{array}$ & $\begin{array}{c}\text { TFP, externally } \\
\text { imputed* }\end{array}$ & $\begin{array}{c}\text { Externally } \\
\text { imputed TFP / } \\
\text { Labor } \\
\text { productivity* }\end{array}$ \\
\hline ITA & $2,010,555$ & $1,748,028$ & $86.9 \%$ & $1,843,820$ & $91.7 \%$ & $1,944,699$ & $96.7 \%$ \\
ESP & $4,383,651$ & $3,675,628$ & $83.8 \%$ & $3,945,899$ & $90.0 \%$ & $4,222,513$ & $96.3 \%$ \\
GBR & 542,875 & 307,595 & $56.7 \%$ & 520,661 & $95.9 \%$ & 555,392 & $102.3 \%$ \\
FRA & $4,034,693$ & $1,556,908$ & $38.6 \%$ & $2,877,769$ & $71.3 \%$ & $3,134,441$ & $77.7 \%$ \\
JPN & $1,432,137$ & 460,628 & $32.2 \%$ & 515,308 & $36.0 \%$ & 867,051 & $60.5 \%$ \\
DEU & 917,426 & 171,408 & $18.7 \%$ & 170,734 & $18.6 \%$ & 174,980 & $19.1 \%$ \\
& & & & & & & \\
EST & 210,969 & 129 & $0.1 \%$ & 140,130 & $66.4 \%$ & 153,124 & $72.6 \%$ \\
GRC & 184,634 & 12 & $0.0 \%$ & 13 & $0.0 \%$ & 162,909 & $88.2 \%$ \\
USA & $19,392,887$ & 8 & $0.0 \%$ & 16 & $0.0 \%$ & 29,142 & $0.2 \%$ \\
\hline Total (OECD) & $42,282,214$ & $10,840,462$ & $25.6 \%$ & $15,167,998$ & $35.9 \%$ & $17,027,212$ & $40.3 \%$ \\
Mean (OECD) & $1,243,595$ & 318,837 & $25.1 \%$ & 446,118 & $59.2 \%$ & 500,800 & $75.1 \%$ \\
\hline
\end{tabular}

Note: Countries are ranked, in a decreasing order, by the coverage of the sample for which the simplest TFP-measure (e.g.

Solow residual) without imputations can be calculated. The selected country groups are intended to represent a broader set of countries with either good coverage (top three countries), poor coverage (bottom three countries) or medium coverage (group in the middle).

The columns referring to TFP show the number of observations where TFP can be calculated, using the following variables (ORBIS variables in parentheses): value added (ADDED_VALUE), capital (TANGIBLE_FIXED_ASSETS and DEPRECIATION), employment (EMPLOYEES). For details on the exact definition of internally imputed TFP-s (using only ORBIS) and externally imputed ones (using also industry-level, external sources), see Table 2.

The data underlying the table refers to the non-farm business sector (NACE Rev 1.1 codes 15-74) for the years 1999-2009, and is derived from filtering out accounts referring to less than complete calendar years and consolidated accounts, using indicator variables prepared by the Statistics Directorate (STD) of the OECD (Gonnard and Ragoussis, 2013). The actual numbers in the TFP database may be lower than here if price indices are not available or other data problems prevent the calculation of TFP measures for some firms. The United States, although giving close to 30 thousand potentially useful observations for productivity calculations, is still limited due to the low number of observations with profits (earnings before interest, taxes, depreciation and amortization, EBITDA) and capital. See more on this in Section 3.1.1.

* The numbers in the column External imputations assume administrative, industry level data on labour costs and employment is available in each industry and country.

the number of observations where turnover-based labour productivity can be calculated. Generally, most large European countries, such as Spain, Italy, and Great Britain, but also smaller ones like Sweden and Portugal, have data which are almost equally well suited for obtaining measures of either labour productivity or TFP. By contrast, for some English-speaking countries (United States, Canada) and small EU countries (Greece, Estonia), the variables required for TFP calculations are not readily available, or only in very small numbers.

For a number of countries, data coverage can be extended via the use of data imputations. The use of internal imputations, which exploits information on other firm-level variables in ORBIS, can significantly increase the number of firms included in the TFP sample for Estonia, France and Great Britain. However, for countries such as the United States and Greece, external imputation methods, i.e. those which rely in part on external, industry level data from OECD STAN, are required to yield an adequate number of observations (see Table 2 for details). The use of external imputation methods also increases the available number of firms for TFP measurement for a number of other countries (e.g. Denmark, Estonia, Japan, the Netherlands, Norway and Portugal, as shown in Table E.1 of the Appendix).

The last row of Table 1 shows that for the average OECD country in ORBIS, the coverage of the nonimputed TFP sample to the labour productivity sample is $25.1 \%$. The coverage increases to $59.2 \%$ and to $75.1 \%$ when using internal and external imputations, respectively. For the total number of observations in all OECD countries pooled (the row Total), the sample goes up from $25.6 \%$ to $35.9 \%$ and $40.3 \%$, 
respectively. $^{7}$

\subsection{Extending the Coverage: Using Imputations}

Table 2 contains information on the specific data requirements for productivity calculations and highlights which values can be imputed in order to extend the coverage. By far the most important variable where imputations help is value added. In some countries, it can be imputed internally, that is, using other variables in ORBIS. Based on correlations across levels and growth rates (see Gonnard and Ragoussis $(2013)$ ), the best substitute for value added $(V A)$ is simply using its definition based on factor incomes. This entails adding up factor incomes going to employees (total wage bill, $w L$, i.e. average labour $w$ cost times the number of employees $L$ ) and to capital owners (profits, $r K$, i.e. the rate of return $r$ times the capital stock $K)$ :

$$
V A=w L+r K
$$

The empirical counterparts to these variables in ORBIS are the COSTS_EMPLOYEES and EBITDA (Earnings Before Interest Taxes Depreciation and Amortisation), where the latter is a measure of profits (i.e. part of the income going to capital) $:^{8}$

$$
V A_{c s i t}^{\text {InternallyImputed }}=C O S T S_{-} E M P L O Y E E S_{c s i t}^{O R B I S}+E B I T D A_{c s i t}^{O R B I S},
$$

where subscripts $c, s, i, t$ denote country, sector, firm and time, respectively, and superscripts denote the source of the variable. Such internally imputed values are essentially alternative definitions of firm value added, and indeed show very high correlations for the log-levels ( 0.98 for an average country and year) and growth rates (around 0.8). ${ }^{9}$

However, in some countries (e.g. the United States), such internal imputations cannot be obtained because of missing labour cost data. ${ }^{10}$ Thus imputations based on external data are required (external imputation). Following Gonnard and Ragoussis (2013), labour costs are imputed by relying on industry level data from OECD STAN. First, by dividing the total labour cost by the number of employees per country, year and 2-digit industry using STAN aggregates, average labour cost per worker is obtained, $\bar{w}_{c s t}^{S T A N}$. This is then multiplied by the number of employees in ORBIS (firm-by-firm and year-by-year) in order to get imputed firm- and year specific labour costs. Finally, this imputed labour cost is added to observed EBITDA-s, resulting in value added measures which vary over firms and time:

$$
V A_{c s i t}^{\text {ExternallyImputed }}=\bar{w}_{c s t}^{S T A N} * L_{c s i t}^{O R B I S}+E B I T D A_{c s i t}^{O R B I S} .
$$

This approach is expected to work well if within-industry wage differentials are not too high. ${ }^{11}$ However, given the existence of a firm-size premium on wages (Brown and Medoff, 1989; Oi and Idson, 1999), primarily driven by large firms' higher productivity (Idson and Oi, 1999), it is important to address this potential problem. ${ }^{12}$ In order to capture part of the dispersion in wages, wage differentials from the

\footnotetext{
${ }^{7}$ Also, for some countries, TFP measures using imputations can actually bring more observations than using turnover based labour productivity, hence some ratios are larger than $100 \%$. Note also that these numbers are based on increases in the availability of variables needed for TFP calculations, but the availability of price indices or other data problems may constrain it. See Table 5 for more details on this issue.

${ }^{8}$ The other possibility for internally imputing value added - taking the difference between output and intermediate inputs (row Internally imputed value added (2) in Table 2) - does not help in practice, because intermediate inputs are only partially available in ORBIS. An important part of it, material costs are captured, but that is also not widely available.

${ }^{9}$ See the entries referring to internal imputations, shown in Table E.3 in the Appendix.

${ }^{10} \mathrm{It}$ is available only in about 10 cases, as mentioned also in Gonnard and Ragoussis (2013).

${ }^{11} \mathrm{~A}$ priori, however, it is difficult to say what is "too high" from the point of view of productivity estimates, hence it is an empirical issue.

${ }^{12}$ The early estimates for the United States concluded that "an employee working at a location with $\ln ($ employment) one standard deviation (which equals about two) above average can be expected to earn 6-15 percent more than a similar
} 
industry average are predicted using a quadratic function of firm size, profit per employee and age as explanatory variables, for each country and two digit industry. ${ }^{13}$ Such predictions, $\hat{w}_{c s i t}^{\text {ORIS }}{ }^{\text {, }}$, serve as the basis for imputing the firm-level wages in the second type, refined external imputations. Formally, they are constructed as follows:

$$
V A_{c s i t}^{\text {ExternallyImputed } 2}=\hat{w}_{c s i t}^{S T A N, O R B I S} * L_{c s i t}^{O R B I S}+E B I T D A_{c s i t}^{O R B I S},
$$

where $\hat{w}_{c s i t}^{S T A N, O R B I S}$ is the sum of the mean industry value of wages $\bar{w}_{c s t}^{S T A N}$ (taken from OECD STAN) and the predicted wage-differentials from the mean $\hat{w}_{c s i t}^{O R B I S}$ :

$$
\hat{w}_{c s i t}^{S T A N, O R B I S}=\bar{w}_{c s t}^{S T A N}+\hat{w}_{c s i t}^{O R B I S} .
$$

Correlations between the non-imputed and the externally imputed value added measures confirm that the approximation works well: correlations are higher than 0.9 for log-levels and around 0.6 for growth rates (see Table E.3 of the Appendix) and they improve when within-industry wage-differentials are taken into account. In Section 4.1, such correlations are calculated directly for the TFP measures, among other checks, in order to explore if TFP measures based on these value added imputations serve as a reasonable approximation for those measures which are based on non-imputed data. ${ }^{14}$

\subsection{Improving Representativeness}

Smaller and younger firms, especially in services sectors, are typically underrepresented in ORBIS. ${ }^{15}$ Therefore, in order to improve representativeness along the sectoral and firm size dimensions, sampling weights are introduced, using information on the number of employees in a country*industry*sizeclass*year cell from the OECD SDBS database, which is based on official sources and the full population of businesses. In short, a time-varying resampling weight is assigned to each firm, which is always greater or equal to one, making sure we do not lose firms which are already in ORBIS, but we only replicate them up to the point where the true size- and sectoral structure is achieved. ${ }^{16,17}$ The procedure is described in detail below.

employee at a location with $\ln ($ employment) one standard deviation below average." (Brown and Medoff, 1989). I am grateful to Chiara Criscuolo for calling attention to this issue.

${ }^{13}$ Profit per employee is a proxy in these regressions for labour productivity, as labour productivity is not always available when profits are. The age of the firm is constructed by subtracting the incorporation year from the actual year. The $R^{2}$-s from these predictions are in the range of 0.3-0.5, depending on the country (detailed results are available upon request). For countries where no labour cost data is available, a country with similar labour market institutions is chosen to estimate the coefficients which serve as the basis for predictions. For the United States, Great Britain is chosen, for Greece, two countries, Spain and Portugal are chosen, based on the proximity of employment protection legislation indicators described in Venn (2009).

${ }^{14}$ Of course, in any analysis, each firm and country should use the same type of imputation (only internal, only external or no imputation), i.e. it is not advisable to mix imputed and non-imputed TFP measures in a single regression, for instance. Accordingly, in the resulting ORBIS-TFP database, several TFP variables are constructed, each of them calculated in a uniform way: either using only non-imputed data or only the same type of imputation, for each firm-year observation (see more on this in the description of the final productivity database in Section $\mathrm{F}$ of the Appendix).

${ }^{15}$ See Table 3 below. For countries with low number of observations, this problem is relatively more important, and this issue can also hamper international comparability.

${ }^{16}$ In software packages such as Stata, some calculations (e.g. standard deviations, correlations, within-group percentiles and panel regressions) cannot be carried by using non-integer weights, but only integer ones - either as an option (e.g. fweight in Stata) or in a two-step manner, after expanding the database with respect to the weight variable.

${ }^{17}$ Experiments were also performed using the number of firms or establishments instead of the number of employees as the the match variable at each country*industry*size-class*year cell. The number of employees was chosen, because it avoids problems of some countries reporting the number of establishments (Japan, Korea) while the rest the number of firms (enterprises), and in ORBIS, the unit of observation is usually the firm (enterprise). An exception is the United States, where it is the plant (establishment) which is the unit of observation. This is taken into account by using only single-establishment firms from the United States database, as multi-establishment firms currently do not have revenue or sales information at this point in the OECD-ORBIS database. The Statistics Directorate (STD) of the OECD is working an a solution and in future versions of the database, large multinational firms from the United States may be included as well. Despite this issue, many large and highly productive firms are observed for the United States, see Tables 3 and 10. 
ECO/WKP(2013)41

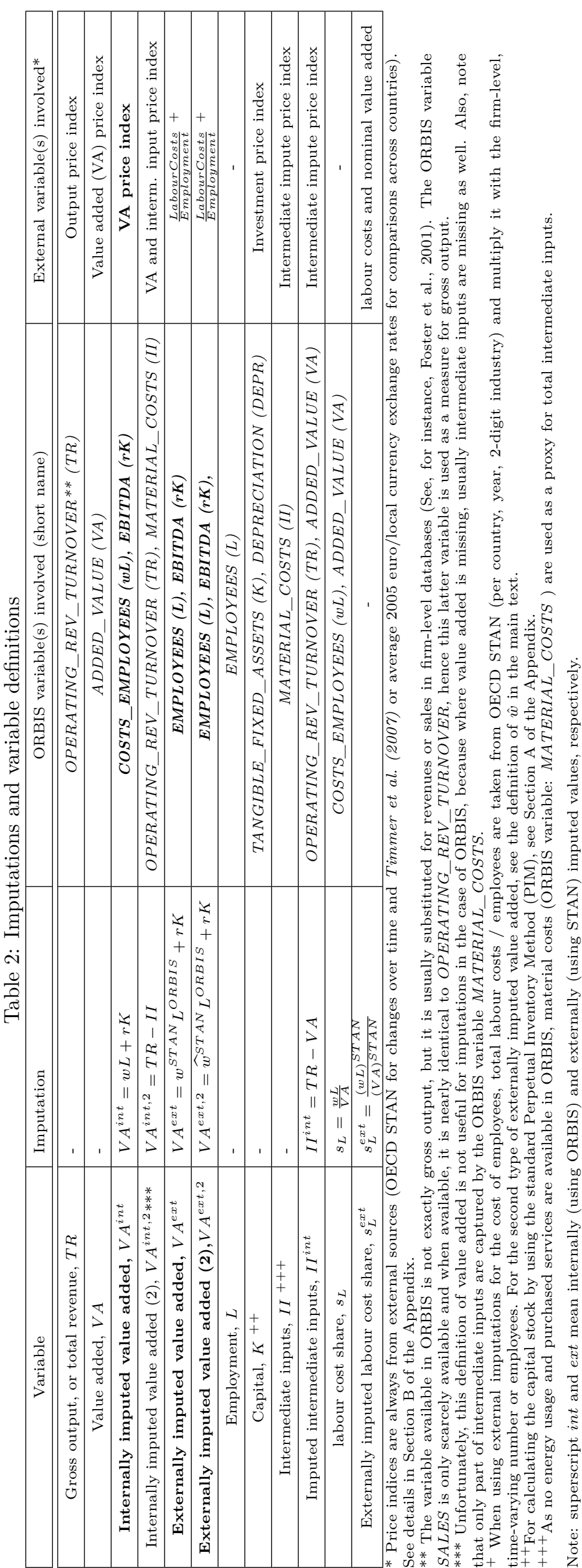


First, the latest available data from OECD.STAT is used on the number of employees, by country, industry, firm size class and year. Since the database is not balanced, i.e. not all dimensions are available for each country and year, some reasonable assumptions are needed to "fill up" the missing cells. For details, see Section $\mathrm{C}$ of the Appendix.

With the resulting SDBS database, the total number of employees, $L_{\text {cist }}^{S D B}$, is compared to what is obtained from ORBIS, $L_{\text {cist }}^{O R B I S}$, in the same country * industry * sizeclass * year cell (denoted by subscripts $c, i, s$, and $t$, respectively). In turn, a weight variable $w_{j t}$ is constructed for each firm $j$ and year $t$, such that the expected value of a weight will be determined by the ratio of SDBS to ORBIS employment within the cell:

$$
E\left(w_{j t}\right)=\frac{L_{\text {cist }}^{S D B S}}{L_{\text {cist }}^{\text {RBIS }}}
$$

where $L$ denotes the number of employees, and the expected value $E($.$) is taken over those firms which$ belong to the same $c, i, s$ cell, for each year $t$. The logic behind such a weighting variable is that it "scales up" ORBIS observations in a cell so that they match those observed in SDBS. ${ }^{18}$ Note that depending on the set of variables one focuses on, $L_{\text {cist }}^{\text {ORBIS }}$ may also differ, since the availability of those in ORBIS may differ. As a result, the resampling weights will differ, and thus in the constructed database, a corresponding resampling weight is calculated for each productivity measure. ${ }^{19}$

The amount of resampling needed per country and firm size class is shown in Table 3. As expected, the smallest firm-size classes tend to be more under-represented, whereas the larger ones usually do not need weights much larger than 1. Also, concentrating on the set of firms with more than 20 employees helps in getting a better coverage. In some countries (e.g. Belgium, Estonia, Finland, and Sweden), resampling weights are very close to one, across all firm sizes, indicating that the structure and coverage of ORBIS is close to that of the true population of firms. Regarding the industry dimension (shown in Table E.5 of the Appendix), the services sectors have on average 2-3 times higher resampling weights than manufacturing. Energy, water and gas, and also construction are the most well covered and need the least amount of scaling up.

Figure 2.1 shows the improvement of ORBIS in matching aggregate employment figures when using the constructed resampling-weights compared to the case when only unweighted employment is used. Furthermore, Figure 2.2 shows the average number of employees when the resampling weights are applied. The numbers look sensible given that large developed economies tend to have larger firms (Great Britain, United States), and Mediterranean European countries (Italy, Portugal, Spain) tend to have smaller firms.

\footnotetext{
${ }^{18}$ It is implemented by assigning a weight to each firm-year observation which is always greater or equal to one, making sure we do not lose firms which are already in ORBIS. For instance, if the ratio $\frac{L_{\text {cist }}^{S D S}}{L_{\text {cist }}^{O R I S}}$ is 1.3 , that is, SDBS employment is $30 \%$ higher than ORBIS employment, then the 30\% "extra" employment is obtained by drawing firms randomly from the pool of ORBIS firms, such that the "extra" firms will make up for the missing 30\%. In a different case, if the ratio is $\frac{L_{\text {cist }}^{S D S}}{L^{O R B I S}}$ is 2.3 , then all firms are taken at least twice and only the remaining extra $30 \%$ will be drawn randomly. In this way, it is ensured that the resampled pool is as close to the original ORBIS pool as possible, and the random selection plays only a limited role in changing the composition of firms within a cell.

Formally, the actual resampling weights $\widetilde{w}_{j t}$ are obtained by

$$
\widetilde{w}_{j t}=1+\left[\frac{L_{c i s t}^{S D B S}-L_{\text {cist }}^{O R B I S}}{L_{\text {cist }}^{O R B S}}\right]+z_{j t}
$$

where $z_{j t}$ is a Bernoulli distribution (having values of either zero or one: $z_{j t} \in\{0,1\}$ ) with expected value $\operatorname{Pr}\left(z_{j t}\right)=$ $\frac{\bmod \left(L_{\text {cist }}^{S D S}, L_{\text {cist }}^{O R B I S}\right)}{L_{\text {cist }}^{O R I S}}$ (i.e. the remainder of $\frac{L_{\text {cist }}^{S D B S}}{L_{\text {cist }}^{O R B S}}$, which is, in the example above, $30 \%$ ), and $[x]$ denotes the floor of $x$ (i.e. the largest integer which is smaller or equal to $x$ ). This construction will ensure that the actual values of $\widetilde{w}_{j t}$ will be integers and always larger or equal to one, as well as their sample mean in a given cell will be close to $\frac{L_{c i s t}^{S D S}}{L_{c i s t}^{O R I S}}$.

${ }^{19}$ This means that for a sample where one calculates, for instance, labour productivity, there should be different resampling weights than for a sample where an estimation based TFP is used.
} 
Table 3: The average of resampling weights by country and sizeclass (2005)

\begin{tabular}{lrrrrrr} 
& $1-9$ & $10-19$ & $20-49$ & $50-249$ & $250+$ & Average \\
\hline AUT & 397.4 & 165.1 & 45.7 & 6.8 & 2.4 & 79.0 \\
BEL & 1.7 & 1.3 & 1.2 & 1.2 & 1.2 & 1.6 \\
CZE & 6.4 & 2.8 & 1.8 & 1.3 & 1.2 & 4.2 \\
DEU & 333.6 & 126.8 & 26.5 & 5.1 & 1.9 & 46.6 \\
DNK & 3.5 & 3.3 & 2.8 & 2.3 & 2.1 & 3.3 \\
EST & 1.5 & 1.6 & 1.5 & 1.8 & 2.1 & 1.6 \\
ESP & 2.4 & 1.7 & 1.5 & 1.4 & 1.2 & 2.1 \\
FIN & 1.4 & 1.3 & 1.3 & 1.3 & 1.6 & 1.4 \\
FRA & 2.1 & 2.0 & 1.7 & 1.6 & 1.6 & 2.0 \\
GBR & 46.6 & 24.2 & 6.2 & 1.9 & 1.1 & 18.2 \\
FRC & 16.2 & 2.7 & 1.5 & 1.4 & 1.8 & 7.7 \\
HUN & 95.2 & 25.3 & 11.4 & 5.6 & 2.7 & 39.7 \\
ITA & 17.7 & 6.0 & 2.3 & 1.3 & 1.2 & 9.4 \\
JPN & 91.5 & 22.6 & 8.4 & 3.6 & 1.1 & 15.7 \\
KOR & 36.0 & 7.7 & 3.1 & & & 11.7 \\
NLD & 101.8 & 49.0 & 10.1 & 3.0 & 1.1 & 40.8 \\
NOR & 39.2 & 48.6 & 63.5 & 67.0 & 19.0 & 41.7 \\
POL & 118.1 & 8.4 & 5.5 & 2.8 & 2.4 & 20.9 \\
PRT & 446.1 & 100.7 & 37.3 & 11.2 & 4.2 & 147.5 \\
SWE & 1.2 & 1.4 & 1.4 & 1.6 & 1.6 & 1.2 \\
SVN & 3.9 & 2.3 & 1.7 & 1.3 & 1.1 & 3.1 \\
SVK & 8.5 & 4.0 & 1.9 & 1.4 & 1.2 & 4.4 \\
USA & 51439.6 & 13690.8 & 1734.0 & 861.1 & 25.7 & 5192.4 \\
\hline Average & 29.6 & 32.6 & 13.4 & 13.8 & 3.5 & 26.4
\end{tabular}

Entries show the average of the constructed resampling weights for 2005, for the Solow-residual TFP sample (using external imputations). For Korea and Japan, some industries and size classes are not contained in the SDBS database, hence no resampling weights can be constructed for those. Differences in coverage mainly reflect differences in the nature of data providers Bureau van Dijk (the vendor of ORBIS) has access to. See also Table E.5 in the Appendix. 

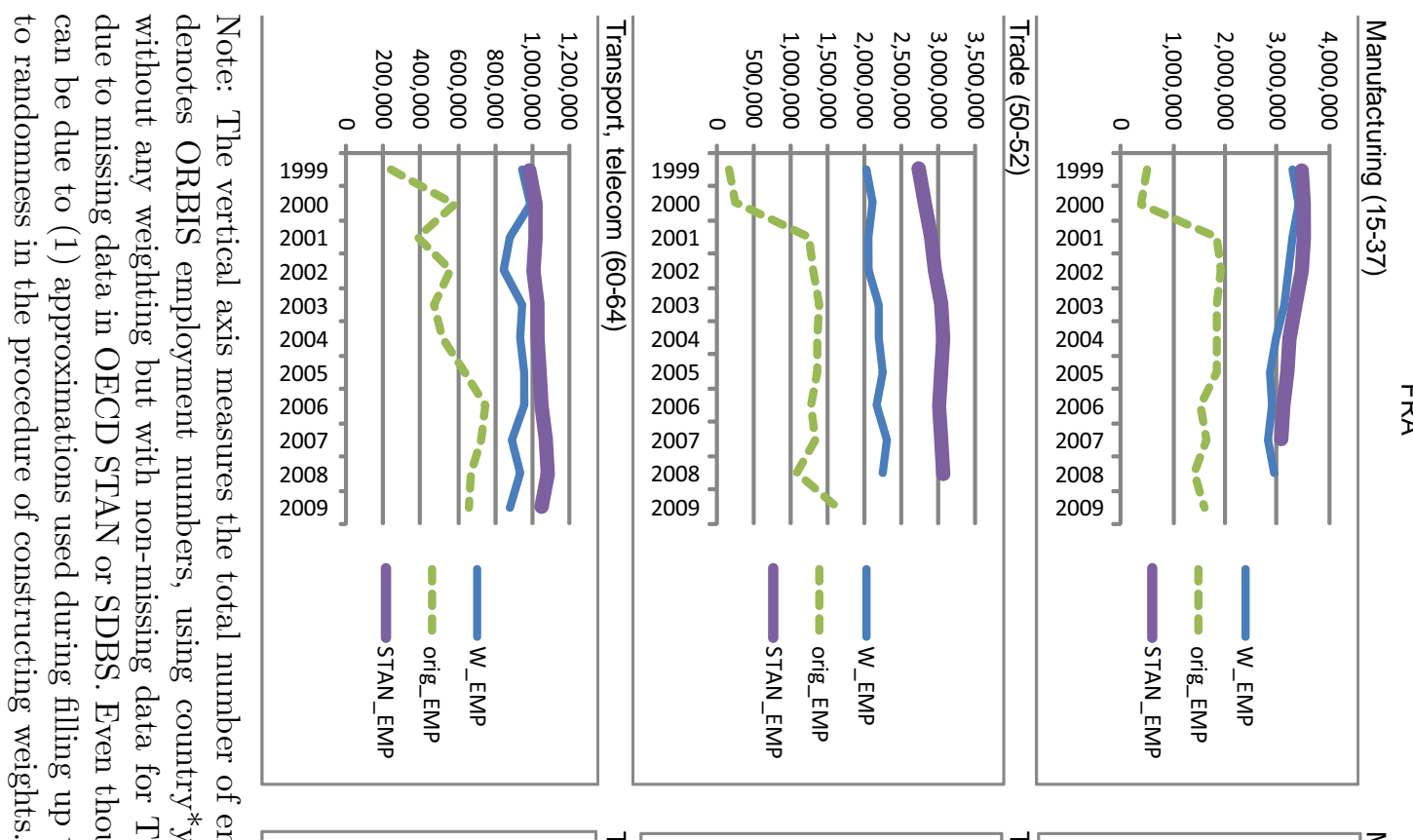

刃

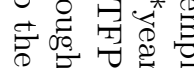

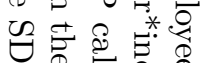

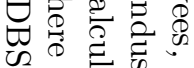

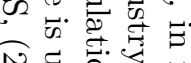

() क्ष क्षे

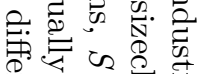

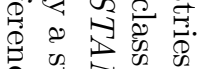

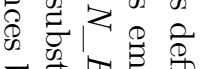

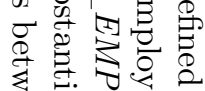

के

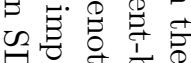

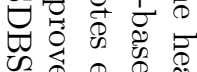

20

造密苛

里象递品

它总兽常

它苨品星

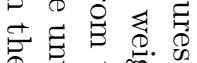

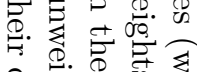

จ웅

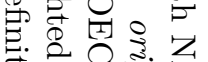

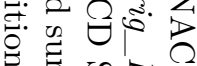

恄闻

舟 8

है द्यू

६

क्ष

艁

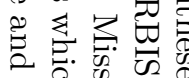

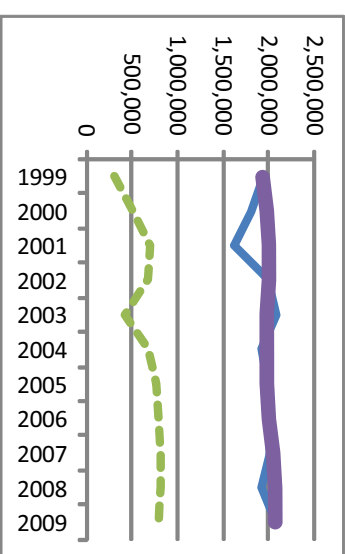

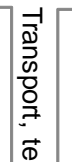
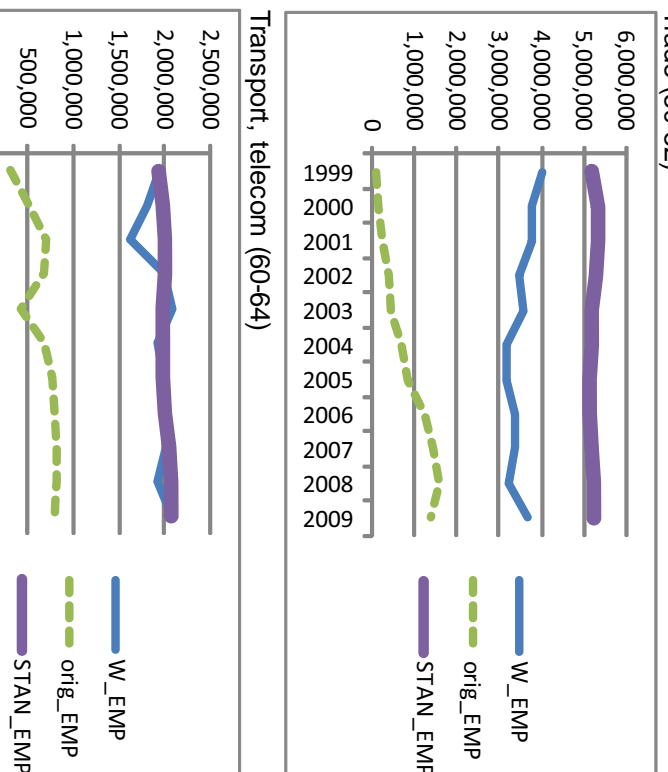

(ن) $\overrightarrow{5}:$.

它岩完 ₹

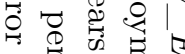

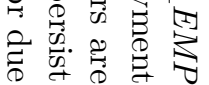
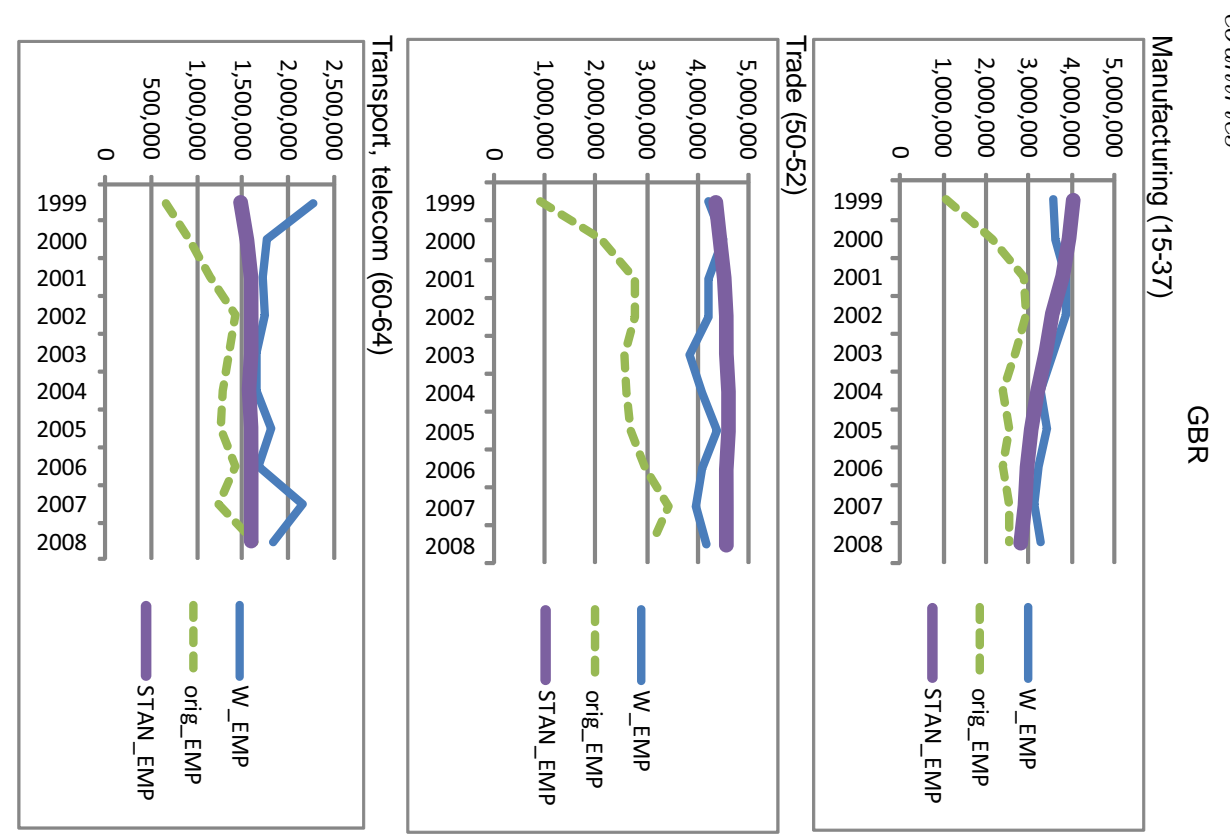
Figure 2.2: Mean employment in the TFP sample using resampling weights (2005)

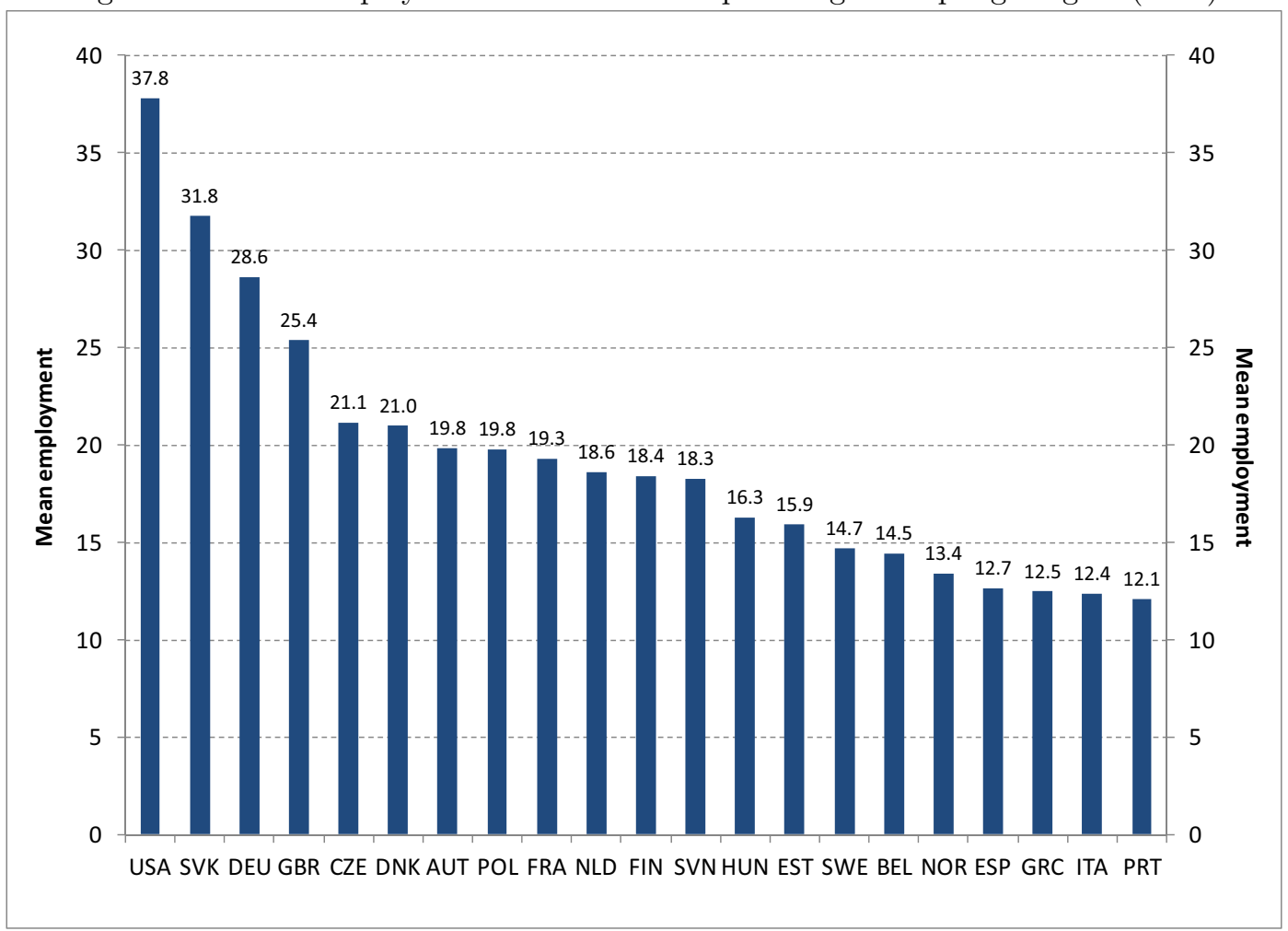

Note: Each column shows the weighted mean of employment for the sample where the simplest, Solowresidual type TFP measure (externally imputed) can be calculated, using the resampling weights described in Section 2.4. Japan and Korea are not included because the external database (SDBS) is not available for each of their sectors and firm size classes.

Finally, resampling implicitly assumes that firms in ORBIS within a specific country * industry * sizeclass * year cell are representative of the true population within that cell. ${ }^{20}$ This is the justification for random replication of firms within cells. Resampling can correct for potential discrepancies between the true population and the ORBIS sample only across those cells . However, it cannot correct for potential selection bias concerning the firms included in ORBIS along other dimensions (e.g. age, profitability) or across more detailed size classes and industries than the ones in SDBS. Consequently, analyses related to firm demographics (entry, exit, etc.) face limitations. ${ }^{21}$

\subsection{Deflation and Internationally Comparable Price Levels}

The procedure of obtaining price indices is fairly standard, by using external information (OECD STAN) on industry level deflators. For internationally comparable price levels, the procedure is a bit more elaborate, involving industry-level PPP estimates by Timmer et al. (2007). As they explain, there are a number of reasons why industry PPPs instead of aggregate ones are preferred when using them for industry- or firm-level productivity analysis. First, price levels may differ substantially across industries; a typical pattern is a higher services-goods price ratio in more developed countries, related to the Balassa-Samuelson effect. Second, aggregate PPPs are based on an expenditure approach rather than an output approach, and the former is less appropriate for productivity analysis as it excludes exports but includes imports, while it is also affected by transport costs, taxes and subsidies. Finally, the output of

\footnotetext{
${ }^{20}$ In other words, those firms which are observed in ORBIS - for instance, with less than 10 employees in retail trade (industry 51) in Germany - are representative of all firms in that cell.

${ }^{21}$ Where available, the incorporation date (INCORP_DATE) variable in ORBIS can be used to construct firm age and investigate firm behaviour upon entry, but young firms are underrepresented. Further, it is difficult to identify real exit.
} 
certain industries, typically used as intermediate goods in other industries, are not captured at all in an expenditure approach. Nevertheless, while the cross-country comparability is likely to improve by using industry PPPs, comparing TFP levels across industries - which is inherently difficult due to inherent differences in the production technologies - may still require caution, as measuring industry PPPs also involves some trade-offs. ${ }^{22}$

The database compiled by Timmer et al. (2007) is the most recent and most complete industry level PPP data, covering a wide range of countries and industries. Given that the comparison year used is relatively dated (1997), local currency deflators are applied changes to proxy more recent changes over time. To the extent that the cross-country and cross-industry differences (as cited above) are likely to be more important than the possible bias caused by not updating PPP estimates over time, this approach is more preferable to using aggregate PPPs. However, productivity analysis for the manufacturing sector may be carried out, as a robustness check, using market exchange rates, since price level differences in manufacturing are less pronounced due to the stronger exposure to international trade. For this reason, the constructed TFP database includes both PPP-adjusted and non-adjusted series. ${ }^{23}$ See the detailed description in Section B of the Appendix.

\section{Productivity Measures and the Resulting TFP-Database}

Having described the preparations necessary to extend the database and enhance international comparability, this section discusses the various productivity measures which are calculated using ORBIS, presents the country-coverage and other properties of the resulting data set, and highlights some caveats to keep in mind.

\section{Productivity Measures: Some Background}

Productivity, in its broadest interpretation, is meant to capture the efficiency by which inputs are turned into outputs (Hulten, 2001). From the least to the most data-demanding methodologies, an array of productivity measures which can be calculated using the OECD-ORBIS database are considered below (see Table 4).

\footnotetext{
${ }^{22}$ For more details, see Section B.2 of the Appendix.

${ }^{23}$ The latter converted at the market exchange rates in the middle of our sample (2005) in order to minimize the impact of short-run exchange rate fluctuations on productivity levels.
} 
Table 4: Productivity measures and possible imputations in ORBIS

\begin{tabular}{|c|c|c|c|}
\hline \multicolumn{2}{|c|}{ Productivity measures } & Definition & Possible imputations \\
\hline \multirow{2}{*}{ Labour productivity } & Based on gross output: $L P \_T R$ & $\log \left(\frac{T R}{L}\right)$ & No \\
\hline & Based on value added: $L P \_V A$ & $\log \left(\frac{V A}{L}\right)$ & For VA \\
\hline \multirow{2}{*}{ TFP: index-numbers } & Solow-residual: TFP_Solow* & $v a-\left(1-s_{L}\right) k-s_{L} l$ & For VA and $s_{L}, s_{K}$ \\
\hline & Superlative index:TFP_SupIn** & $\widetilde{v a}-\left(1-\alpha_{L}\right) \widetilde{k}-\alpha_{L} \widetilde{l}$ & For VA and and $\alpha_{L}$ \\
\hline \multirow{4}{*}{ TFP: prod.fn. based } & OLS: TFP_OLS*** & $v a-\widehat{\beta}_{K}^{O L S} k-\widehat{\beta}_{L}^{O L S} l$ & For VA \\
\hline & OLS fixed effects: $T F P \_O L S \_F E^{* * *}$ & $v a-\widehat{\beta}_{K}^{O L S \_}{ }^{F E} k-\widehat{\beta}_{L}^{O L S \_}{ }^{F E} l$ & For VA \\
\hline & Levinsohn-Petrin : TFP_LevPet*** & $v a-\widehat{\beta}_{K}^{L e v P e t} k-\widehat{\beta}_{L}^{L e v P e t} l$ & For $\mathrm{VA}$ and $\mathrm{II}^{+}$ \\
\hline & Wooldridge: TFP_Wooldridge*** & $v a-\widehat{\beta}_{K}^{W} k-\widehat{\beta}_{L}^{W} l$ & For $\mathrm{VA}$ and $\mathrm{II}^{+}$ \\
\hline
\end{tabular}

Note: Each measure varies over firm and time, though for simplicity, firm and time indices are not shown. Each variable with a monetary value (turnover, value added, capital) refers to real (i.e. deflated) values. Small letters $(v a, l, k)$ denote natural logarithms. For calculating the capital stock by using the standard Perpetual Inventory Method (PIM) using the book value of fixed tangible assets and depreciation, see Section A of the Appendix.

* $s_{L}$ denotes the share of value added which goes to labour, and calculated using the OECD STAN database, per country and industry or only per industry (both measures are calculated), as the ratio of labour costs to value added. ** $\alpha_{L}$ denotes the average of the labour share in the reference firm (taken to be the average across firms in the same country*industry) and the current firm. For each variable $X, \widetilde{X}$ is the difference from the current firm and the reference value, which is taken to be the industry average, over time and over firms, either per country or using cross-country average. In the ORBIS-TFP database, both measures are present, see Table F.1 in the Appendix.).

*** Estimation based measures assume that the production function parameters $\beta_{K}$ and $\beta_{L}$ are the same for a group of firms. In the calculations below using ORBIS, it is taken to be 2-digit industry groups (see Table E.4 for the exact breakdown).

+ II stands for intermediate inputs.

Gross output or total revenue $(T R)$ based labour productivity is the most widely available, thus serves as a benchmark for the analysis, but its most immediate problem is that it does not control for intermediate input usage. $^{1}$ In other words, a company with a lot of reselling activity (e.g. retail companies) will probably rank very high in this measure. Value added based labour productivity takes care of this problem, as value added itself is the difference between output (sales or revenue) and intermediate inputs (including resold goods, typical in retail trade).

However, labour productivity does not control for differences in capital intensity across firms. Therefore, in order to control for capital intensity, total factor productivity (TFP) should be calculated. Two broad types of TFP measures are considered: index number approaches and estimationbased methods.

Index number measures are easy to calculate: they simply relate output to a weighted sum of inputs. However, they usually assume constant returns to scale. ${ }^{2}$ Two widely used index numbers are the Solow-type and the Superlative-index ${ }^{3}$ measures. The latter takes a reference value (an average across firms or a specific firm, e.g. the median) and implicitly compares productivity levels to that reference value, and more importantly, it uses firm-level factor shares. As such, it is more prone to measurement error than the Solow measure (see Biesebroeck (2007)).

Turning to the estimation based TFP-s, the simplest benchmark is the residual from OLS regressions when estimating the production function, usually run industry-by-industry, on firm-level data. However, the coefficients obtained through this exercise are likely to be inconsistent and biased. In the case of the labour coefficient, for instance, firms with higher productivity hire more workers, but productivity is not directly observed during production function estimation, hence it enters the error term. Firms' behavior will thus introduce a positive correlation between the error term and the labour input, rendering standard OLS inconsistent and biased. ${ }^{4}$ Fixed effect estimators can only partially solve the problem since they take into account only a time-invariant firm-specific productivity effect and cannot control for cases where productivity shocks occur differently across firms and time. A well-known remedy for this problem was proposed by the semi-parametric approach 
of Olley and Pakes (1996), who took investment as a proxy variable for unobserved TFP. However, investment is proven to be a 'lumpy' variable and hence potentially a poor proxy for productivity. ${ }^{5}$ The method of Levinsohn and Petrin (2003) takes a similar approach, but instead of investment, it uses intermediate inputs as proxies. More recently, Wooldridge (2009) developed a technique which is built upon the Levinsohn and Petrin (2003) method, and it deals with the critique of Ackerberg et al. (2006) on a technical issue, while also being a quicker, one-step procedure with consistent standard errors without bootstrapping. ${ }^{6}$

Overall, the theoretical advantage of the estimation based methods (no assumption of constant returns to scale needed) comes at a cost: their data requirement is usually higher, both in terms of the number and the quality of the available variables. Finally, it is interesting to note that, irrespective of the sophistication of the measures, it has been shown that firms' productivity levels and dynamics vary a lot, even in narrowly defined industries (see Bartelsman and Doms (2000); Syverson (2011)). This issue will be addressed again below in Section 4.1 for the TFP measures from ORBIS.

\subsection{Details of the Resulting TFP Database}

\subsubsection{Country Coverage}

The potential set of countries for TFP measurement is contained in Tables E.1 and E.2 in the Appendix. What constrains this set is the availability of external data on price indices (large emerging economies like Brazil, China, India, Indonesia, Russia, South Africa and Turkey do not have 2-digit price indices, the same applies for Ireland and Chile) and/or industry PPPs for cross-country productivity level comparisons (Switzerland and Norway are not included in the ICOP industry PPP database). Nevertheless, for the latter two countries, by using local currencies or using 2005 euro/local currency exchange rates, productivity can also be calculated or estimated. Finally, countries with a very low number of observations in ORBIS (Australia, Canada, Chile, Iceland, Ireland, Israel, Mexico, New Zealand) are also omitted from the current calculations. A summary of the final set of countries included in the database is shown in Table 5

In the June 2011 version of OECD-ORBIS, data for the United States and Canada covers only singleestablishment firms. The Statistics Directorate of the OECD developed a procedure to aggregate the data of establishments which belong to the same firm into firm-level data, but this procedure was not carried out for variables required for value added based labour productivity calculations and TFP estimation

\footnotetext{
${ }^{1}$ Note that if one considers within-sector patterns, this is less of a problem, since firms in the same sector tend to have similar intensities of intermediate input usage. Revenue based labour productivity has been used, for instance, in Foster et al. (2001), where the authors mention that the results in terms of their decompositions and relative productivity are very similar across productivity measures.

${ }^{2}$ Note that usually all TFP measures assume that firms are price takers on both output and input markets and maximize profits. Also note that assumptions about returns to scale are not an important empirical issue, as the approaches below score relatively well irrespective of such assumptions according to the experiments on productivity measurement by Biesebroeck (2007).

${ }^{3}$ For the original idea, see Caves et al. (1982) and for applications, see Griffith et al. (2009) and Arnold et al. (2008).

${ }^{4}$ Endogeneity arises because as productivity changes, optimizing firms react by adjusting their inputs (right hand side variables), and productivity also directly affects value added (the left hand side variable).

${ }^{5}$ Their method also controls for selection bias. Selection can cause a problem since firms with higher capital stock will more easily weather negative productivity shocks and stay in the sample than others.

${ }^{6}$ The Ackerberg et al. (2006) critique basically refers to a collinearity problem: the joint inclusion of the nonparametric, polynomial terms of the variable input (e.g. labour) together with its structural coefficient in the production function makes the latter potentially unidentified.
} 
$\mathrm{ECO} / \mathrm{WKP}(2013) 41$

Table 5: The set of OECD countries in ORBIS and in the ORBIS-TFP database

\begin{tabular}{|c|c|c|c|c|}
\hline $\begin{array}{l}\text { Country } \\
\text { code }\end{array}$ & $\begin{array}{l}\text { In the TFP } \\
\text { sample }\end{array}$ & $\begin{array}{l}\text { In the Labour } \\
\text { Productivity } \\
\text { sample }\end{array}$ & $\begin{array}{c}\text { Resampling } \\
\text { weights }\end{array}$ & $\begin{array}{l}\text { Currency } \\
\text { conversion using } \\
\text { industry PPP-s* }\end{array}$ \\
\hline AUT & yes & yes & yes & yes \\
\hline AUS & no & no & & \\
\hline BEL & yes & yes & yes & yes \\
\hline CAN & no & no & & \\
\hline $\mathrm{CHE}$ & yes & yes & yes & no \\
\hline $\mathrm{CHL}$ & no & no & & \\
\hline CZE & yes & yes & yes & yes \\
\hline DEU & yes & yes & yes & yes \\
\hline DNK & yes & yes & yes & yes \\
\hline EST & yes & yes & yes & yes \\
\hline ESP & yes & yes & yes & yes \\
\hline FIN & yes & yes & yes & yes \\
\hline FRA & yes & yes & yes & yes \\
\hline GBR & yes & yes & yes & yes \\
\hline GRC & yes & yes & yes & yes \\
\hline HUN & yes & yes & yes & yes \\
\hline $\mathrm{IRL}$ & no & no & & \\
\hline ISR & no & no & & \\
\hline ISL & no & no & & \\
\hline ITA & yes & yes & yes & yes \\
\hline JPN & yes & yes & yes $^{+}$ & yes \\
\hline KOR & yes & yes & yes $^{+}$ & yes \\
\hline LUX & no & no & & \\
\hline MEX & no & no & & \\
\hline NLD & yes & yes & yes & yes \\
\hline NOR & yes & yes & yes & no \\
\hline NZD & no & no & & \\
\hline POL & yes & yes & yes & yes \\
\hline PRT & yes & yes & yes & yes \\
\hline SWE & yes & yes & yes & yes \\
\hline SVN & yes & yes & yes & yes \\
\hline SVK & yes & yes & yes & yes \\
\hline TUR & no & no & & \\
\hline USA & yes & yes & yes $^{++}$ & yes \\
\hline
\end{tabular}

${ }^{+}$Japan and Korea have resampling weights for only a subset of their firms due to the lack of complete availability of the SDBS database on which resampling is based.

${ }^{++}$For the United States, only single establishment firms are used from the ORBIS database. See more on this issue in Section 3.1.1.

* Switzerland and Norway are not in the industry-level ICOP PPP 1997 database which is used for the calculations. They are in the database which uses 2005 actual euro-local currency exchange rates as the conversion.

Countries not included in the productivity database have very few observations where variables for TFP are available (Australia, Canada, Chile, Iceland, Ireland, Israel, Luxembourg, Mexico, New Zealand, Turkey, see Tables E.1 and E.2 in the Appendix). Large emerging non-OECD countries (Brazil, China, India, Indonesia, Russia and South Africa) are excluded mainly due to the lack of price indices, but for some, there are few observations available for productivity calculations. Switzerland has no external, industry-level wage data (labour compensation) available in OECD STAN, hence it cannot be used with the externally imputed TFP calculations. 
(Tangible fixed assets and EBITDA are missing). ${ }^{24,25}$

\subsubsection{Sectoral Coverage}

Throughout the analysis, the coverage is always the non-farm business sector (i.e. without agriculture and public services). ${ }^{26}$ Productivity estimates for the financial sector (NACE Rev 1.1 codes 65-67) can be calculated in principle, but they should be treated with caution due to the inherent difficulties in measuring output. ${ }^{27}$

\subsubsection{Industry Breakdown}

It is not obvious at which level of industry breakdown homogeneity in the production function parameters can be safely assumed. More detailed, lower levels of aggregation are desirable, but the resulting reduction in sample size during industry-by-industry production function estimation might create problems, especially for small countries. While assuming homogeneity at the 2-digit industry level is generally considered a good compromise and is feasible in most industries and countries in ORBIS, it still yields a very low number of observations for certain country-industry pairs. In such cases, the EU-KLEMS industry classification is applied (O'Mahony and Timmer, 2009) ${ }^{28}$, which merges and treats together some 2-digit industries producing similar goods (e.g., in NACE Rev 1.1, Textiles (17), Wearing Apparel (18) and Leather and Footwear (19) are merged into one industry group (17-19).) See Table E.4 of the Appendix for more details.

\subsubsection{Filtering for Outliers}

By default, no outlier-filtering is implemented, but in principle, there are two possibilities:

1. Filtering observations before the computation / estimation, based on extreme levels of ratios $(K / L, M / Y$, etc.) and erratic movements $(d V A, d L)$ of inputs or output.

2. Filtering observations after the estimation, based on extreme levels and changes of productivity.

Both methods should be done by country and industry, that is, at the aggregation level at which

the estimations are run. The first type of filtering is probably more important for estimation based approaches, whereas the second technique provides a useful crosscheck for the results in any case. In the current version of the database, no such filtering is implemented, but the second type can be easily carried out using the available productivity estimates. ${ }^{29}$

\subsubsection{Further Criteria for TFP Estimates}

The following criteria is applied when using TFP estimates based on production functions:

\footnotetext{
${ }^{24} \mathrm{As}$ such, in the future, there may be scope for including additional, multi-establishment firms of these countries in the productivity calculations if the procedure is extended to these variables.

${ }^{25}$ The number of observations for each country, year and imputation type, for the Superlative Index measure, are contained in the TFP_Sample.xlsx file in the root directory of the TFP database.

${ }^{26}$ That is, industries 15-74 in the NACE industry classification Rev 1.1. Mining and quarrying is also excluded due to the low number of firms present in those industries in many countries.

${ }^{27}$ Note that to a lesser extent, this is also true for other business services, where output measurement is more problematic than in manufacturing sectors.

${ }^{28}$ In the core database, estimation based measures are calculated at the EU-KLEMS 2-digit industry group levels, and the index number approaches are calculated at the 2-digit industry levels.

${ }^{29}$ There is one exception though: as the Superlative Index measures seem particularly sensitive to imputations, in line with the findings in Biesebroeck (2007) about its sensitivity to measurement errors, a type of filtering method called Winsorisation is applied when constructing the expenditure shares needed for the calculations. This means that values in the extremes, i.e. outside some pre-defined top and bottom percentiles, are replaced by those top and bottom percentile values. In the current situation, the labour cost shares in the top and bottom 1 percent of observations are replaced by the 1st or the 99th percentile values, for extreme small and extreme large values, respectively, per industry (and per country, in the case of country-by-country reference values). This is a practice followed by recent studies using firm-level data (e.g. Sivadasan (2009); Gabaix (2011)).
} 
1. Within each country * industry group, at least 50 observations are required for the estimation.

2. Both the labour and capital coefficients need to be larger than zero.

In the few cases where these do not hold (typically, for small countries and with the more detailed industry breakdowns), values of estimation based TFP measures are left empty. ${ }^{30}$

\subsection{Qualifications and Limitations with TFP Measures from ORBIS}

The strength of the data set is that it allows users to compare many countries and industries throughout more than a decade, using standardized methodologies for firm-level TFP estimations. Nevertheless, a number of caveats should be kept in mind:

- Regarding the measurement of output, as in most other firm-level data sets, ORBIS does not contain firm-level price indices, hence only industry-level deflators can be used, following the best practice in the literature (see Section B of the Appendix for details). The disadvantage is that measured productivity differences within the same industry may also reflect differences in market power embodied in prices (Syverson, 2011).

- Regarding labour input, the database does not contain the number of hours worked, only the number of employees. It is also not possible to consider different types of workers (i.e. low skilled or high skilled) as there are no information on the characteristics of employees. This could in principle be circumvented by assuming that total labour costs are a measure of quality and intensity adjusted labour, but it is not always available. ${ }^{31}$ Also, total labour costs are directly influenced by changes in the regulatory environment (social security contributions, minimum wages, etc.). For this reason, only the number of employees is used as labour input, thus the productivity measures should be interpreted as also capturing labour quality and intensity (i.e. capacity utilization).

- The type of capital goods in ORBIS are differentiated only to the extent of being tangible and intangible, but there is no differentiation regarding the type of the asset (e.g. structures or equipment). In order to avoid conceptual difficulties in measuring and valuing intangibles, which are poorly reported in ORBIS, only data on total tangible fixed assets are used. Further, since only the stocks but not actual capital services are observed, measured productivity changes may capture changes in capacity utilization, similarly to the lack of available hours worked information in the case of labour input.

- Intermediate inputs are not differentiated across materials, energy and purchased services, only materials can be observed. ${ }^{32}$ The lack of availability of detailed intermediate inputs prevents the calculation of output based TFP-s using a more detailed production function (see final point below).

- Finally, in the resulting TFP-database, only value added based TFP measures are considered in order to minimise the potential problems related to the measurement of intermediate inputs, and output based measures are left out. ${ }^{33}$

\footnotetext{
${ }^{30}$ These results are available on request. Coefficients for further inspection are stored next to the database in separate files, see Section $\mathrm{F}$ of the Appendix on the structure of the database.

${ }^{31}$ In fact, the lack of availability of labour costs in some countries (notably, the United States) necessitates the use of external imputations, see Section 2.3

${ }^{32}$ Alternatively, intermediate inputs can be calculated as the difference between output (measured by turnover) and value added. This is the method used in the specifications with internal imputations.

${ }^{33}$ Output based measures estimate the production function as having production as output and capital, labour and intermediate input (preferably broken down by energy, purchased services and materials) as inputs. As such, they can better control for differences in the production structure across industries, but they require more information, and their aggregation is more complicated than those of value added based measures. On the relationship between the two measures, and on the unsettled issues regarding their relative merit, see the detailed description in OECD (2001).
} 


\section{Comparison of Productivity Measures}

This section explores two main issues for countries with either reasonably good data availability (Spain, Italy and Great Britain, in that order), or medium level data availability (France, Germany): (1) how well the productivity measures based on imputed data approximate the ones based on actual data, in terms of levels as well as growth rates, (2) do we get a distorted picture of within-industry productivity distributions when using imputations? Indeed, it is essential to check whether TFP measures using imputations still preserve a large part of the within-industry heterogeneity, since imputing firm-level values for the labour cost component of value added by relying partly on industry-level data can reduce the within-industry variation, both in value added and TFP.

The results of these analyses show that using internally imputed values give a very good approximation of actual values. Hence such imputations can be applied to increase sample size. External imputations, although less accurately approximating actual values, also work reasonably well. ${ }^{34}$

The relationship among productivity measures using different methodologies is also investigated. The measures considered are the Solow-residual and the superlative index, which are index-number based, and estimated measures based on OLS-residuals and on the recent semi-parametric approach by Wooldridge (2009). This analysis relies exclusively on non-imputed data and can potentially shed light on the extent to which the underlying assumptions behind these different methodologies result in different TFP values.

\subsection{Quality of Imputations for TFP Measures}

\subsubsection{Correlations}

Table 6 shows correlations of TFP measures based on imputations with those based on actual, nonimputed data, on the subset of firms where both can be calculated. As such, each entry in the table shows

$$
\operatorname{Corr}\left(\ln \left(T F P_{i t}^{\text {non-imputed }}\right), \ln \left(T F P_{i t}^{\text {imputed }}\right)\right)
$$

for the left panel, and

$$
\operatorname{Corr}\left(\Delta \ln \left(T F P_{i t}^{\text {non-impute } d}\right), \Delta \ln \left(T F P_{i t}^{\text {imputed }}\right)\right)
$$

for the right panel, where subscript $i$ refers to firms, $t$ refers to years, and $\Delta$ is the first difference operator. In order to isolate the time dimension, these correlations are computed for a particular year. In Table 6 , it is $t=2008 .^{35}$ A number of key findings emerge:

- First, the variation in the internal and the refined external imputations is very similar to the variation in the non-imputed values, with correlations around 0.8-0.9 for all types of productivity measures and for levels, and around 0.6-0.85 for growth rates, in the average of the five countries considered in the comparison. The refined external imputations perform consistently better than the non-refined ones, making the case for predicting wage differentials from the industry average (see equation 2.4). ${ }^{36}$

\footnotetext{
${ }^{34}$ Given the potential for more serious measurement problems with small firms' data for each of these exercises, estimates are constructed and comparisons are carried out both for all firms and for the subset of firms with 20 or more employees. On the structure of the resulting ORBIS-TFP database, see the description in Section F of the Appendix.

${ }^{35}$ Correlations for other years show very similar patterns and are available upon request.

${ }^{36}$ Note that for countries where labour costs are not observed at all (United States and Greece), predictions are based on regressions of within-industry wage differentials on firm characteristics in countries with similar labour market characteristics (for the United States, Great Britain is used, and for Greece, Spain and Portugal are used). These predictions hence may be less accurate than for the countries presented in this section. Nevertheless, correlations with external imputations not involving wage predictions serve as a lower bound for the correlation between the refined externally imputed values and the true unobserved values also for the United States and Greece, which stand at acceptable 0.7-0.8 for TFP levels and 0.6 for growth rates, the Superlative Index performing a bit worse than the others.
} 
- Second, external imputations yield the strongest relationship with non-imputed values for the Solowtype measure, both in levels and growth rates: on average, around 0.9 and 0.7 , respectively. The Superlative Index measure is somewhat less well captured $(0.8,0.7)$. Among estimation type measures, OLS gives a slightly closer match than Wooldridge, for which correlations between the growth rate show the lowest values (0.6 on average).

- These patterns are true for the subsample of firms with at least 20 employees as well as for the whole economy, or using simple correlations versus rank correlations. When using rank correlations, imputations for the Superlative Index measure tends to show a bit stronger relationship with the non-imputed values than just looking at simple correlations (see Table E.6 in Appendix). In addition, even though Table 6 is based on the whole market sector and for the year 2008, the patterns are preserved also when the comparisons are made sector-by-sector (Table 7) and in other years. 
Table 6: The effect of imputations on productivity measures: correlation between non-imputed, internally and externally imputed measures, for selected countries

\begin{tabular}{|c|c|c|c|c|c|c|c|c|c|}
\hline \multicolumn{10}{|c|}{ ESP } \\
\hline \multicolumn{5}{|c|}{ Correlations for $\operatorname{In}(\mathrm{TFP})$} & \multicolumn{5}{|c|}{ Correlations for TFP growth } \\
\hline TFP measures & Solow & Sup.In. & OLS & Wooldridge & TFP measures & Solow & Sup.In. & OLS & Wooldridge \\
\hline imputation types & 098 & & 0.97 & 0.97 & imputation types & & ० 9? & & 0.95 \\
\hline $\begin{array}{l}\text { internal } \\
\text { external }\end{array}$ & $\begin{array}{l}0.98 \\
0.85\end{array}$ & $\begin{array}{l}0.90 \\
0.54\end{array}$ & 0.75 & 0.78 & $\begin{array}{l}\text { Internal } \\
\text { external }\end{array}$ & $\begin{array}{l}0.97 \\
0.81\end{array}$ & $\begin{array}{l}0.92 \\
0.69\end{array}$ & $\begin{array}{l}0.95 \\
0.74\end{array}$ & $\begin{array}{l}0.95 \\
0.71\end{array}$ \\
\hline external, refined & 0.92 & 0.77 & 0.84 & 0.85 & external, refined & 0.88 & 0.82 & 0.78 & 0.71 \\
\hline \multicolumn{10}{|c|}{ ITA } \\
\hline \multicolumn{5}{|c|}{ Correlations for $\ln (\mathrm{TFP})$} & \multicolumn{5}{|c|}{ Correlations for TFP growth } \\
\hline TFP measures & Solow & Sup.In. & OLS & Wooldridge & TFP measures & Solow & Sup.In. & OLS & Wooldridge \\
\hline imputation types & & & & & imputation types & & & & \\
\hline internal & 0.98 & 0.91 & 0.96 & 0.96 & internal & 0.90 & 0.87 & 0.89 & 0.87 \\
\hline external & 0.86 & 0.66 & 0.72 & 0.73 & external & 0.72 & 0.64 & 0.64 & 0.56 \\
\hline external, refined & 0.92 & 0.82 & 0.82 & 0.80 & external, refined & 0.80 & 0.73 & 0.71 & 0.60 \\
\hline \multicolumn{10}{|c|}{ GBR * } \\
\hline \multicolumn{5}{|c|}{ Correlations for $\operatorname{In}($ TFP) } & \multicolumn{5}{|c|}{ Correlations for TFP growth } \\
\hline TFP measures & Solow & Sup.In. & OLS & Wooldridge & TFP measures & Solow & Sup.In. & OLS & Wooldridge \\
\hline imputation types & & & & & imputation types & & & & \\
\hline internal & 0.96 & 0.76 & 0.92 & & internal & 0.84 & 0.79 & 0.81 & \\
\hline external & 0.82 & 0.52 & 0.70 & & external & 0.64 & 0.49 & 0.58 & \\
\hline external, refined & 0.90 & 0.76 & 0.86 & & external, refined & 0.69 & 0.67 & 0.61 & \\
\hline \multicolumn{10}{|c|}{ FRA } \\
\hline \multicolumn{5}{|c|}{ Correlations for $\operatorname{In}(\mathrm{TFP})$} & \multicolumn{5}{|c|}{ Correlations for TFP growth } \\
\hline TFP measures & Solow & Sup.In. & OLS & Wooldridge & TFP measures & Solow & Sup.In. & OLS & Wooldridge \\
\hline imputation typFR & & & & & imputation typFR & & & & \\
\hline internal & 0.93 & 0.81 & 0.90 & 0.88 & internal & 0.78 & 0.73 & 0.76 & 0.74 \\
\hline external & 0.74 & 0.52 & 0.62 & 0.68 & external & 0.52 & 0.46 & 0.48 & 0.44 \\
\hline external, refined & 0.84 & 0.68 & 0.76 & 0.78 & external, refined & 0.60 & 0.53 & 0.52 & 0.45 \\
\hline \multicolumn{10}{|c|}{ DEU } \\
\hline \multicolumn{5}{|c|}{ Correlations for $\ln ($ TFP $)$} & \multicolumn{5}{|c|}{ Correlations for TFP growth } \\
\hline TFP measures & Solow & Sup.In. & OLS & Wooldridge & TFP measures & Solow & Sup.In. & OLS & Wooldridge \\
\hline imputation types & & & & & imputation types & & & & \\
\hline internal & 0.95 & 0.81 & 0.90 & 0.89 & internal & 0.81 & 0.77 & 0.77 & 0.76 \\
\hline external & 0.88 & 0.71 & 0.67 & 0.72 & external & 0.60 & 0.59 & 0.58 & 0.56 \\
\hline external, refined & 0.94 & 0.84 & 0.86 & 0.79 & external, refined & 0.69 & 0.68 & 0.64 & 0.61 \\
\hline \multicolumn{10}{|c|}{ Average over ESP, ITA, GBR, FRA, DEU } \\
\hline \multicolumn{5}{|c|}{ Correlations for $\ln (\mathrm{TFP})$} & \multicolumn{5}{|c|}{ Correlations for TFP growth } \\
\hline TFP measures & Solow & Sup.In. & OLS & Wooldridge & TFP measures & Solow & Sup.In. & OLS & Wooldridge \\
\hline imputation types & & & & & imputation types & & & & \\
\hline internal & 0.96 & 0.84 & 0.93 & 0.92 & internal & 0.86 & 0.82 & 0.84 & 0.83 \\
\hline external & 0.83 & 0.59 & 0.69 & 0.73 & external & 0.66 & 0.57 & 0.60 & 0.56 \\
\hline external, refined & 0.90 & 0.78 & 0.83 & 0.81 & external, refined & 0.73 & 0.69 & 0.65 & 0.59 \\
\hline
\end{tabular}

Note: correlations are based for observations in the year 2008, according to equations 4.1 and 4.2 , for the non-farm business sector. TFP growth is defined as the first differences of $\ln (T F P)$. For a description of the imputation types, see Section 2.3. *For Great Britain, non-imputed Wooldridge type estimates are not available due to the lack of the availability of proxies for intermediate inputs. 
Table 7: The effect of imputations on productivity measures: correlation between non-imputed, internally and externally imputed measures, by sectors

\begin{tabular}{|c|c|c|c|c|c|c|c|c|c|}
\hline \multicolumn{10}{|c|}{ Manutacturıng } \\
\hline \multicolumn{5}{|c|}{ Correlations for $\ln ($ TFP) } & \multicolumn{5}{|c|}{ Correlations for TFP growth } \\
\hline TFP measures & Solow & Sup.In. & OLS & Wooldridge & TFP measures & Solow & Sup.In. & OLS & Wooldridge \\
\hline imputation types & & & & & imputation types & & & & \\
\hline internal & 0.96 & 0.85 & 0.94 & 0.94 & internal & 0.85 & 0.82 & 0.84 & 0.84 \\
\hline external & 0.82 & 0.59 & 0.77 & 0.78 & external & 0.63 & 0.58 & 0.61 & 0.58 \\
\hline external, refined & 0.89 & 0.73 & 0.86 & 0.82 & external, refined & 0.68 & 0.64 & 0.64 & 0.58 \\
\hline \multicolumn{10}{|c|}{ Construction } \\
\hline \multicolumn{5}{|c|}{ Correlations for $\ln ($ TFP) } & \multicolumn{5}{|c|}{ Correlations for TFP growth } \\
\hline TFP measures & Solow & Sup.In. & OLS & Wooldridge & TFP measures & Solow & Sup.In. & OLS & Wooldridge \\
\hline imputation types & & & & & imputation types & & & & \\
\hline internal & 0.97 & 0.93 & 0.95 & 0.96 & internal & 0.91 & 0.90 & 0.90 & 0.91 \\
\hline external & 0.79 & 0.62 & 0.68 & 0.73 & external & 0.70 & 0.63 & 0.66 & 0.60 \\
\hline external, refined & 0.86 & 0.73 & 0.76 & 0.79 & external, refined & 0.78 & 0.69 & 0.70 & 0.60 \\
\hline \multicolumn{10}{|c|}{ Trade } \\
\hline \multicolumn{5}{|c|}{ Correlations for $\ln ($ TFP) } & \multicolumn{5}{|c|}{ Correlations for TFP growth } \\
\hline TFP measures & Solow & Sup.In. & OLS & Wooldridge & TFP measures & Solow & Sup.In. & OLS & Wooldridge \\
\hline imputation types & & & & & imputation types & & & & \\
\hline internal & 0.96 & 0.89 & 0.95 & 0.90 & internal & 0.87 & 0.84 & 0.85 & 0.85 \\
\hline external & 0.81 & 0.63 & 0.73 & 0.62 & external & 0.67 & 0.61 & 0.63 & 0.61 \\
\hline external, refined & 0.90 & 0.79 & 0.84 & 0.77 & external, refined & 0.76 & 0.70 & 0.68 & 0.70 \\
\hline \multicolumn{10}{|c|}{ Other business services } \\
\hline \multicolumn{5}{|c|}{ Correlations for $\ln (\mathrm{TFP})$} & \multicolumn{5}{|c|}{ Correlations for TFP growth } \\
\hline TFP measures & Solow & Sup.In. & OLS & Wooldridge & TFP measures & Solow & Sup.In. & OLS & Wooldridge \\
\hline imputation types & & & & & imputation types & & & & \\
\hline internal & 0.95 & 0.81 & 0.89 & 0.89 & internal & 0.84 & 0.77 & 0.80 & 0.78 \\
\hline external & 0.83 & 0.58 & 0.66 & 0.68 & external & 0.67 & 0.55 & 0.60 & 0.54 \\
\hline external, refined & 0.91 & 0.80 & 0.78 & 0.78 & external, refined & 0.76 & 0.71 & 0.66 & 0.59 \\
\hline
\end{tabular}

Note: correlations are based for observations in the year 2008, according to equations 4.1 and 4.2 . Each value is an average of the values obtained in the five selected countries (Spain, Italy and Great Britain, France, Germany). TFP growth is defined as the first differences of $\ln (T F P)$. For a description of the imputation types, see Section 2.3. 


\subsubsection{Distributions}

Having established that the correlations are high between imputed and non-imputed productivity measures, it is also interesting to check whether they give the same overall shape of cross-sectional distribution. Figures 4.1 and 4.2 compare the within-industry distribution of firm-level TFP-s using non-imputed and imputed values for Spain, for levels and growth rates, respectively, for four types of productivity measures. Internal imputations present a nearly identical picture for productivity levels, irrespective of the measures used. External imputations perform the best for the Wooldridge and the Solow type measures. For growth rates, the relationship is less tight, there is clearly less dispersion in the imputed values (i.e. there are more small changes). Nevertheless, a large amount of the variation is well preserved. Further, in order to see more precisely whether lower dispersion may interfere with cross-country, cross-industry analyses, the next section analyses this issue more closely. 
Figure 4.1: Comparing imputed and non-imputed TFP distributions for Spain: productivity levels

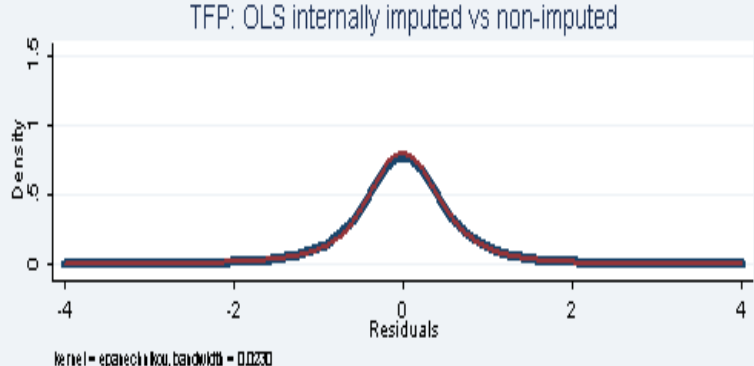

TFP: W internally imputed vs non-imputed

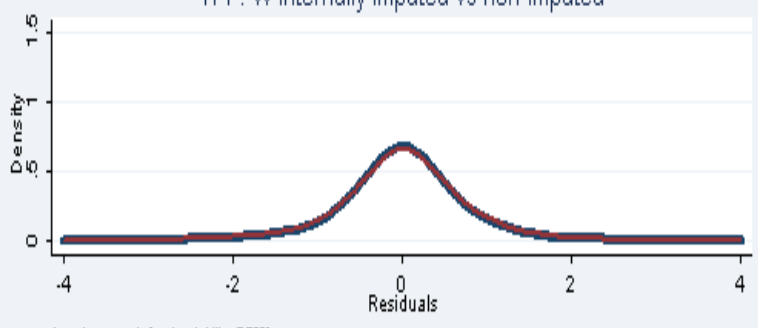

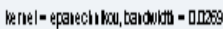

TFP: Supln internally imputed vs non-imputed

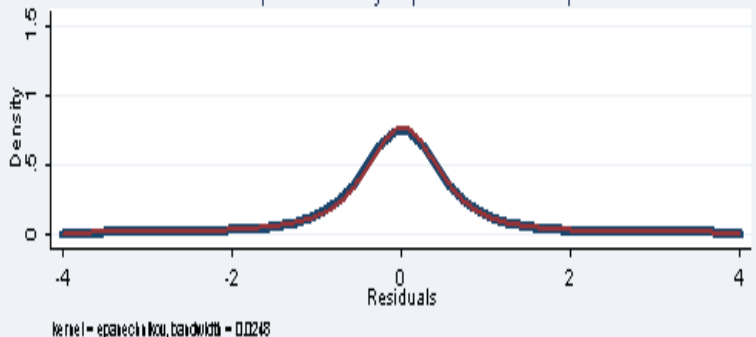

TFP: Solow_W internally imputed vs non-imputed

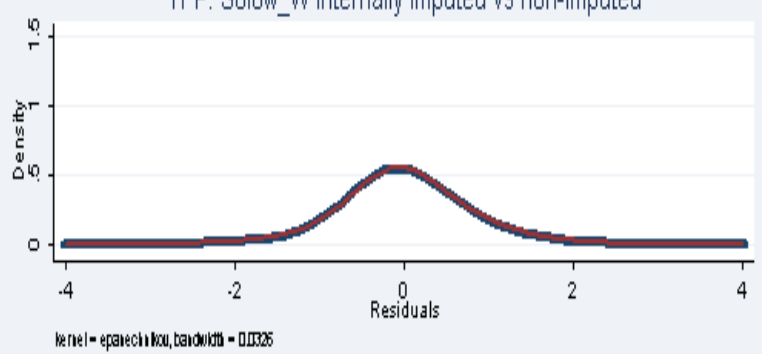

TFP: OLS externally imputed vs non-imputed

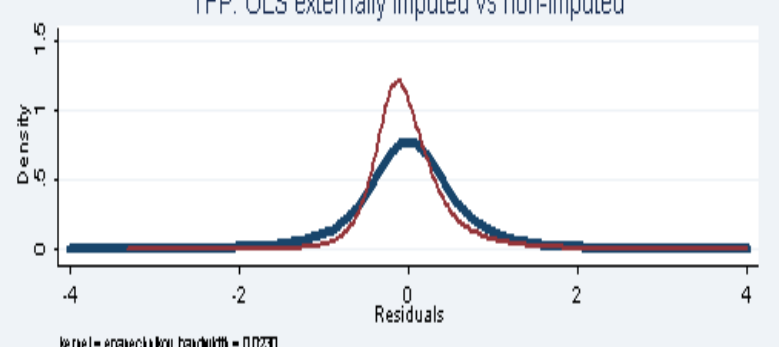

TFP: Wexternally imputed vs non-imputed

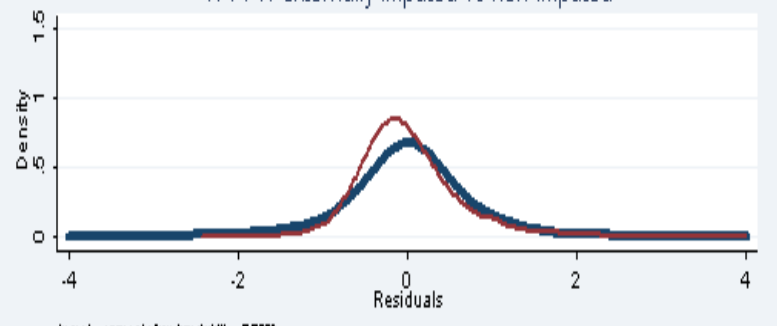

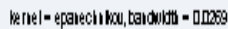

TFP: Supln externally imputed vs non-imputed

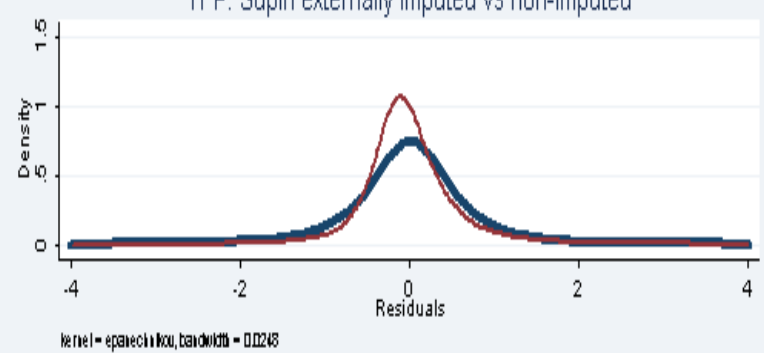

TFP: Solow_ W externally imputed vs non-imputed

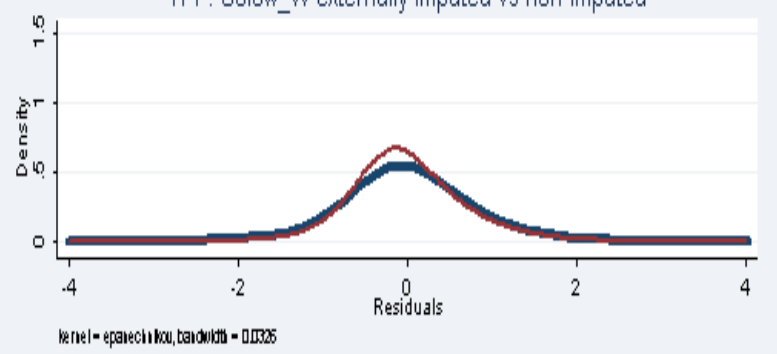

Note: Figures show kernel densities of within-industry and year $\ln (T F P)$ distributions, that is, after controlling for industry * year effects. $O L S$ and $W$ stand for OLS and Wooldridge production function estimation based measures, SupIn and Solow_ $W$ stands for Superlative index and Solow-residual type measures. The thick lines indicate the values using no imputations, and the thin ones indicate the ones based on imputations (left panel: internal, right panel: refined external). For each productivity measure, the sample where the densities are shown is the joint sample where both imputed and non-imputed values are available. 
Figure 4.2: Comparing imputed and non-imputed TFP distributions for Spain: productivity growth

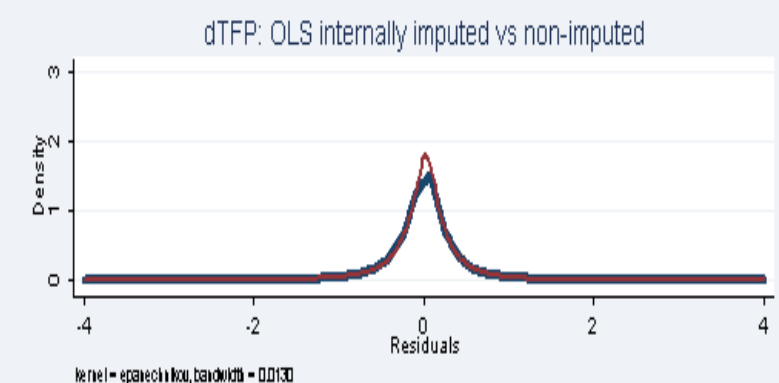

dTFP: W internally imputed vs non-imputed

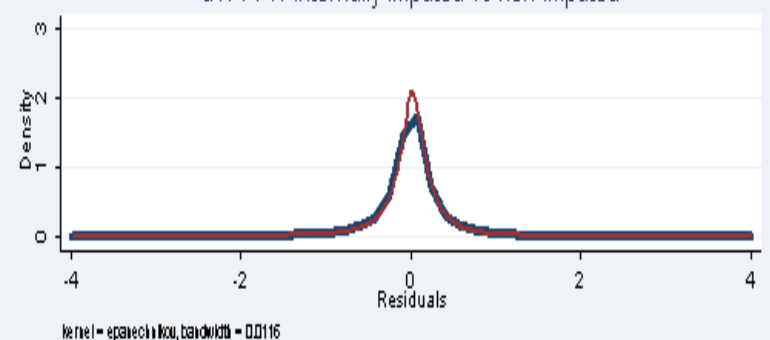

dTFP: Supln internally imputed vs non-imputed

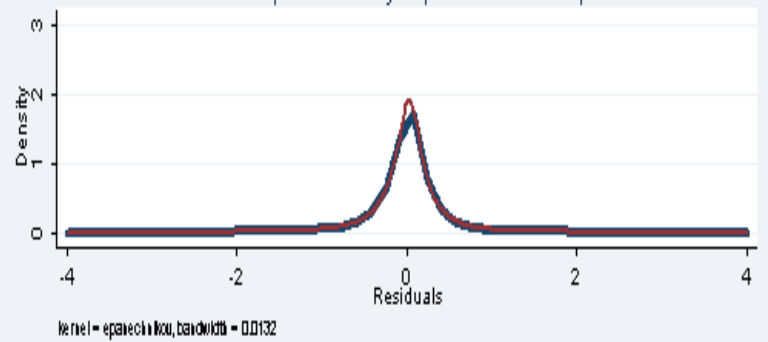

dTFP: Solow_ W internally imputed vs non-imputed

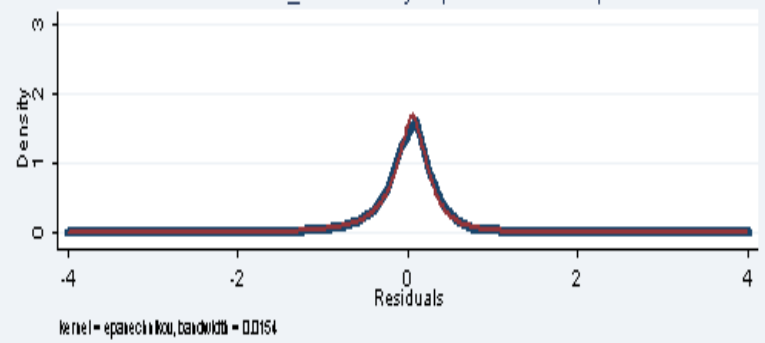

dTFP: OLS externally imputed vs non-imputed

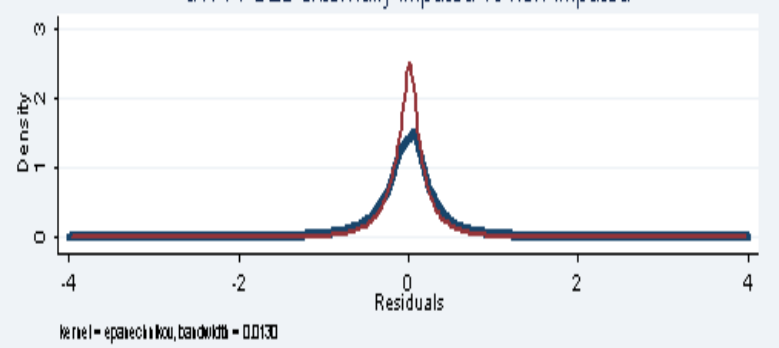

dTFP: Wexternally imputed vs non-imputed

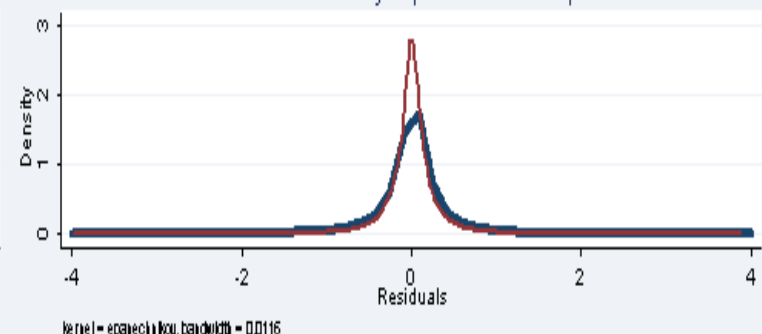

dTFP: Supln externally imputed vs non-imputed

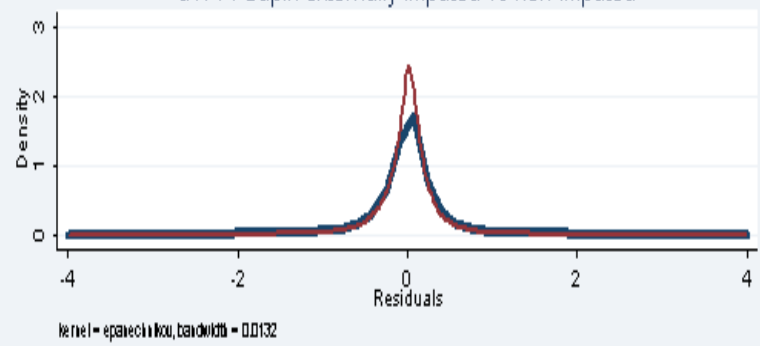

dTFP: Solow_ W externally imputed vs non-imputed

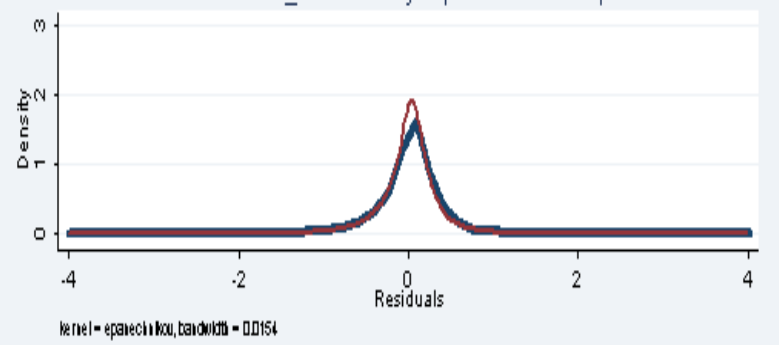

Note: Figures show kernel densities of within-industry and year $\Delta \ln (T F P)$ distributions, that is, firmlevel TFP growth, after controlling for industry* year effects. $O L S$ and $W$ stand for OLS and Wooldridge production function estimation based measures, SupIn and Solow_ $W$ stands for Superlative index and Solow-residual type measures. The thick lines indicate the values using no imputations, and the thin ones indicate the ones based on imputations (left panel: internal, right panel: refined external). For each productivity measure, the sample where the densities are shown is the joint sample where both imputed and non-imputed values are available. 


\subsubsection{Dispersion by Industry}

As noted above in the Box on Productivity Measures, a key stylized fact from firm-level empirical studies is that productivity is widely dispersed even within narrowly defined industries. A large observed dispersion may indicate that there is a large room for aggregate productivity increases by re-allocating resources from the less to the more productive firms (see Hsieh and Klenow, 2009). At the same time, a wider range of outcomes may indicate a greater degree of experimentation and learning by doing (see Bartelsman et al., 2010). For these reasons, it is important to check how differences in dispersion are preserved when TFP measures based on imputed data are used.

Table 8 summarizes some key statistics on dispersion for selected countries and for the measures based on production function estimations, comparing imputed and non-imputed measures. Dispersion is calculated as the difference between the 90th and the 10th percentile of log TFP (see Syverson, 2011). The key lesson from the results based on our five selected countries in Table 8 is that dispersion levels are lower for the externally imputed values (on average, 0.99 for OLS, 1.45 for Wooldridge) than for the nonimputed (OLS: 1.31, Wooldridge: 1.55) or internally imputed values (OLS: 1.35, Wooldridge: 1.74). This is clearly driven by the fact that part of the within-industry dispersion in productivity is not captured when using external values for the average labour costs. The pattern is similar across all five selected countries, and the differences are in the range of $0.3-0.4 \mathrm{log}$ points for each country for OLS measures and 0.2-0.3 for the Wooldridge measure. For illustrative purposes, the dispersion levels by industry are shown for Spain on Figure 4.3. ${ }^{37}$ Note that the range of values is plausible in light of the reported values in Syverson (2004) (in the range of 0.65-1), using business register data for the United States and finer (four-digit) industry aggregation than what is done here (2-digit or higher).

However, the correlation across industries between the dispersions of the imputed and non-imputed values are quite high (around 0.9, see again Table 8, the lines with Corr.). Such high values mean that the relative differences in dispersion remain very well preserved across industries. ${ }^{38}$ This result is potentially important for researchers interested in using ORBIS to explore issues related to firm-level heterogeneity.

\footnotetext{
${ }^{37}$ Looking at Figure 4.3 for Spain, it is also interesting to note the differences across industries in the productivity dispersions (the patterns are quite similar in the other countries as well). First, industries with the highest productivity dispersion are energy (water and gas) transport and management (industries 40 and 41), telecommunications (64) and other business services (70-74). It is not clear what may stand behind such large dispersions of those sectors. Second, industries with the lowest dispersions are usually characterised by a high degree of homogeneity (wood processing, 20; metallic products, 27-28) or relatively strong competition (construction, 45; hotels and catering, 55). These results may warrant further exploration, as the literature is not quite settled on the reasons behind and implications of within industry TFP-dispersions.

${ }^{38}$ This pattern holds also for the restricted sample which contains only firms with at least 20 employees, although correlations are somewhat lower.
} 


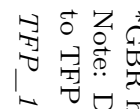

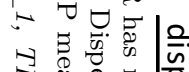

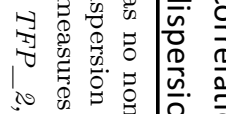

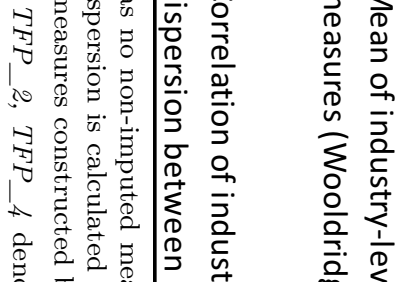

若

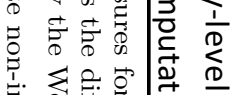

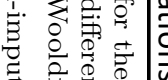

के

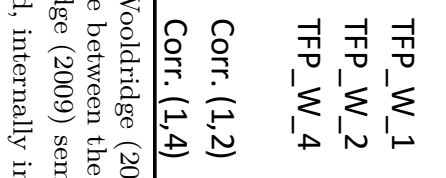

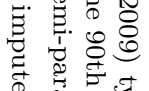

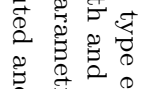

它

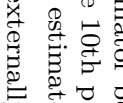

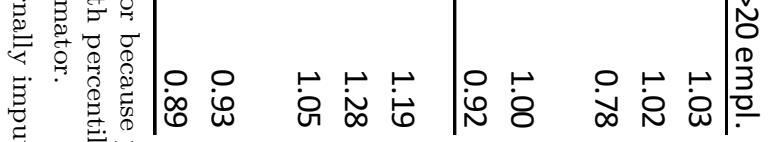

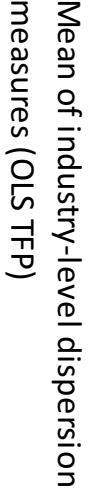

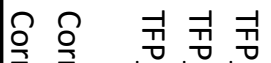

点

'

$\stackrel{2}{=}$

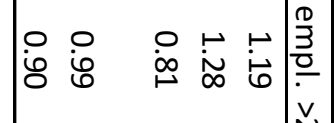

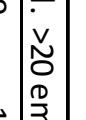

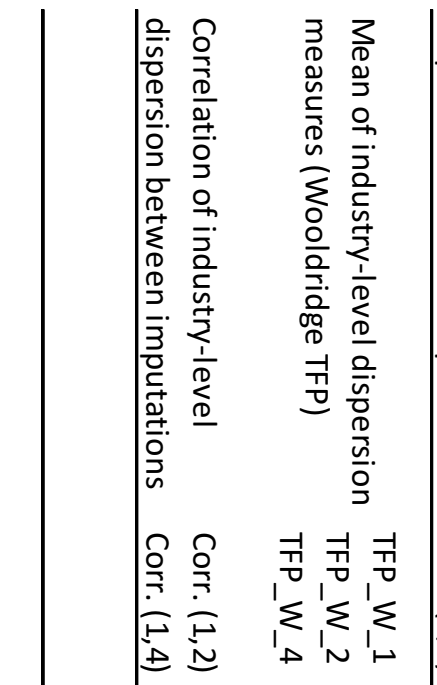

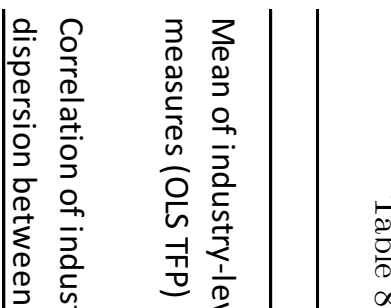

$\vec{P}$
$\stackrel{0}{0}$
$\infty$

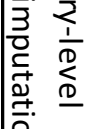

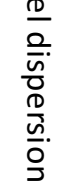

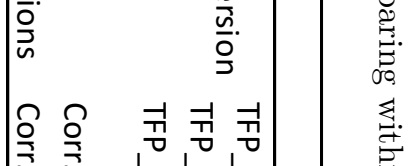

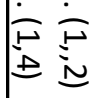

is $\frac{0}{5} \frac{0}{5}$

○

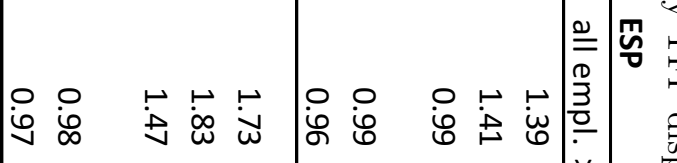

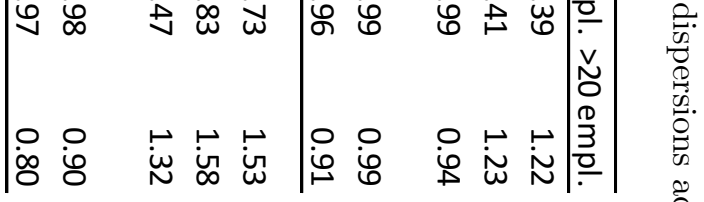

赵

虽

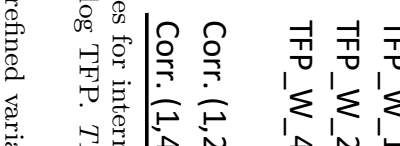

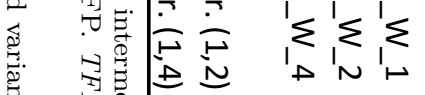

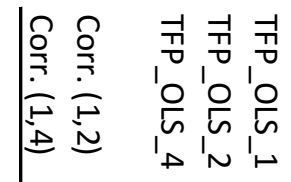

牙

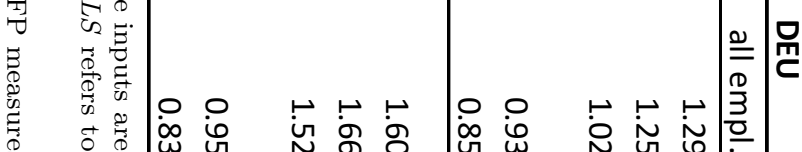

牙先

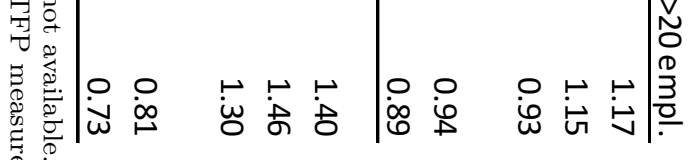

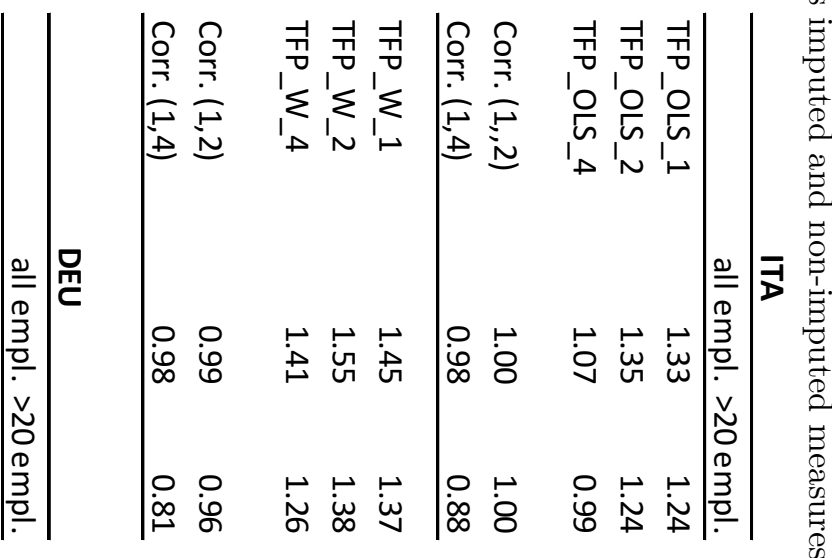

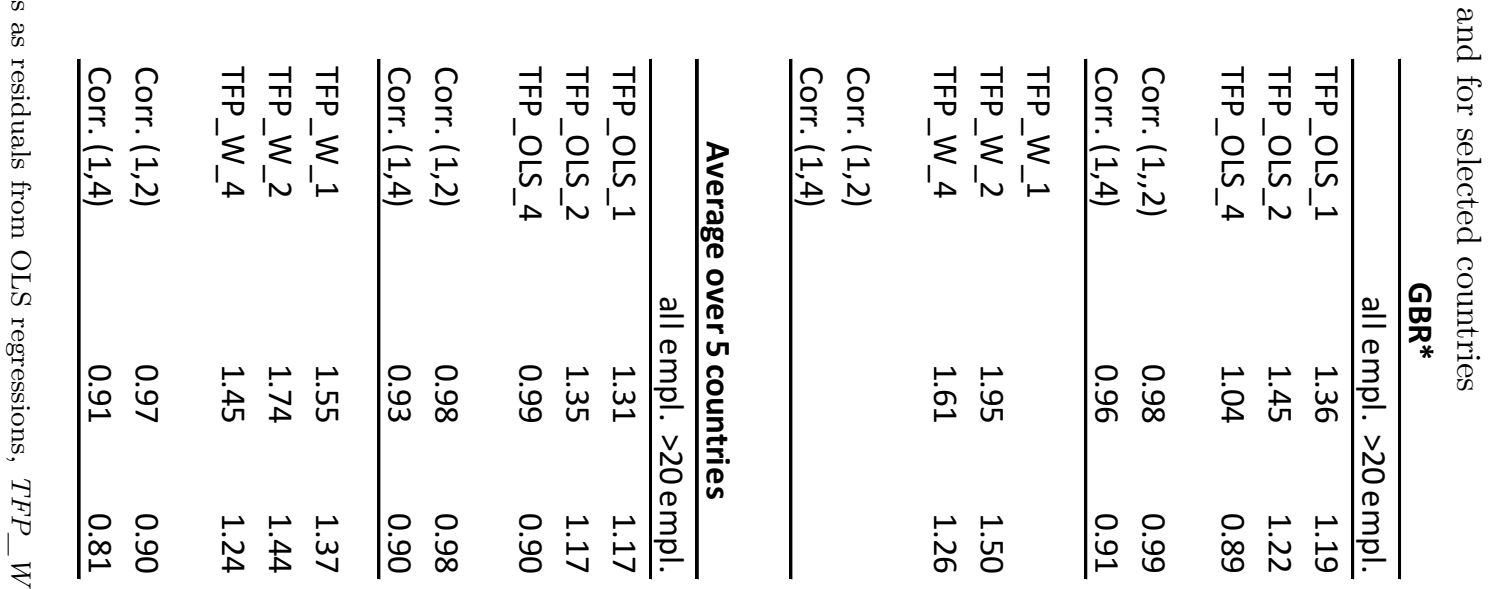

兽 

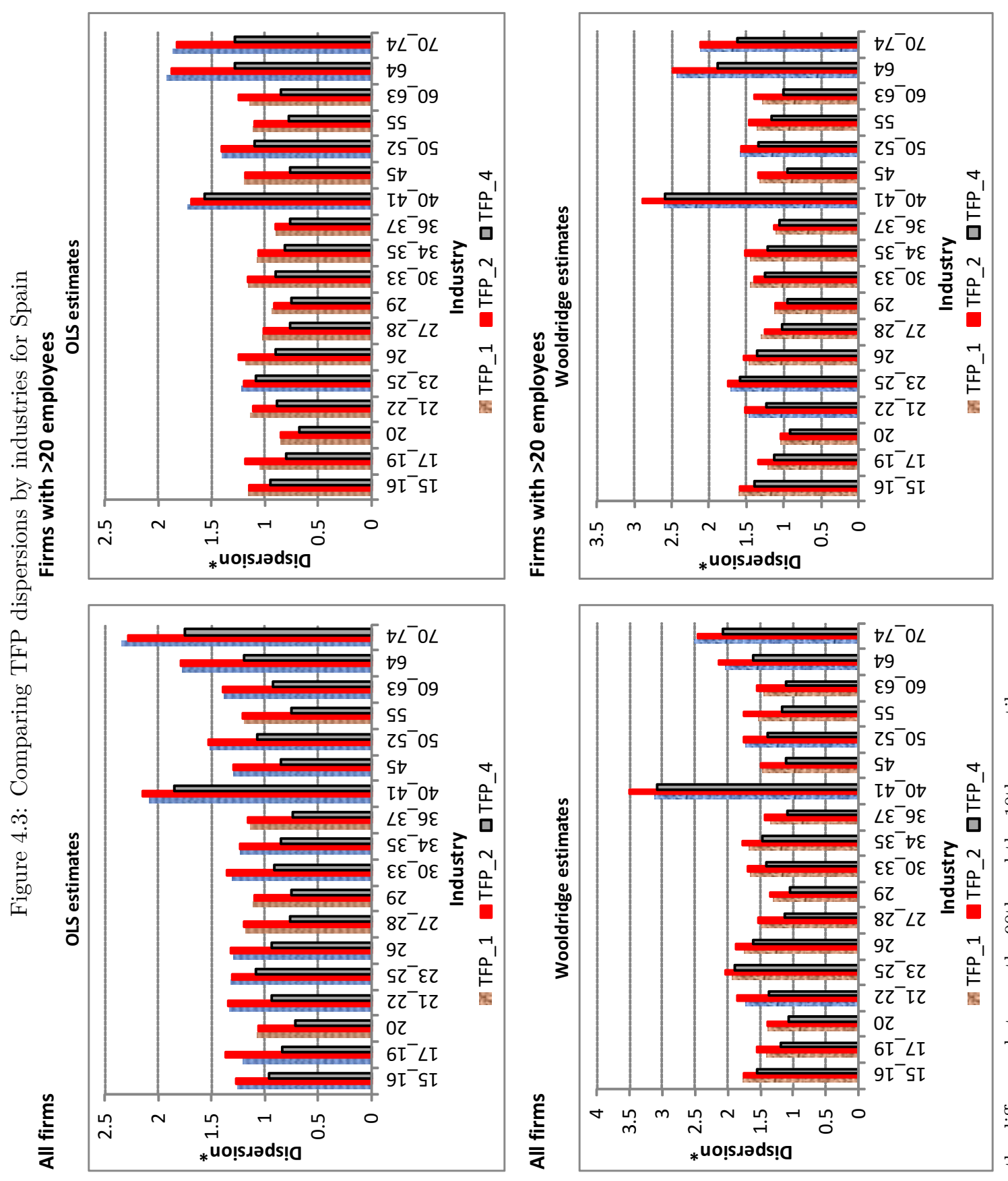

च 


\subsection{Comparing Different Methodologies}

From a methodological point of view, it is also interesting to check how the productivity numbers differ when comparing estimation based vs. index number approaches for TFP and how these measures relate to labour productivity. For such comparisons, we always use measures which are based on readily available (i.e. non-imputed) data. Table 9 summarizes the results.

The correlations between labour productivity (value added based) and the TFP estimates are usually quite high, both in terms of levels and growth rate, as averages across the five selected countries stand around 0.9 (for levels) and 0.95 (for growth rates). Correlations between labour productivity and TFP are usually lower and vary more across countries if we consider index-number type TFP measures $(0.5$, 0.8 ), and are usually higher for growth rates than for levels.

Turning to the relationship among TFP measures, correlations for growth rates tend to be higher than for levels, reaching nearly one for the growth rates between OLS and Wooldridge estimates. For levels, the weakest correlation is observed between the Solow residual and the Superlative Index measure, but that is also reasonably high (around 0.75).

Overall, the results indicate that different types of productivity measures, and especially their growth rates, are generally strongly related. The relationship between estimation-based measures is especially strong. ${ }^{39}$

\footnotetext{
${ }^{39}$ On the relationship between the OLS and Wooldridge production function estimates, see Section D of the Appendix.
} 
Table 9: Comparing productivity measures using different methodologies

Correlations based on measures using only non-imputed variables

ESP

\begin{tabular}{|c|c|c|c|c|c|c|c|c|c|c|c|}
\hline \multicolumn{6}{|c|}{ Correlations for $\operatorname{In}($ TFP) } & \multicolumn{6}{|c|}{ Correlations (TFP growth) } \\
\hline & VA & Solow & Supln & OLS & Wooldridge & & VA & Solow & Supln & OLS & Wooldridge \\
\hline VA & 1.00 & & & & & VA & 1.00 & & & & \\
\hline Solow & 0.49 & 1.00 & & & & Solow & 0.73 & 1.00 & & & \\
\hline Supln & 0.56 & 0.70 & 1.00 & & & Supln & 0.76 & 0.87 & 1.00 & & \\
\hline OLS & 0.90 & 0.76 & 0.72 & 1.00 & & OLS & 0.94 & 0.88 & 0.88 & 1.00 & \\
\hline Wooldridge & 0.93 & 0.60 & 0.64 & 0.91 & 1.00 & Wooldridge & 0.97 & 0.80 & 0.82 & 0.98 & 1.00 \\
\hline \multicolumn{12}{|c|}{ ITA } \\
\hline \multicolumn{6}{|c|}{ Correlations for $\ln (\mathrm{TFP})$} & \multicolumn{6}{|c|}{ Correlations (TFP growth) } \\
\hline & VA & Solow & Supln & OLS & Wooldridge & & VA & Solow & Supln & OLS & Wooldridge \\
\hline VA & 1.00 & & & & & VA & 1.00 & & & & \\
\hline Solow & 0.41 & 1.00 & & & & Solow & 0.70 & 1.00 & & & \\
\hline Supln & 0.54 & 0.75 & 1.00 & & & Supln & 0.81 & 0.89 & 1.00 & & \\
\hline OLS & 0.90 & 0.71 & 0.73 & 1.00 & & OLS & 0.94 & 0.84 & 0.92 & 1.00 & \\
\hline Wooldridge & 0.94 & 0.55 & 0.63 & 0.95 & 1.00 & Wooldridge & 0.96 & 0.78 & 0.89 & 0.99 & 1.00 \\
\hline \multicolumn{12}{|c|}{ GBR * } \\
\hline \multicolumn{6}{|c|}{ Correlations for $\operatorname{In}($ TFP) } & \multicolumn{6}{|c|}{ Correlations (TFP growth) } \\
\hline & VA & Solow & Supln & OLS & Wooldridge & & VA & Solow & Supln & OLS & Wooldridge \\
\hline VA & 1.00 & & & & & VA & 1.00 & & & & \\
\hline Solow & 0.69 & 1.00 & & & & Solow & 0.90 & 1.00 & & & \\
\hline Supln & 0.48 & 0.73 & 1.00 & & & Supln & 0.88 & 0.94 & 1.00 & & \\
\hline OLS & 0.86 & 0.83 & 0.66 & 1.00 & & OLS & 0.96 & 0.96 & 0.94 & 1.00 & \\
\hline Wooldridge & & & & & & Wooldridge & & & & & \\
\hline \multicolumn{12}{|c|}{ FRA } \\
\hline \multicolumn{6}{|c|}{ Correlations for $\operatorname{In}(\mathrm{TFP})$} & \multicolumn{6}{|c|}{ Correlations (TFP growth) } \\
\hline & VA & Solow & Supln & OLS & Wooldridge & & VA & Solow & Supln & OLS & Wooldridge \\
\hline VA & 1.00 & & & & & VA & 1.00 & & & & \\
\hline Solow & 0.67 & 1.00 & & & & Solow & 0.87 & 1.00 & & & \\
\hline Supln & 0.68 & 0.78 & 1.00 & & & Supln & 0.89 & 0.92 & 1.00 & & \\
\hline OLS & 0.90 & 0.86 & 0.79 & 1.00 & & OLS & 0.95 & 0.93 & 0.96 & 1.00 & \\
\hline Wooldridge & 0.89 & 0.67 & 0.70 & 0.90 & 1.00 & Wooldridge & 0.96 & 0.89 & 0.94 & 0.99 & 1.00 \\
\hline \multicolumn{12}{|c|}{ DEU } \\
\hline \multicolumn{6}{|c|}{ Correlations for $\ln (\mathrm{TFP})$} & \multicolumn{6}{|c|}{ Correlations (TFP growth) } \\
\hline & VA & Solow & Supln & OLS & Wooldridge & & VA & Solow & Supln & OLS & Wooldridge \\
\hline VA & 1.00 & & & & & VA & 1.00 & & & & \\
\hline Solow & 0.28 & 1.00 & & & & Solow & 0.86 & 1.00 & & & \\
\hline Supln & 0.50 & 0.75 & 1.00 & & & Supln & 0.86 & 0.94 & 1.00 & & \\
\hline OLS & 0.80 & 0.55 & 0.65 & 1.00 & & OLS & 0.94 & 0.93 & 0.95 & 1.00 & \\
\hline Wooldridge & 0.74 & 0.21 & 0.45 & 0.82 & 1.00 & Wooldridge & 0.95 & 0.89 & 0.92 & 0.99 & 1.00 \\
\hline \multicolumn{12}{|c|}{ Average over ESP, ITA, GBR, FRA, DEU } \\
\hline \multicolumn{6}{|c|}{ Correlations for $\ln (\mathrm{TFP})$} & \multicolumn{6}{|c|}{ Correlations (TFP growth) } \\
\hline & VA & Solow & Supln & OLS & Wooldridge & & VA & Solow & Supln & OLS & Wooldridge \\
\hline VA & 1.00 & & & & & VA & 1.00 & & & & \\
\hline Solow & 0.51 & 1.00 & & & & Solow & 0.81 & 1.00 & & & \\
\hline Supln & 0.55 & 0.74 & 1.00 & & & Supln & 0.84 & 0.91 & 1.00 & & \\
\hline OLS & 0.87 & 0.74 & 0.71 & 1.00 & & OLS & 0.95 & 0.91 & 0.93 & 1.00 & \\
\hline Wooldridge & 0.88 & 0.51 & 0.60 & 0.90 & 1.00 & Wooldridge & 0.96 & 0.84 & 0.89 & 0.99 & 1.00 \\
\hline
\end{tabular}

Note: $V A$ refers to value added based labour productivity, Solow refers to the Solow residual, SupIn refers to the SuperlativeIndex, OLS refers to the residual from an OLS production function, Wooldridge refers to the semi-parametric estimation method developed by Wooldridge (2009). Correlations are based for observations in the year 2008 (the pattern is similar in other years). TFP growth is defined as the first differences of $\ln (T F P)$. For Great Britain, non-imputed Wooldridge type estimates are not available due to the lack of the availability of proxies for intermediate inputs. 


\section{Empirical Illustrations}

To illustrate the potential use of the cross-country firm-level TFP database, this section presents some novel results which exploit the increased cross-country coverage, the enhanced representativeness and price-level corrections described in the previous sections. In particular, it describes the globally most productive firms, investigates the extent of productivity convergence, and examines the link between product market regulations and productivity growth. For further illustrations and uses, see the recent work of Andrews and Cingano (2012), which utilises the resampling weights as they are described above, Andrews et al. (2013) and Andrews and Criscuolo (2013) who investigate the role of patenting on productivity and the use of labor and capital.

\subsection{Which Countries Make it to the Global Frontier?}

To see if the cross-country differences in productivity levels are plausible, Table 10 shows the fraction of firms in the global top $10 \%$ productivity level by country. ${ }^{40}$ For example, in 2008, on average across industries, $35.5 \%$ of firms in the United States and $27.3 \%$ of Sweden are in the global top $10 \%$. As expected, firms in other EU countries (Finland, France, the Netherlands, Belgium, Denmark, Germany and Great Britain) are also overrepresented in the top 10\%, while firms in Spain, Italy and Portugal are less represented. At the other end, Central-Eastern European countries and Greece are clearly underrepresented. ${ }^{41}$

Changes over time, from 2000 to 2008, also seem plausible. Countries which increased their presence among the global frontier firms are the United States, Sweden, Finland and the Netherlands. Others which lost ground include Spain and to a lesser extent also France, while the same is true for Italy in manufacturing. While this investigation is preliminary, it shows that using industry-level PPP conversions to get internationally comparable prices and applying the imputations described above can yield some interesting and intuitive cross-country patterns.

\subsection{The Impact of Product Market Regulations on Productivity Growth}

Following Griffith et al. (2004), Nicoletti and Scarpetta (2003) and Bourlès et al. (2010), but using a wider set of countries (notably, also including non-European ones) and more recent years, we explore the impact of product market regulations on firm-level TFP using a neo-Schumpeterian framework (i.e. catch-up to the frontier) of the following form:

$$
\Delta a_{i c s t}=\alpha_{1} \Delta a_{F s t}+\alpha_{2} \widetilde{a}_{i c s, t-1}+\beta \text { RegImpact } c_{c s, t-1}+\eta_{s}+\eta_{c t}+\varepsilon_{i c s t},
$$

where $\Delta$ is the first difference operator, $a=\ln (T F P)$ is the $\log$ of $T F P$, subscripts $i, c, s, t$ denote firm, country, sector and time, respectively, and the gap to the productivity frontier $\widetilde{a}_{i c s t}$ is defined by

$$
\widetilde{a}_{i c s t}=a_{i c s}-a_{F s t}
$$

where subscript $F$ denotes the frontier firm. The frontier firm, following Arnold et al. (2008), is defined as "the average TFP of the $5 \%$ most productive firms in sector $s$ in year $t$ in our sample of countries." The fixed effects $\eta_{s}$ and $\eta_{c t}$ control for industry-specific and country*time specific (i.e. also including business cycle) effects. The coefficient of the frontier firm's growth is expected to be positive, $\alpha_{1}>0$, reflecting technological pass-through from the frontier, and the coefficient of the distance from the frontier

\footnotetext{
${ }^{40}$ More precisely, the top $10 \%$ best performing firms are first selected for each industry; then the percentage of firms of a given industry and in a given country is within the top $10 \%$ group is calculated; finally, the average across industries is calculated for each country, and those figures are presented in Table 10.

${ }^{41}$ The relatively low position of Japan in this ranking probably warrants further examination.
} 


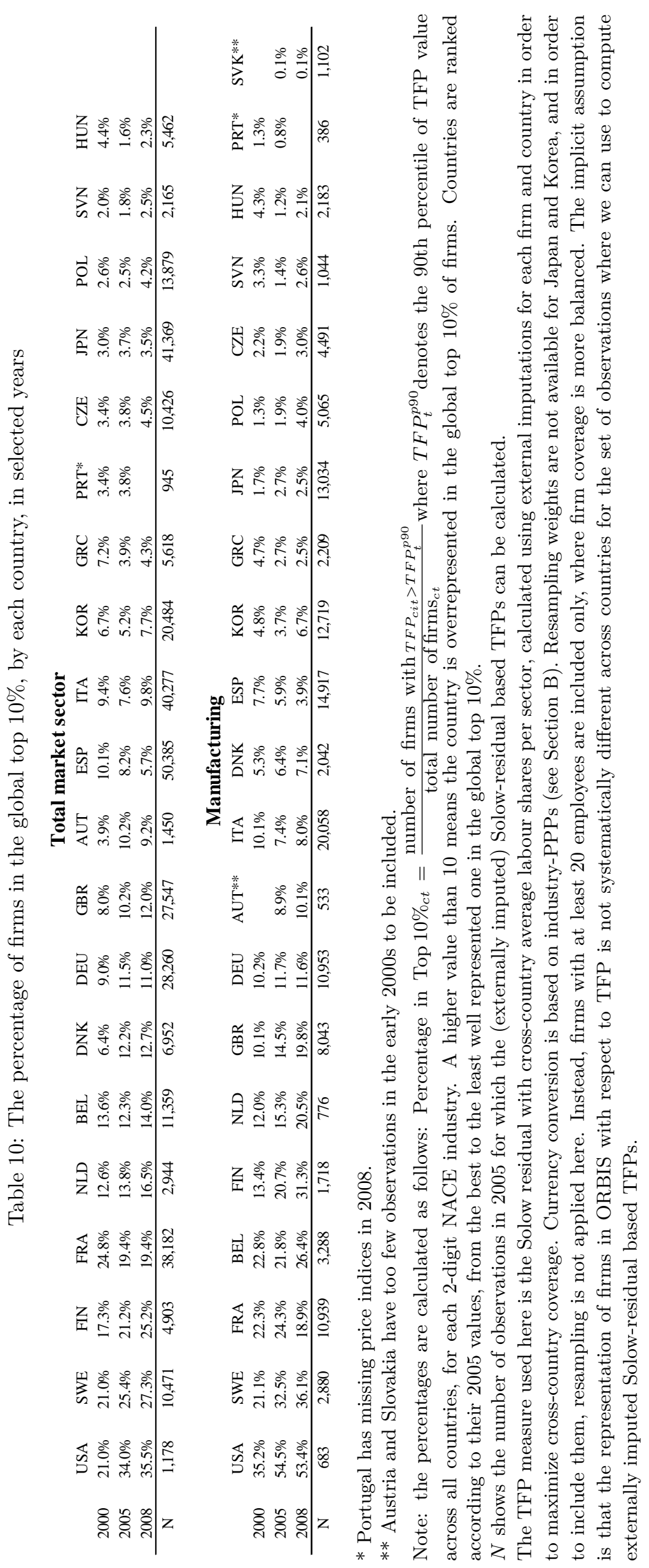


Table 11: The effect of regulations on firm-level productivity growth Left hand side variable:

\section{TFP measures}

\begin{tabular}{|c|c|c|c|c|}
\hline$\Delta a_{i c s t}$ & Superlativ & ex measure & Solow 1 & lual measure \\
\hline$\Delta a_{F s t}$ & $\begin{array}{c}0.103 * * * \\
(5.6)\end{array}$ & $\begin{array}{c}0.103 * * * \\
(5.6)\end{array}$ & $\begin{array}{c}0.0999 * * * \\
\quad(5.29)\end{array}$ & $\begin{array}{c}0.0998^{* * *} * \\
(5.29)\end{array}$ \\
\hline$a_{i c s, t-1}-a_{F s, t-1}$ & $\begin{array}{c}-0.148 * * * \\
(-12.92)\end{array}$ & $\begin{array}{c}-0.148 * * * \\
(-12.96)\end{array}$ & $\begin{array}{c}-0.155^{* * *} * \\
(-13.65)\end{array}$ & $\begin{array}{c}-0.155 * * * \\
(-13.72)\end{array}$ \\
\hline $\operatorname{RegImpact}_{c s, t-1}$ & $\begin{array}{c}-0.317 * * * \\
(-3.66)\end{array}$ & & $\begin{array}{c}-0.392 * * * \\
(-3.88)\end{array}$ & \\
\hline RegImpact_PO $O_{c s, t-1}$ & & $\begin{array}{c}-0.258 * * * \\
(-3.31)\end{array}$ & & $\begin{array}{c}-0.324 * * * \\
(-3.62)\end{array}$ \\
\hline $\begin{array}{l}\text { Country*year fixed effects } \\
\text { Industry fixed effects }\end{array}$ & $\begin{array}{l}\text { yes } \\
\text { yes }\end{array}$ & $\begin{array}{l}\text { yes } \\
\text { yes }\end{array}$ & $\begin{array}{l}\text { yes } \\
\text { yes }\end{array}$ & $\begin{array}{l}\text { yes } \\
\text { yes }\end{array}$ \\
\hline $\begin{array}{l}R^{2} \\
N\end{array}$ & $\begin{array}{c}0.173 \\
25,590,249\end{array}$ & $\begin{array}{c}0.171 \\
25,590,249\end{array}$ & $\begin{array}{c}0.182 \\
25,941,974\end{array}$ & $\begin{array}{c}0.178 \\
25,941,974\end{array}$ \\
\hline Number of countries & 18 & 18 & 18 & 18 \\
\hline
\end{tabular}

$t$-statistics in parentheses

$* \mathrm{p}<0.10, * * \mathrm{p}<0.05, * * * \mathrm{p}<0.01$

Note: $\Delta a_{i c s t}$ denotes firm-level TFP growth, $\Delta a_{F s t}$ is growth of the global frontier (defined as the average of the top $5 \%$ globally most productive firms of the same industry and year), $a_{i c s, t-1}-a_{F s, t-1}$ is the lagged difference from the global frontier, RegImpact Rs,$t-1_{1}$ stands for the knock-on impact of regulations in upstream, services industries (see Conway and Nicoletti (2006)), and

RegImpact_PO $O_{c s, t-1}$ is a variant of this measure incorporating the effect of the prevalence Public Ownership. Subscripts $c, s, i, t$ denote country, sector, firm and year, respectively. See equation 5.1 for details. Standard errors are clustered at country*industry cells. Resampling weights are used (see details in Section 2.4). The estimation sample covers all non-frontier firms in the non-farm, non-financial business sector for the years 1999-2009 for the broadest set of countries where TFP measures using only external imputations can be calculated, resampling weights are available, industry PPP-s can be calculated, and the RegImpact variable is also available (18 countries): AUT, BEL, CZE, DEU, DKN, ESP, FIN, FRA, GBR, GRC, HUN, ITA, NLD, POL, PRT, SWE, SVK, USA.

Both TFP measures use uniform, cross-country average labour shares (Solow) or reference values (Superlative Index) in order to ensure international comparability of productivity levels. 
is expected to be negative, $\alpha_{2}<0$, reflecting the fact that as a firm gets closer to the frontier, the speed of catching-up slows down. The main variable of interest is $\operatorname{RegImpact~}_{c s, t-1}$ which is a country $*$ industry * time-varying measure of the knock-on impact of regulations in upstream, services industries. ${ }^{42}$ If its coefficient is significant and negative, it means that regulations hamper productivity growth at the firm-level, even after controlling for the potential catch-up behaviour of firms to the global frontier.

Equation 5.1 is estimated with all non-frontier firms in the sample and using two types of TFP measures best suited to international comparisons: the Superlative index measure with uniform crosscountry average reference values for each firm and the Solow residual, with the same factor shares for each country, calculated as the average of factor shares across countries for each industry. In order to maximize cross-country and firm coverage, externally imputed TFP measures are used.

Results are presented in Table 11. They show that the frontier growth and the distance from the frontier are significant and have the expected signs and similar magnitudes across specifications. These results are comparable to what was found by Arnold et al. (2008) using the Amadeus data set for 10 European countries and for the early 2000s. Furthermore, the impact of regulations is also significant and negative, meaning that firm-level TFP growth is slower if regulations are more stringent.

\section{Conclusions}

Recent OECD research has utilized harmonized cross-country firm level data from ORBIS to explore the contribution of public policies to cross-country differences in productivity, innovation and resource allocation. This paper describes the steps taken before the analysis in order to improve the reliability and international comparability of these firm level data as well as the specific trade-offs involved when using ORBIS for productivity analysis. Moreover, it carries out a wide range of quality and robustness checks of the measures obtained, also highlighting various potential uses of the data. As such, it aims to serve as a reference for current and future firm-level analyses utilizing ORBIS either within or outside the OECD.

Since certain variables are not available or not with wide enough coverage for some countries, most importantly the United States, productivity measures using internal (using other variables from ORBIS) or external imputations (using external data) are required. When the properties of these imputed measures are compared with those of using non-imputed data, for a set of countries where data coverage is relatively high (France, Germany, Great Britain, Italy and Spain), a number of key results emerge:

- The correlations between imputed and non-imputed TFP estimates are reasonably high, both in terms of levels and growth rates, and this relationship is stable over time and across sectors.

- There are some differences across productivity measures in the quality of the imputations: the Solow residual and the estimation based approaches have correlations around 0.8-0.9 with the non-imputed values, for levels, and around 0.6-0.85 for growth rates.

- When comparing the dispersion of productivity estimates calculated using the imputed and nonimputed variables, dispersion levels are lower for externally imputed values, but the relative differences across industries are well preserved.

As a contribution to the literature on productivity measurement, this paper also compared productivity using different methodologies (index numbers and estimation-based approaches for TFP and labour

\footnotetext{
${ }^{42}$ The RegImpact variable is a continuous measure, developed by the OECD using national sources based on legislation, with higher values showing a stronger potentially negative effect of non-manufacturing regulations on entry and competition downstream sectors, depending on the sector's use of the output of the regulated sectors (energy, transport, telecommunication, retail distribution and professional services). For more details, see Conway and Nicoletti (2006).
} 
productivity), for countries with good data coverage. The estimation based approaches deliver TFP estimates very close to each other, whereas the index numbers are somewhat less closely related.

Finally, the database uses industry-level PPP conversions in order to ensure the comparability of estimates across countries with different currencies. Also, differences in the coverage of firms across countries are taken care of by using resampling weights in order to match the observed industry and size class structure of employment in administrative databases.

To illustrate the potential of the data set for cross-country comparisons and policy analysis, some preliminary results are presented on the global productivity frontier of firms, the catch-up to those firms and the effect of regulations on productivity growth. These results are in an explorative phase, but they seem to be plausible and confirm earlier findings, namely that the global productivity frontier is disproportionately dominated by the most developed and innovative countries (e.g. United States and Sweden), and that productivity growth is hampered by product market regulations.

Despite all the efforts, some limitations remain - some of them more serious than others, depending on the purpose of the analysis where the data is used. First, in cases where resampling weights are high, typically, in the early years (up to 2004), and in countries with generally poor coverage (see Table 3), results need to be treated with more caution. Further, the measurement of entry and especially exit is noisy. As the data vendor BvD continuously broadens and refines its sources, these issues may be better addressed in future vintages of ORBIS. 


\section{Appendix}

\section{A Estimating Capital Stock at the Firm Level}

For calculating capital stock at the firm-level, the standard Perpetual Inventory Method (PIM) is used. It defines the level of real capital stock $K_{i t}$ in firm $i$ in year $t$ as

$$
K_{i t}=K_{i, t-1}\left(1-\delta_{i t}\right)+I_{i t},
$$

where real investments $I_{i t}$ are calculated as the difference between the current and lagged book value of fixed tangible assets plus depreciation, deflated by country and industry specific investment deflators

$$
I_{i t}=\left(K_{i t}^{B V}-K_{i, t-1}^{B V}+D E P R_{i t}^{B V}\right) / P I_{t}
$$

and where $K^{B V}$ and $D E P R^{B V}$ denote the book value of fixed tangible assets and depreciation, respectively (TANGIBLE_FIXED_ASSETS and DEPRECIATION in ORBIS) and $P I_{t}$ is the investment price deflator at the 2-digit industry level (see more on this in Section B). The depreciation rate is defined $\operatorname{as} \delta_{i t}=D E P R_{i t}^{B V} / K_{i, t-1}^{B V}$. ${ }^{43}$.

For the first observed year of the firm $(t=0)$, where $K_{i, t-1}$ in equation A.1 is not defined, the real capital stock is simply the observed net capital stock deflated by the investment price index:

$$
K_{i 0}=K_{i 0}^{B V} / P I_{0}
$$

\section{B Deflation and Construction of Internationally Comparable Price Levels}

\section{B.1 Deflation - Price Indices over Time}

The variables in ORBIS are given in thousands of euros, converted from local currencies at the market exchange rate, in each year (see Gonnard and Ragoussis (2013)). In order to be able to compare values over time, adjusted for price changes, we need to deflate the nominal variables using price indices. Similarly to most firm-level data sets, ORBIS does not include firm-level price indices. ${ }^{44}$ Hence, following the standard practice, external data sources are used to deflate nominal values: 2-digit industry deflators from the OECD STAN database, separately for output, value added, intermediate inputs and investments.

However, these deflators refer to national currencies, hence before they can be applied to nominal variables in ORBIS (which are in thousands of euros), those nominal variables need to be converted back to the original currency values. For this, the variable called EXCHANGE_RATE is used from ORBIS, which is the euro / local currency conversion rate for each country and year, to be denoted by $(€ / \$)_{c t}$.

\footnotetext{
${ }^{43}$ Since different asset types (i.e. structures and equipment) are summed together in ORBIS, but their depreciation rates differ, this constructed depreciation rate reflects differences in the asset structure (i.e. firms with more equipment will have higher depreciation rates)

${ }^{44}$ It is a general problem in productivity measurement that in most firm-level data sets, firm-level prices are not observed. Hence what researchers usually are able to measure is revenue based productivity (TFPR), and not quantity based productivity $(T F P Q)$. The former is also influenced by idiosyncratic firm-level prices, and as such, it captures a combination of market power and productivity (Syverson, 2011).
} 
Thus we obtain for each variable $X_{i t}$, for firm $i$ and year $t$, a conversion from the euro based value $\left(X_{i t}^{€}\right)$ to the local currency value $\left(X_{i t}^{\$}\right)$ :

$$
X_{i t}^{\$}=\frac{X_{i t}^{€}}{(€ / \$)_{c t}} .
$$

Then at the second stage, deflation over time is implemented:

$$
X_{i t}^{\$, t_{o}}=\frac{X_{i t}^{\$}}{P_{c j t}^{t_{0}}}
$$

where $P_{c j t}^{t_{0}}$ refers to the appropriate deflator from OECD STAN (e.g. value added, output, etc.) in year $t$ with reference year $t_{0}$ in country $c$ in industry $j$. This procedure will ensure that the growth rates of the variables used for productivity calculations (value added, output, investment, etc.) are not distorted by price changes. ${ }^{45}$

\section{B.2 Price-level Corrections across Countries}

In order to be able to compare productivity levels across countries, as for instance in Arnold et al. (2008), Bartelsman et al. (2008) and Griffith et al. (2009) when defining the global frontier firms, we need to use a conversion which corrects for price-level differences across countries. The ICOP 1997 database from the Groningen Growth and Development Center, by Timmer et al. (2007), was prepared using a comprehensive and well documented approach.

To give a quick background on industry-level PPPs, there are two approaches for their measurement (Pilat, 1996): (1) The output approach, which is theoretically more preferable as it uses producer prices. But these are more difficult to obtain for services, and are more suited for industries producing rather homogeneous goods as they utilize an "average price". (2) The other approach is the expenditure approach, which is more widely available across the economy, but needs to be adjusted for transport and distributional costs, taxes and subsidies, international trade and intermediate use. Timmer et al. (2007) select between the two approaches for each industry and country, based on the quality of these adjustments, which in turn depend on the degree of international trade and intermediate use. Their final database contains industry level PPP exchange rates for each country and each industry (mostly at the 2-digit level). ${ }^{46}$ The PPPs there refer to 1997 values in the form of local currency / euro conversion rates which we denote here by $(\$ / €)_{c, j, P P P 97}$. Comparable values across countries, for the reference year of 1997 , can thus be obtained by

$$
X_{i, 1997}^{€, P P P 97}=\frac{X_{i, 1997}^{\$}}{(\$ / €)_{c, j, P P P 97}}
$$

\section{B.3 Combining Deflation over Time and across Countries}

In order to get comparable values both across countries and over time, we need to combine the two steps, i.e. deflating over time and correcting for price level differences across countries. Hence we choose 1997 as the reference year in equation B.2, i.e. $t_{0}=1997$, and then apply both the across-time deflator $P_{c, j, t}^{1997}$

\footnotetext{
${ }^{45}$ Where 2-digit values are not available, higher aggregation levels are used. If those are also not available for certain deflators, value added deflators are used, as they are the most widely available.

${ }^{46}$ From the set of countries included in the TFP calculations, Norway and Switzerland do not have values in the ICOP PPP database, hence they are left out of the calculations using industry PPP-s. They are still included in another set of calculations, using a simpler and more crude way of correcting cross-country price differences, see Section B.3 below.
} 
and the conversion rates $(\$ / €)_{c, j, P P P 97}:{ }^{47}$

$$
X_{i t}^{€, P P P 97}=\frac{X_{i t}^{\$} / P_{c j t}^{1997}}{\left(\$ / \epsilon_{c, j, P P P 97}\right.}=\frac{X_{i t}^{\$, 1997}}{(\$ / €)_{c, j, P P P 97}} .
$$

An alternative, less sophisticated way than using industry level PPPs is to convert the local currency nominal values using observed market exchange rates to a common currency. It is more acceptable to use in industries prone to strong international competition (typically, manufacturing). In order to mitigate the impact of fluctuating exchange rates on the productivity numbers, we fix local currency vs. euro exchange rates at the average of 2005 , corresponding to the middle of the sample period $1999-2009 .{ }^{48}$

\section{Balancing the SDBS Database}

The Structural and Demographic Business Statistics (SDBS) of the OECD is built up using administrative data from national sources on the number of firms, employees and other economic variables, by country, year, industry and firm size class cells. It is used as the benchmark when constructing the resampling weights by cells. For some cells, however, values are missing. Below are the main steps of balancing, i.e. filling up missing values:

- There are two employment variables available in SDBS: number of employees and number of persons engaged. The difference can be quite substantial for small firm size classes, as the latter captures also managers. However, the number of employees is closer to the definition in ORBIS, hence more preferable for our uses, but is not available in some cases where the number of persons engaged is. Therefore, we predict the number of employees for those country*firms*sizeclass*year cells where it is not available, by using country, sizeclass*industry and year fixed effects and interacting these fixed effects with the number of persons engaged.

- Next, the industry aggregation is chosen uniformly across countries, in such a way that it yields the most widely available data (somewhat less detailed than 2-digit, see Table E.4 in the Appendix, the column on NACE 2-digit industry groups).

- Then, for missing years, we use the average values for the period later than 2005 or earlier than 2006, depending on to which interval the actual missing year belongs to. For instance, values for 2009 will get the average available years starting from 2005, possibly those of 2005-2008 but perhaps only those of 2005-2006. Similarly, values for 2001 will be the averages before and including 2006. This approximation is expected to work well, since most of the variation in SDBS is along the cross-sectional and not in the time dimension. In other words, it is more important to get a good sense of the average share of industries and firm-size classes than to exactly follow their evolution over time.

\footnotetext{
${ }^{47}$ During the actual implementation, we first construct a series of deflators $P_{c j t}^{P P P 97}$ :$$
P_{c j t}^{P P P 97}=(\$ / €)_{c, j, P P P 97} \times P_{c j t}^{1997},
$$

and apply those to the nominal values (in local currencies) in ORBIS:

$$
X_{i t}^{€, P P P 97}=X_{i t}^{\$} / P_{c j t}^{P P P 97} .
$$

This procedure is equivalent to what is written in equation B.3.

${ }^{48} \mathrm{~A}$ relative advantage of this approach is that it is available for those countries (Switzerland and Norway) that are not in the ICOP-PPP database. In the final TFP database, both approaches are implemented, see the database description in Section F of the Appendix.
} 
- Finally, for completely missing sizeclass categories in certain countries and industries, we apply the average share from other countries and industries. ${ }^{49}$ In principal, we aim to get the most detailed size-class categories. These are, for most countries, the following intervals, defined by the number of employees: 1-9, 10-19, 20-49, 50-249, 250+. One exception is the United States, where the sizeclass definitions are 1-9, 10-19, 20-99, 100-499, 500+ ${ }^{50}$

\section{Comparing Production Function Parameters}

Regarding the estimation based approaches, one expects the semi-parametric methods to improve on the potential bias of the input coefficients. As expected, compared to OLS, the coefficient of employment is lower when we control for endogeneity of inputs (i.e. when using Wooldridge (2009)). Another interesting result is that the sum of the coefficients is usually less than unity for the semi-parametric approaches, implying decreasing returns to scale. Note that this holds both for the coefficients based on non-imputed data and for the ones based on imputations. ${ }^{51}$

\footnotetext{
${ }^{49}$ For instance, if in a 2-digit industry, the information referring to the smallest size-class is not available, than the average share of small firms in that industry is assumed, using all other countries for the same industry.

${ }^{50}$ Japan and Korea are problematic countries because some industries are completely missing or present only with leaving out the smallest firm category. See for details the SDBS database on the OECD website. Therefore, resampling weights there should be used with caution.

${ }^{51}$ These results are available on request. Coefficients for further inspection are stored next to the database in separate files, see Section F of the Appendix on the structure of the database.
} 


\section{E Additional Tables}

Table E.1: Comparing the availability of different productivity measures (2008, market sector)

\begin{tabular}{|c|c|c|c|c|c|c|c|c|}
\hline $\begin{array}{l}\text { Country } \\
\text { Code }\end{array}$ & Country & $\begin{array}{l}\text { Labor Prod. } \\
\text { using } \\
\text { Turnover }\end{array}$ & $\begin{array}{l}\text { TFP, non } \\
\text { imputed }\end{array}$ & $\begin{array}{l}\text { Non-imputed } \\
\text { TFP/ } \\
\text { Labor } \\
\text { productivity } \\
\end{array}$ & $\begin{array}{c}\text { TFP, } \\
\text { internally } \\
\text { imputed }\end{array}$ & $\begin{array}{c}\text { Internally } \\
\text { imputed TFP / } \\
\text { Labor } \\
\text { productivity } \\
\end{array}$ & $\begin{array}{l}\text { TFP, externally } \\
\text { imputed* }\end{array}$ & $\begin{array}{c}\text { Externally } \\
\text { imputed TFP / } \\
\text { Labor } \\
\text { productivity* } \\
\end{array}$ \\
\hline ESP & Spain & 503,334 & 464,600 & $92.30 \%$ & 466,197 & $92.62 \%$ & 508,424 & $101.01 \%$ \\
\hline PRT & Portugal & 231,378 & 204,603 & $88.43 \%$ & 199,859 & $86.38 \%$ & 239,208 & $103.38 \%$ \\
\hline ITA & Italy & 345,577 & 300,704 & $87.02 \%$ & 322,347 & $93.28 \%$ & 334,927 & $96.92 \%$ \\
\hline SWE & Sweden & 166,810 & 112,808 & $67.63 \%$ & 133,532 & $80.05 \%$ & 150,550 & $90.25 \%$ \\
\hline GRB & Great Britain & 45,832 & 27,465 & $59.93 \%$ & 45,492 & $99.26 \%$ & 48,603 & $106.05 \%$ \\
\hline FIN & Finland & 37,971 & 19,885 & $52.37 \%$ & 31,918 & $84.06 \%$ & 33,445 & $88.08 \%$ \\
\hline SVN & Slovenia & 9,724 & 4,531 & $46.60 \%$ & 9,296 & $95.60 \%$ & 9,463 & $97.32 \%$ \\
\hline NZL & New Zealand & 18 & 8 & $44.44 \%$ & 10 & $55.56 \%$ & 10 & $55.56 \%$ \\
\hline KOR & Korea & 80,712 & 32,889 & $40.75 \%$ & 59,398 & $73.59 \%$ & 63,167 & $78.26 \%$ \\
\hline NOR & Norway & 3,366 & 1,180 & $35.06 \%$ & 1,667 & $49.52 \%$ & 2,099 & $62.36 \%$ \\
\hline CZE & Czech Republic & 62,536 & 21,414 & $34.24 \%$ & 35,411 & $56.62 \%$ & 38,636 & $61.78 \%$ \\
\hline FRA & France & 398,776 & 134,300 & $33.68 \%$ & 301,115 & $75.51 \%$ & 334,499 & $83.88 \%$ \\
\hline DEU & Germany & 105,487 & 35,255 & $33.42 \%$ & 35,107 & $33.28 \%$ & 35,811 & $33.95 \%$ \\
\hline JPN & Japan & 220,388 & 70,988 & $32.21 \%$ & 80,731 & $36.63 \%$ & 117,404 & $53.27 \%$ \\
\hline HUN & Hungary & 14,072 & 4,276 & $30.39 \%$ & 14,019 & $99.62 \%$ & 14,419 & $102.47 \%$ \\
\hline POL & Poland & 48,449 & 14,044 & $28.99 \%$ & 29,566 & $61.02 \%$ & 32,285 & $66.64 \%$ \\
\hline BEL & Belgium & 34,852 & 9,708 & $27.85 \%$ & 116,520 & $334.33 \%$ & 118,521 & $340.07 \%$ \\
\hline AUT & Austria & 9,969 & 1,750 & $17.55 \%$ & 1,681 & $16.86 \%$ & 1,807 & $18.13 \%$ \\
\hline SVK & Slovak Republic & 40,711 & 5,948 & $14.61 \%$ & 7,357 & $18.07 \%$ & 7,805 & $19.17 \%$ \\
\hline LUX & Luxembourg & 467 & 56 & $11.99 \%$ & 61 & $13.06 \%$ & 64 & $13.70 \%$ \\
\hline AUS & Australia & 1,067 & 99 & $9.28 \%$ & 150 & $14.06 \%$ & 895 & $83.88 \%$ \\
\hline IRL & Ireland & 665 & 27 & $4.06 \%$ & 28 & $4.21 \%$ & 34 & $5.11 \%$ \\
\hline CHE & Swizerland & 8,024 & 315 & $3.93 \%$ & 369 & $4.60 \%$ & 387 & $4.82 \%$ \\
\hline TUR & Turkey & 3,577 & 69 & $1.93 \%$ & 72 & $2.01 \%$ & 84 & $2.35 \%$ \\
\hline NLD & Netherlands & 3,853 & 62 & $1.61 \%$ & 4,944 & $128.32 \%$ & 5,292 & $137.35 \%$ \\
\hline ISR & Israel & 402 & 4 & $1.00 \%$ & 4 & $1.00 \%$ & 393 & $97.76 \%$ \\
\hline ISL & Iceland & 1,347 & 3 & $0.22 \%$ & 936 & $69.49 \%$ & 2,213 & $164.29 \%$ \\
\hline GRC & Greece & 19,544 & 4 & $0.02 \%$ & 4 & $0.02 \%$ & 17,324 & $88.64 \%$ \\
\hline DNK & Denmark & 11,647 & 2 & $0.02 \%$ & 39,106 & $335.76 \%$ & 42,892 & $368.27 \%$ \\
\hline EST & Estonia & 30,077 & 2 & $0.01 \%$ & 19,728 & $65.59 \%$ & 21,661 & $72.02 \%$ \\
\hline USA & United States & $5,036,569$ & 1 & $0.00 \%$ & 1 & $0.00 \%$ & 2,214 & $0.04 \%$ \\
\hline CAN & Canada & 640,965 & - & $0.00 \%$ & - & $0.00 \%$ & 12 & $0.00 \%$ \\
\hline CHN & Chile & 340 & - & $0.00 \%$ & - & $0.00 \%$ & 1 & $0.29 \%$ \\
\hline MEX & Mexico & 43,539 & - & $0.00 \%$ & - & $0.00 \%$ & 1 & $0.00 \%$ \\
\hline BRA & Brazil & 7,297 & 14 & $0.19 \%$ & 14 & $0.19 \%$ & 40 & $0.55 \%$ \\
\hline CHN & China & 182,206 & 108 & $0.06 \%$ & 110 & $0.06 \%$ & 1,645 & $0.90 \%$ \\
\hline IND & India & 259 & - & $0.00 \%$ & - & $0.00 \%$ & 1 & $0.39 \%$ \\
\hline RUS & Russia & 620,827 & - & $0.00 \%$ & - & $0.00 \%$ & - & $0.00 \%$ \\
\hline ZAF & South Africa & 142 & 38 & $26.76 \%$ & 38 & $26.76 \%$ & 42 & $29.58 \%$ \\
\hline \multicolumn{2}{|c|}{ Total (OECD) } & $8,162,045$ & $1,467,000$ & $17.97 \%$ & $1,956,626$ & $23.97 \%$ & $2,184,550$ & $26.76 \%$ \\
\hline \multicolumn{2}{|c|}{ Mean (OECD) } & 240,060 & 43,147 & $26.52 \%$ & 57,548 & $64.12 \%$ & 64,251 & $79.33 \%$ \\
\hline \multicolumn{2}{|c|}{ Total (All) } & $8,972,776$ & $1,467,160$ & $16.35 \%$ & $1,956,788$ & $21.81 \%$ & $2,186,278$ & $24.37 \%$ \\
\hline \multicolumn{2}{|c|}{ Mean (All) } & 230,071 & 37,619 & $23.81 \%$ & 50,174 & $56.59 \%$ & 56,058 & $69.96 \%$ \\
\hline
\end{tabular}

Note: OECD countries are ranked by the 5 th column (the ratio of the sample for which the simplest TFP measures without imputations can be calculated to the Labour Productivity sample).

The column referring the TFP shows the number of observations where TFP can be calculated, using only the following variables (ORBIS variables in parentheses): value added (ADDED_VALUE), capital (TANGIBLE_FIXED_ASSETS and DEPRECIATION), employment (EMPLOYEES). Internally imputed TFP means that the value added numbers are calculated as the sum of labour costs (COSTS_EMPLOYEES) and capital costs (more precisely, earnings before interest, taxes, depreciation and amortization, EBITDA). Externally imputed TFP means that the labour costs are imputed externally as the product of firm-specific employment and country, industry, year specific average labour costs using OECD STAN. The data underlying the table refers to the non-farm business sector (NACE Rev 1.1 codes 15-74) for the years 1999-2009, and is derived from filtering out accounts referring to less than complete calendar years and consolidated accounts, using flags prepared by the Statistics Directorate of the OECD (STD) (Gonnard and Ragoussis, 2013). Note that in the June 2011 version of OECD-ORBIS, data in the United States and Canada contain only single-establishment firms. The actual numbers in the TFP database may be lower than here if price indices are not available or data problems prevent the calculation of TFP measures for some firms. 
Table E.2: Comparing the availability of different productivity measures (2002, market sector)

\begin{tabular}{|c|c|c|c|c|c|c|c|c|}
\hline Country Code & Country & $\begin{array}{l}\text { Labor Prod. } \\
\text { using Turnover }\end{array}$ & $\begin{array}{l}\text { TFP, non } \\
\text { imputed }\end{array}$ & $\begin{array}{l}\text { Non-imputed } \\
\text { TFP / } \\
\text { Labor } \\
\text { productivity }\end{array}$ & $\begin{array}{c}\text { TFP, } \\
\text { internally } \\
\text { imputed }\end{array}$ & $\begin{array}{c}\text { Internally } \\
\text { imputed TFP / } \\
\text { Labor } \\
\text { productivity }\end{array}$ & $\begin{array}{l}\text { TFP, externally } \\
\text { imputed* }\end{array}$ & $\begin{array}{c}\text { Externally } \\
\text { imputed TFP / } \\
\text { Labor } \\
\text { productivity* }\end{array}$ \\
\hline PRT & Portugal & 1,379 & 1,307 & $94.78 \%$ & 1,325 & $96.08 \%$ & 1,366 & $99.06 \%$ \\
\hline ITA & Italy & 238,158 & 193,966 & $81.44 \%$ & 200,756 & $84.30 \%$ & 227,529 & $95.54 \%$ \\
\hline FIN & Finland & 37,416 & 30,266 & $80.89 \%$ & 34,103 & $91.15 \%$ & 35,936 & $96.04 \%$ \\
\hline ESP & Spain & 395,132 & 315,485 & $79.84 \%$ & 351,440 & $88.94 \%$ & 373,323 & $94.48 \%$ \\
\hline SWE & Sweden & 126,632 & 98,442 & $77.74 \%$ & 111,199 & $87.81 \%$ & 119,189 & $94.12 \%$ \\
\hline DNK & Denmark & 885 & 617 & $69.72 \%$ & 1,686 & $190.51 \%$ & 1,761 & $198.98 \%$ \\
\hline FRA & France & 267,910 & 174,463 & $65.12 \%$ & 251,787 & $93.98 \%$ & 265,998 & $99.29 \%$ \\
\hline FBR & Great Britain & 57,764 & 35,405 & $61.29 \%$ & 58,153 & $100.67 \%$ & 61,650 & $106.73 \%$ \\
\hline POL & Poland & 15,056 & 8,181 & $54.34 \%$ & 10,874 & $72.22 \%$ & 10,999 & $73.05 \%$ \\
\hline KOR & Korea & 67,010 & 29,267 & $43.68 \%$ & 51,214 & $76.43 \%$ & 53,695 & $80.13 \%$ \\
\hline SVK & Slovak Republic & 2,320 & 1,008 & $43.45 \%$ & 2,053 & $88.49 \%$ & 2,187 & $94.27 \%$ \\
\hline CZE & Czech Republic & 21,242 & 6,583 & $30.99 \%$ & 16,122 & $75.90 \%$ & 18,064 & $85.04 \%$ \\
\hline JPN & Japan & 93,200 & 28,080 & $30.13 \%$ & 30,310 & $32.52 \%$ & 65,792 & $70.59 \%$ \\
\hline NOR & Norway & 66,526 & 17,388 & $26.14 \%$ & 19,389 & $29.14 \%$ & 57,027 & $85.72 \%$ \\
\hline IRL & Ireland & 114 & 28 & $24.56 \%$ & 24 & $21.05 \%$ & 47 & $41.23 \%$ \\
\hline BEL & Belgium & 42,332 & 8,057 & $19.03 \%$ & 94,179 & $222.48 \%$ & 95,354 & $225.25 \%$ \\
\hline AUS & Australia & 692 & 110 & $15.90 \%$ & 114 & $16.47 \%$ & 191 & $27.60 \%$ \\
\hline SVN & Slovenia & 6,199 & 905 & $14.60 \%$ & 3,559 & $57.41 \%$ & 3,619 & $58.38 \%$ \\
\hline CHE & Switzerland & 2,354 & 297 & $12.62 \%$ & 327 & $13.89 \%$ & 352 & $14.95 \%$ \\
\hline LUX & Luxembourg & 200 & 21 & $10.50 \%$ & 20 & $10.00 \%$ & 21 & $10.50 \%$ \\
\hline NZL & New Zealand & 14 & 1 & $7.14 \%$ & 2 & $14.29 \%$ & 12 & $85.71 \%$ \\
\hline DEU & Germany & 64,986 & 4,464 & $6.87 \%$ & 4,358 & $6.71 \%$ & 4,533 & $6.98 \%$ \\
\hline HUN & Hungary & 6,598 & 146 & $2.21 \%$ & 2,544 & $38.56 \%$ & 2,634 & $39.92 \%$ \\
\hline ISL & Iceland & 576 & 12 & $2.08 \%$ & 448 & $77.78 \%$ & 889 & $154.34 \%$ \\
\hline ISR & Israel & 52 & 1 & $1.92 \%$ & 1 & $1.92 \%$ & 40 & $76.92 \%$ \\
\hline NLD & Netherlands & 7,727 & 94 & $1.22 \%$ & 7,997 & $103.49 \%$ & 8,429 & $109.09 \%$ \\
\hline AUT & Austria & 9,139 & 79 & $0.86 \%$ & 78 & $0.85 \%$ & 81 & $0.89 \%$ \\
\hline TUR & Turkey & 872 & 4 & $0.46 \%$ & 4 & $0.46 \%$ & 22 & $2.52 \%$ \\
\hline EST & Estonia & 17,075 & 19 & $0.11 \%$ & 11,715 & $68.61 \%$ & 12,735 & $74.58 \%$ \\
\hline USA & United States & 19,606 & 1 & $0.01 \%$ & 2 & $0.01 \%$ & 3,115 & $15.89 \%$ \\
\hline CAN & Canada & 9,829 & - & $0.00 \%$ & - & $0.00 \%$ & 83 & $0.84 \%$ \\
\hline CHL & Chile & 21 & - & $0.00 \%$ & - & $0.00 \%$ & 8 & $38.10 \%$ \\
\hline GRC & Greece & 18,515 & - & $0.00 \%$ & - & $0.00 \%$ & 16,339 & $88.25 \%$ \\
\hline MEX & Mexico & 143 & - & $0.00 \%$ & - & $0.00 \%$ & 67 & $46.85 \%$ \\
\hline $\mathrm{BRA}$ & Brazil & 111 & 25 & $22.52 \%$ & 26 & $23.42 \%$ & 64 & $57.66 \%$ \\
\hline $\mathrm{CHN}$ & China & 149,185 & 60 & $0.04 \%$ & 61 & $0.04 \%$ & 385 & $0.26 \%$ \\
\hline IND & India & 310 & 2 & $0.65 \%$ & 2 & $0.65 \%$ & 2 & $0.65 \%$ \\
\hline RUS & Russia & 83 & - & $0.00 \%$ & - & $0.00 \%$ & - & $0.00 \%$ \\
\hline ZAF & South Africa & 203 & 36 & $17.73 \%$ & 34 & $16.75 \%$ & 40 & $19.70 \%$ \\
\hline Total (OECD) & & $1,597,674$ & 954,697 & $59.76 \%$ & $1,265,783$ & $79.23 \%$ & $1,443,087$ & $90.32 \%$ \\
\hline Mean (OECD) & & 46,990 & 28,079 & $28.22 \%$ & 37,229 & $54.77 \%$ & 42,444 & $73.29 \%$ \\
\hline Total (All) & & $1,747,566$ & 954,820 & $54.64 \%$ & $1,265,906$ & $72.44 \%$ & $1,443,578$ & $82.61 \%$ \\
\hline Mean (All) & & 44,809 & 24,483 & $25.66 \%$ & 32,459 & $48.79 \%$ & 37,015 & $65.90 \%$ \\
\hline
\end{tabular}

Note: Same as below Table E.1 
Table E.3: Correlation between levels and growth rates of value added: imputed vs. non-imputed values

ESP

\begin{tabular}{|c|c|c|c|c|c|c|}
\hline & \multicolumn{3}{|c|}{$\ln ($ Value added $)$} & \multicolumn{3}{|c|}{$\Delta \ln ($ Value added $)$} \\
\hline & 2002 & 2005 & 2008 & 2002 & 2005 & 2008 \\
\hline internal & 0.988 & 0.984 & 0.990 & 0.886 & 0.865 & 0.945 \\
\hline external & 0.928 & 0.927 & 0.922 & 0.626 & 0.639 & 0.713 \\
\hline ernal_refined & 0.960 & 0.960 & 0.960 & 0.672 & 0.698 & 0.752 \\
\hline
\end{tabular}

ITA

\begin{tabular}{rcccccccc} 
& \multicolumn{3}{c}{$\ln ($ Value added $)$} & & \multicolumn{3}{c}{$\Delta \ln ($ Value added $)$} \\
\cline { 2 - 4 } \cline { 3 - 4 } \cline { 6 - 8 } internal & 2002 & 2005 & 2008 & & 2002 & 2005 & 2008 \\
\cline { 2 - 4 } external & 0.979 & 0.989 & 0.987 & & 0.837 & 0.814 & 0.856 \\
external_refined & 0.949 & 0.954 & 0.913 & & 0.721 & 0.589 & 0.657 \\
& 0.978 & 0.953 & & 0.794 & 0.656 & 0.711 \\
\hline
\end{tabular}

GBR

\begin{tabular}{rccccccc} 
& \multicolumn{3}{c}{$\ln ($ Value added $)$} & & \multicolumn{3}{c}{$\Delta \ln ($ Value added $)$} \\
\cline { 2 - 4 } \cline { 6 - 8 } internal & 2002 & 2005 & 2008 & & 2002 & 2005 & 2008 \\
\cline { 2 - 4 } \cline { 6 - 8 } external & 0.986 & 0.982 & 0.982 & & 0.806 & 0.800 & 0.813 \\
external_refined & 0.940 & 0.941 & 0.937 & & 0.631 & 0.613 & 0.625 \\
& 0.969 & 0.970 & 0.966 & & 0.676 & 0.679 & 0.661 \\
\hline
\end{tabular}

FRA

\begin{tabular}{rccc} 
& \multicolumn{3}{c}{$\ln ($ Value added $)$} \\
\cline { 2 - 4 } internal & 2002 & 2005 & 2008 \\
\cline { 2 - 4 } external & 0.985 & 0.983 & 0.980 \\
refined & 0.946 & 0.940 & 0.930 \\
nal_refind & 0.970 & 0.966 & 0.958 \\
\hline
\end{tabular}

\begin{tabular}{ccc}
\multicolumn{3}{c}{$\Delta \ln ($ Value added $)$} \\
\hline 2002 & 2005 & 2008 \\
\hline 0.762 & 0.741 & 0.724 \\
0.557 & 0.530 & 0.499 \\
0.616 & 0.579 & 0.523 \\
\hline
\end{tabular}

DEU

$\ln ($ Value added $)$

\begin{tabular}{|c|c|c|c|c|c|c|}
\hline \multirow[t]{2}{*}{ DEU } & \multicolumn{3}{|c|}{$\ln ($ Value added $)$} & \multicolumn{3}{|c|}{$\Delta \ln ($ Value added $)$} \\
\hline & 2002 & 2005 & 2008 & 2002 & 2005 & 2008 \\
\hline internal & 0.968 & 0.974 & 0.971 & 0.724 & 0.736 & 0.776 \\
\hline external & 0.922 & 0.932 & 0.925 & 0.412 & 0.506 & 0.567 \\
\hline external_refined & 0.952 & 0.952 & 0.959 & 0.411 & 0.609 & 0.642 \\
\hline \multirow[t]{2}{*}{ Country average* } & \multicolumn{3}{|c|}{$\ln ($ Value added $)$} & \multicolumn{3}{|c|}{$\Delta \ln ($ Value added $)$} \\
\hline & 2002 & 2005 & 2008 & 2002 & 2005 & 2008 \\
\hline internal & 0.980 & 0.981 & 0.975 & 0.778 & 0.806 & 0.794 \\
\hline external & 0.925 & 0.922 & 0.914 & 0.578 & 0.598 & 0.595 \\
\hline external refined & 0.959 & 0.956 & 0.950 & 0.645 & 0.680 & 0.638 \\
\hline
\end{tabular}

* Unweighted average across all those countries where the non-imputed value added measure is available and the number of observations is at least 200 for the specific year. Internal, external and external refined refer to the type of imputations which are used to construct imputed value added measures (see equations 2.2-2.4 in Section 2.3). The numbers stay almost identical when the value added measures are regressed first on industry*year fixed effects and the residual variations are correlated. 
Table E.4: Industry Breakdowns by their NACE Codes and Descriptions

\begin{tabular}{|c|c|c|c|c|c|}
\hline \multicolumn{2}{|c|}{ 2-digit industires (nace2) } & \multicolumn{2}{|c|}{ 2-digit industry groups (nace2_groups) } & \multicolumn{2}{|c|}{ 1-letter industry-groups (nace1) } \\
\hline 15 & Food and beverages & $15 \_16$ & $\begin{array}{l}\text { FOOD , BEVERAGES AND } \\
\text { TOBACCO }\end{array}$ & $\overline{\mathrm{D}}$ & MANUFACTURING \\
\hline 16 & Tobacco & & & & \\
\hline 17 & Textiles & 17_19 & $\begin{array}{l}\text { TEXTILES, TEXTILE, LEATHER } \\
\text { AND FOOTWEAR }\end{array}$ & & \\
\hline 18 & $\begin{array}{l}\text { Wearing Apparel, Dressing And } \\
\text { Dying Of Fur }\end{array}$ & & & & \\
\hline 19 & Leather, leather and footwear & & & & \\
\hline 20 & $\begin{array}{l}\text { WOOD AND OF WOOD AND } \\
\text { CORK }\end{array}$ & 20 & $\begin{array}{l}\text { WOOD AND OF WOOD AND } \\
\text { CORK }\end{array}$ & & \\
\hline 21 & Pulp, paper and paper & $21 \_22$ & $\begin{array}{l}\text { PULP, PAPER, PAPER, } \\
\text { PRINTING AND PUBLISHING }\end{array}$ & & \\
\hline 22 & $\begin{array}{l}\text { Printing, publishing and } \\
\text { reproduction }\end{array}$ & & & & \\
\hline 23 & $\begin{array}{l}\text { Coke, refined petroleum and nuclear } \\
\text { fuel }\end{array}$ & $23 \_25$ & $\begin{array}{l}\text { CHEMICAL, RUBBER, } \\
\text { PLASTICS AND FUEL }\end{array}$ & & \\
\hline 24 & Chemicals and chemical & & & & \\
\hline 25 & Rubber and plastics & & & & \\
\hline 26 & OTHER NON-METALLIC & 26 & OTHER NON-METALLIC & & \\
\hline & MINERAL & & MINERAL & & \\
\hline 27 & Basic metals & 27_28 & BASIC METALS AND & & \\
\hline 28 & Fabricated metal & & 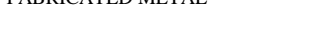 & & \\
\hline 29 & MACHINERY, NEC & 29 & MACHINERY, NEC & & \\
\hline 30 & $\begin{array}{l}\text { Office, accounting and computing } \\
\text { machinery }\end{array}$ & 30_33 & $\begin{array}{l}\text { ELECTRICAL AND OPTICAL } \\
\text { EQUIPMENT }\end{array}$ & & \\
\hline 31 & $\begin{array}{l}\text { Electrical machinery and apparatus, } \\
\text { nec }\end{array}$ & & & & \\
\hline 32 & $\begin{array}{l}\text { Radio, television and } \\
\text { communication equipment }\end{array}$ & & & & \\
\hline 33 & $\begin{array}{l}\text { Medical, precision and optical } \\
\text { instruments }\end{array}$ & & & & \\
\hline 34 & $\begin{array}{l}\text { Motor vehicles, trailers and semi- } \\
\text { trailers }\end{array}$ & 34_35 & TRANSPORT EQUIPMENT & & \\
\hline 35 & Other transport equipment & & & & \\
\hline 36 & Manufacturing nec & 36_37 & $\begin{array}{l}\text { MANUFACTURING NEC; } \\
\text { RECYCLING }\end{array}$ & & \\
\hline 37 & Recycling & & & & \\
\hline 40 & ELECTRICITY AND GAS & 40_41 & $\begin{array}{l}\text { ELECTRICITY, GAS AND } \\
\text { WATER SUPPLY }\end{array}$ & E & $\begin{array}{l}\text { ELECTRICITY, GAS AND } \\
\text { WATER SUPPLY }\end{array}$ \\
\hline 41 & WATER SUPPLY & & & & \\
\hline 45 & CONSTRUCTION & 45 & CONSTRUCTION & $\mathrm{F}$ & CONSTRUCTION \\
\hline 50 & $\begin{array}{l}\text { Sale, maintenance and repair of } \\
\text { motor vehicles and motorcycles; } \\
\text { retail sale of fuel }\end{array}$ & $50 \_52$ & $\begin{array}{l}\text { WHOLESALE AND RETAIL } \\
\text { TRADE }\end{array}$ & G & $\begin{array}{l}\text { WHOLESALE AND RETAIL } \\
\text { TRADE }\end{array}$ \\
\hline 51 & $\begin{array}{l}\text { Wholesale trade and commission } \\
\text { trade, except of motor vehicles and } \\
\text { motorcycles }\end{array}$ & & & & \\
\hline 52 & $\begin{array}{l}\text { Retail trade, except of motor } \\
\text { vehicles and motorcycles; repair of } \\
\text { household goods }\end{array}$ & & & & \\
\hline 55 & HOTELS AND RESTAURANTS & 55 & HOTELS AND RESTAURANTS & $\mathrm{H}$ & HOTELS AND RESTAURANTS \\
\hline 60 & Other Inland transport & $60 \_63$ & TRANSPORT AND STORAGE & I & $\begin{array}{l}\text { TRANSPORT AND STORAGE } \\
\text { AND COMMUNICATION }\end{array}$ \\
\hline 61 & Other Water transport & & & & \\
\hline 62 & Other Air transport & & & & \\
\hline 63 & $\begin{array}{l}\text { Other Supporting and auxiliary } \\
\text { transport activities; activities of } \\
\text { travel agencies }\end{array}$ & & & & \\
\hline 64 & $\begin{array}{l}\text { POST AND } \\
\text { TELECOMMUNICATIONS }\end{array}$ & 64 & $\begin{array}{l}\text { POST AND } \\
\text { TELECOMMUNICATIONS }\end{array}$ & & \\
\hline 65 & $\begin{array}{l}\text { Financial intermediation, except } \\
\text { insurance and pension funding }\end{array}$ & $65 \_67$ & FINANCIAL INTERMEDIATION & $\mathrm{J}$ & FINANCIAL INTERMEDIATION \\
\hline 66 & $\begin{array}{l}\text { Insurance and pension funding, } \\
\text { except compulsory social security }\end{array}$ & & & & \\
\hline 67 & $\begin{array}{l}\text { Activities related to financial } \\
\text { intermediation }\end{array}$ & & & & \\
\hline 70 & Real estate activities & 70_74 & $\begin{array}{l}\text { REAL ESTATE, RENTING AND } \\
\text { BUSINESS ACTIVITIES }\end{array}$ & K & $\begin{array}{l}\text { REAL ESTATE, RENTING AND } \\
\text { BUSINESS ACTIVITIES }\end{array}$ \\
\hline 71 & $\begin{array}{l}\text { Renting of machinery and } \\
\text { equipment }\end{array}$ & & & & \\
\hline 72 & Computer and related activities & & & & \\
\hline 73 & Research and development & & & & \\
\hline 74 & Other business activities & & & & \\
\hline
\end{tabular}

Note: The classification is based on NACE Rev 1.1. The middle column is based on the grouping used in the EU-KLEMS database O'Mahony and Timmer (2009). Since 2008, NACE Rev 2 has been introduced, and firms who started appearing in ORBIS after that were converted using conversion tables from NACE Rev 2 to NACE Rev 1.1, available from Eurostat at http://epp.eurostat.ec.europa.eu/portal/page/portal/nace_rev2/correspondence_tables. Firms appearing in the database before 2008 have their original NACE Rev 1.1 values stored and used throughout the paper and the resulting productivity database. 
Table E.5: The average of resampling weights by broad sectors (2005)*

\begin{tabular}{lrrrrrrr} 
& D & E & F & G-H & I & K & Average \\
\hline AUT & 38.8 & 8.9 & 177.5 & 81.5 & 38.8 & 115.3 & 79.0 \\
BEL & 1.4 & 1.0 & 1.3 & 1.5 & 1.1 & 2.4 & 1.6 \\
CZE & 3.4 & 1.6 & 4.8 & 4.3 & 2.4 & 5.1 & 4.2 \\
DEU & 30.3 & 5.1 & 105.7 & 54.1 & 27.2 & 56.3 & 46.6 \\
DNK & 3.3 & 18.5 & 3.9 & 2.8 & 1.8 & 3.7 & 3.3 \\
EST & 1.9 & 2.1 & 1.8 & 1.4 & 1.2 & 1.6 & 1.6 \\
ESP & 1.7 & 1.1 & 2.9 & 1.9 & 1.1 & 2.4 & 2.1 \\
FIN & 1.5 & 1.6 & 1.7 & 1.2 & 1.1 & 1.5 & 1.4 \\
FRA & 2.4 & 1.8 & 2.6 & 1.5 & 1.4 & 2.6 & 2.0 \\
GBR & 11.7 & 2.0 & 32.5 & 20.2 & 5.8 & 19.7 & 18.2 \\
FRC & 4.5 & 11.7 & 28.0 & 7.4 & 4.5 & 7.6 & 7.7 \\
HUN & 21.2 & 6.2 & 51.0 & 39.4 & 7.6 & 127.5 & 39.7 \\
ITA & 5.7 & 1.6 & 13.4 & 10.9 & 3.0 & 15.6 & 9.4 \\
JPN & 15.7 & & & & & & 15.7 \\
KOR & 11.9 & & & 13.8 & 8.0 & 7.8 & 11.7 \\
NLD & 27.4 & 5.0 & 42.2 & 35.3 & 11.7 & 60.3 & 40.8 \\
NOR & 50.7 & 110.5 & 56.2 & 41.8 & 30.0 & 35.7 & 41.7 \\
POL & 14.9 & 3.1 & 31.1 & 23.2 & 9.3 & 33.3 & 20.9 \\
PRT & 118.4 & 12.0 & 231.6 & 132.9 & 35.2 & 207.3 & 147.5 \\
SWE & 1.3 & 1.3 & 1.3 & 1.1 & 1.1 & 1.2 & 1.2 \\
SVN & 2.4 & 3.2 & 5.7 & 2.3 & 1.2 & 7.7 & 3.1 \\
SVK & 4.0 & 1.7 & 5.4 & 3.9 & 1.3 & 7.0 & 4.4 \\
USA & 683.0 & 86.8 & 5485.2 & 14123.5 & 5140.7 & 5340.1 & 5192.4 \\
\hline Average & 10.9 & 4.8 & 7.9 & 26.3 & 29.6 & 22.6 & 26.4
\end{tabular}

* The sectoral description can be found in Table E.4.

Note: Entries show the average of the constructed resampling weights for 2005, for the Solow-residual (using external imputations). For Korea and Japan, some industries and size classes are not in the SDBS database which are used for constructing the weights.

Table E.6: Rank Correlations across TFP measures based on Imputed and Non-Imputed variables Average over ESP, ITA, GBR, FRA, DEU

\begin{tabular}{|c|c|c|c|c|c|c|c|c|c|}
\hline \multicolumn{5}{|c|}{ Rank correlations for In(TFP) } & \multicolumn{5}{|c|}{ Rank correlations for TFP growth } \\
\hline TFP measures & Solow & Sup.In. & OLS & $\overline{\text { Wooldridge }}$ & TFP measures & Solow & Sup.In. & OLS & Wooldridge \\
\hline imputation types & & & & & imputation types & & & & \\
\hline internal & 0.97 & 0.92 & 0.95 & 0.94 & internal & 0.91 & 0.89 & 0.90 & 0.83 \\
\hline external & 0.83 & 0.66 & 0.69 & 0.75 & external & 0.69 & 0.64 & 0.64 & 0.56 \\
\hline external, refined & 0.89 & 0.74 & 0.81 & 0.80 & external, refined & 0.71 & 0.66 & 0.65 & 0.59 \\
\hline
\end{tabular}

Note: rank correlations are based for observations in the year 2008 for the non-farm business sector. TFP growth is defined as the first differences of $\ln (T F P)$. For Great Britain, non-imputed Wooldridge type estimates are not available due to the lack of the availability of proxies for intermediate inputs. For a description of the imputation types, see Section 2.3 . 


\section{F Structure of the Resulting ORBIS-TFP Database}

The data in the TFP-database uses the non-farm business sector (NACE Rev 1.1 codes 15-74) for the years 1993-2010, and is derived from filtering out accounts referring to less than complete calendar years and consolidated accounts, using flags prepared by the Statistics Directorate of the OECD (STD) (Gonnard and Ragoussis, 2013). Most countries and observations are in the period 1999-2009, the year 2010 is not complete in the June 2011 version of ORBIS. The number of observations for each country, year and imputation type, for the Superlative Index measure, are contained in the TFP_Sample.xlsx file in the root directory of the TFP database.

\section{F.1 The File Structure}

The database containing the productivity estimates and resampling weights is structured in the following way:

1. "core data", containing the most important productivity measures, using such an industry breakdown which is most appropriate (Directory: Core|Data)

- Index-number approaches (in parentheses the level of industry breakdown where the average factor shares are calculated)

- Solow-residuals with cross-country average labour shares (computed at the 2-digit industry level)

- two types of Superlative-index measures, using country-level means and cross-country means as reference values, (computed at the 2-digit industry level) ${ }^{52}$

- Estimation based approaches (in parentheses the level of industry breakdown where homogeneity of the production function parameters are assumed):

- OLS (2-digit industry groups)

- Wooldridge (2-digit industry groups)

2. "additional data", containing additional productivity measures (Directory: Additional|Data)

- Index-number approaches (in parentheses the level of industry breakdown where the average factor shares are calculated):

- Solow-residuals with country-level labour shares (computed at the 2-digit industry level)

- Superlative-index measures, using country-level means (at the 2-digit industry level) as reference firms

- Estimation based approaches (in parentheses the level of industry breakdown where homogeneity of the production function parameters are assumed):

- OLS (2-digit level)

- OLS with firm fixed effects (2-digit level, 2-digit industry groups)

- Levinsohn Petrin (2003) (2-digit level, 2-digit industry groups)

- Wooldridge (2-digit level)

3. labour productivity data, containing only turnover-based labour productivity measures, for the widest available set of firms.

\footnotetext{
${ }^{52}$ The measure using cross-country means as reference firms are stored only in the large, cross-country data files.
} 
As benchmark, labour productivity measures (revenue based and value added based) are also included in the core and additional databases.

The index number approaches assume homogeneity at the 2-digit level, but for estimation based approaches, it is more advisable to use a higher level of aggregation in order to have more observations when running the estimations country-by-country and industry-by-industry. Therefore, the classification in EU-KLEMS (Timmer et al., 2007) is used, where the non-farm business sector is classified into industrygroups by merging together some 2-digit industries (which typically have few firms) (see Table E.4 for details). The additional files contain estimates for the 2 digit level, but that comes at a cost of some countries with fewer firms in the database will have many industries missing due to a low number of observations to run the estimations.

Each of the estimations come with 4 types of imputations: (1) no imputation (2) internal imputation (i.e. using the alternative definition of value added as the sum of costs of capital and labour), (3) external imputations (4) external imputations using wage predictions (see Section 2.3).

All of the estimates are stored in country-by-country files. For the core estimates, large cross-country databases can also be found, containing all productivity numbers as in the country-by-country files, and in addition, also the Superlative index measures which use the cross-country, firm-level averages, for each industry, as the reference firm.

Furthermore, each estimations are constructed by using all firms with at least one employees and for the subsample of firms with at least 20 employees. The latter subsample has the advantage that the potentially weaker data quality of small firms does not influence the results, and also, the coverage of very small firms is usually weaker in most of the countries in ORBIS. Also, currencies are either converted to a common currency using industry-level PPP values from Timmer et al., 2007 or by using the 2005 average exchange rates between local currencies and the euro. For analysing developments in industries which are prone to strong international competition (typically manufacturing), the latter approach may be more preferable, as the first approach uses industry PPP numbers which refer to $1997 .{ }^{53}$

Reflecting all of these possibilities, the structure of the file names is the following:

$$
\begin{gathered}
<\text { 2-letter country code }>\text { _MinSize__minimum of mean employment }>\ldots \\
<\text { conversion type }>\_<\text {date of creating the file }>\text {.dta }
\end{gathered}
$$

- where the set of countries included in the database is marked in Table 5. Also, large cross-country files are created in the core database, with their first characters being cross_co. Only these files contain Superlative Index measures with world averages, and they also contain other measures which are included in the country-by-country files.

- minimum of mean employment can take values:

- 0: no restriction, except the essential one that at least 1 employees are needed for each firm

- 20: the minimum of mean employment, for each firm, over its observed lifetime, should be at least 20

- conversion type can take values:

- euro_2005: for using 2005 average market exchange rates between euro and local currencies

\footnotetext{
${ }^{53}$ There is no more up to date data available, to the best of our knowledge. I am grateful for Colin Webb for providing information on this.
} 
- PPP97_chained: for using the ICOP industry-level PPP values (Timmer et al., 2007) in 1997 and using local currency price indices over time to get to actual values for the sample period 1999-2009

- date of creating the file is 01May2012.

Normally, one would prefer to use the files with no employment restrictions and which uses the PPP conversions. However, if the question at hand may be sensitive to cross-country level comparisons, as a robustness check, the euro_2005 versions can also be used. Also, if one wants to focus only on firms with probably better quality of data (more than 20 employees), then that sample can be used (which is also much smaller hence estimations run much faster).

Besides the Stata data files with the productivity estimates, the database contains also small Stata files containing the coefficient values, standard errors and number of observations used for the estimation, for each industry where the estimation is run. They are located in the directories Core|Coefficients or Additional $\mid$ Coefficients and have the following file format:

$<2$-letter country code $\rangle_{\_}<$conversion type $\rangle_{\_}<$minimum of mean employment $>$_ estimation type $>$_... $<$ industry breakdown level $>$ _ imputation type $>$ < date of creating the file $>$.dta,

- estimation type can take values of $O L S, W$ (stands for Wooldridge) (in the core database), OLS_FE, LevPet (only in the additional database)

- industry breakdown level can take values of nace2_groups (estimations run for each 2-digi industry group, shown in Table E.4) and nace2 (estimations run for each 2-digit industries - carries the risk of unreliable / impossible estimation for certain industries in countries with low number of observations)

- imputation type can take values of 1 (no imputations used), 2 (only internal imputations used), 3 (only external imputations are used), 4 (only refined external imputations are used). For a description on imputations, see Table 2 and Section 2.3 in the main text.

and the other dimensions are the same as for the file names containing the estimates.

Finally, detailed estimation outputs are collected in the log files with the following formats:

$$
\begin{aligned}
& \mathrm{TFP} \text { _estim_<2-letter country code }>\text { _date of creating the file }>\text {.txt } \\
& \mathrm{TFP} \_ \text {stats_<2-letter country code }>\text { _ }<\text { date of creating the file }>\text {.txt, }
\end{aligned}
$$

where the former contains detailed estimation outputs for each round of estimations, and the latter contains descriptive statistics which compares different productivity measures along several dimensions. The tables in this document (Tables 6,9) are prepared using these outputs.

\section{F.2 Variables in the Productivity Data Files}

The content of the data files (the .dta files under Core|Data and Additional|Data) is summarized in Table F.1. Note that the estimation based measures are residuals of the estimated production functions, and estimations are run only if the number of observations is at least 50 for the given country and industry. In other cases, the estimation is not carried out and the productivity variable is empty for the particular country and industry. Furthermore, if either labour or capital coefficients are non-positive, the productivity numbers are missing. The number of such cases is negligible for countries with a reasonable 
number of observations (i.e. at least around 10,000). Minimizing the number of cases in as many countries as possible is the main motivation for recommending 2-digit industry group breakdowns for the estimation based approaches and including those in the core data set. 
Table F.1: Variables in the ORBIS Productivity Database

\begin{tabular}{|c|c|c|}
\hline & Variable name & Description \\
\hline \multirow[t]{6}{*}{ Identifiers } & COUNTRY_CODE & 2-letter country code \\
\hline & OECD_ID & Unique firm id constructed by STD \\
\hline & $Y E A R$ & Year \\
\hline & nace 2 & 2-digit NACE Rev 1.1 industry code \\
\hline & nace2_groups & 2-digit NACE Rev 1.1 industry groups, based on EU-KLEMS groupings \\
\hline & sector & 1-letter NACE Rev 1.1 \\
\hline \multirow{12}{*}{$\begin{array}{l}\text { Economic } \\
\text { variables for } \\
\text { the } \\
\text { productivity } \\
\text { calculations }\end{array}$} & OPERATING_REV_TURNOVER & Revenues or turnover \\
\hline & EMPLOYEES & Number of employees \\
\hline & orig_ADDED_VALUE & Original value added (as given in OECD-ORBIS) \\
\hline & $A D D E D \_V A L U E \_2$ & $\begin{array}{l}\text { Added value, imputed using the definition as the sum of labour (orig_COSTS_EMPLOYEES) and } \\
\text { capital income (EBITDA) (internal imputation) }\end{array}$ \\
\hline & $A D D E D \_V A L U E \_3$ & Added value, imputed using the definition as for ADDED_VALUE_2 but using \\
\hline & & $\begin{array}{l}\text { COSTS_EMPLOYEES_3 (average wages from OECD STAN at the 2-digit level; external } \\
\text { imputation) }\end{array}$ \\
\hline & $A D D E D \_V A L U E \_4$ & $\begin{array}{l}\text { Added value, imputed using external average wages at the 2-digit level and predictors of wage- } \\
\text { differences }\end{array}$ \\
\hline & orig_COSTS_EMPLOYEES & Total labour costs (as given in OECD-ORBIS) \\
\hline & COSTS_EMPLOYEES_3 & Total labour costs, imputed using external average wages at the 2-digit level \\
\hline & COSTS_EMPLOYEES_4 & $\begin{array}{l}\text { Total labour costs, imputed using external average wages at the 2-digit level and predictors of wage- } \\
\text { differences }\end{array}$ \\
\hline & lCAPITAL & Log of real tangible capital (constructed using the PIM-method) \\
\hline & $V A L P$ & value added deflator (at the 2-digit NACE Rev 1.1 level) from OECD STAN \\
\hline \multirow{5}{*}{$\begin{array}{l}\text { Productivity } \\
\text { variables* }\end{array}$} & $L P \_V A \_l$ & Labour productivity, using value added and no imputations \\
\hline & $L P_{-} T R$ & Labour productivity, using turnover \\
\hline & $L P \_V A \_2$ & Labour productivity, using value added with internal imputations \\
\hline & $L P \_V A_{-} 3$ & Labour productivity, using value added with external imputations \\
\hline & $L P \_V A \_4$ & Labour productivity, using value added with external imputations and wage-differential predictions \\
\hline \multirow[t]{8}{*}{$\begin{array}{l}\text { Only in the } \\
\text { Core database }\end{array}$} & TFP_nace2_Solow_CO_l & $\begin{array}{l}\text { Total factor productivity (TFP), obtained as a Solow-residual, using 2-digit NACE Rev 1.1, country } \\
\text { level labour cost shares from OECD STAN, with no imputations }\end{array}$ \\
\hline & $T F P \_n a c e 2 \_S o l o w \_W_{-} I$ & $\begin{array}{l}\text { TFP, obtained as a Solow-residual, using 2-digit NACE Rev 1.1, cross-country average labour cost } \\
\text { shares from OECD STAN, with no imputations }\end{array}$ \\
\hline & TFP_nace2_SupIn_CO_I & $\begin{array}{l}\text { TFP, Superlative-index measure, using } 2 \text {-digit NACE Rev 1.1, country level averages as reference } \\
\text { values, with no imputations }\end{array}$ \\
\hline & TFP_nace2_groups_OLS_I & TFP, OLS, using 2-digit industry groups, no imputations \\
\hline & TFP_nace2_groups_W_1 & TFP, Wooldridge (2009), using 2-digit industry groups, no imputations \\
\hline & TFP_nace2_Solow_CO_2 & The same as above but with internal imputations \\
\hline & $\begin{array}{l}T F P \_n a c e 2 \_S o l o w \_C O \_3 \\
\cdots\end{array}$ & The same as above but with external imputations \\
\hline & $\begin{array}{l}\text { TFP_nace2_Solow_CO_4 } \\
\ldots\end{array}$ & The same as above but with refined external imputations \\
\hline $\begin{array}{l}\text { Only in the } \\
\text { Core, cross }\end{array}$ & TFP_nace2_SupIn_W_1_O & $\begin{array}{l}\text { TFP, Superlative-index measure, using 2-digit NACE Rev 1.1, cross-country average levels as } \\
\text { reference values, with no imputations }\end{array}$ \\
\hline
\end{tabular}
reference values, with no imputations, resampling weights applied already at the stage of constructing the Superlative Index

The same as above, for all types of imputations

\begin{tabular}{|c|c|c|}
\hline \multirow{12}{*}{$\begin{array}{l}\text { Only in the } \\
\text { Additional } \\
\text { database }\end{array}$} & TFP_nace2_groups_Solow_CO_I & $\begin{array}{l}\text { Total factor productivity (TFP), obtained as a Solow-residual, using 2-digit NACE Rev 1.1, country } \\
\text { level labour cost shares from OECD STAN, with no imputations }\end{array}$ \\
\hline & TFP_nace2_groups_Solow_W_1 & $\begin{array}{l}\text { TFP, obtained as a Solow-residual, using 2-digit industry groups, cross-country average labour cost } \\
\text { shares from OECD STAN, with no imputations }\end{array}$ \\
\hline & $T F P \_n a c e 2 \_g r o u p s \_S u p I n \_C O \_l$ & $\begin{array}{l}\text { TFP, Superlative-index measure, using 2-digit industry groups, country level averages as reference } \\
\text { values, with no imputations }\end{array}$ \\
\hline & $T F P \_n a c e 2 \_O L S \_l$ & TFP, OLS, using 2-digit industries, no imputations \\
\hline & $T F P \_n a c e 2 \_W \_l$ & TFP, Wooldridge (2009, using 2-digit industries, no imputations \\
\hline & $T F P \_n a c e 2 \_O L S \_F E \_l$ & TFP, OLS with firm fixed effects, using 2-digit industries, no imputations \\
\hline & $T F P \_n a c e 2 \_g r o u p s \_O L S \_F E \_1$ & TFP, OLS with firm fixed effects, using 2-digit industry groups, no imputations \\
\hline & TFP_nace2_LevPet_l & TFP, Levinsohn-Petrin (2003), with firm fixed effects, using 2-digit industries, no imputations \\
\hline & TFP_nace2_groups_LevPet_l & TFP, Levinsohn-Petrin (2003), with firm fixed effects, using 2-digit industry groups, no imputations \\
\hline & TFP_nace2_groups_Solow_CO_2 & The same as above but with internal imputations \\
\hline & TFP_nace2_groups_Solow_CO_3 & The same as above but with external imputations \\
\hline & $\overline{T F P \_n a c e} 2_{-}$ & \\
\hline
\end{tabular}

* All productivity variables have a corresponding variable with the same name but with a "w_" prefix, which contain resampling weights appropriate for the specific productivity variable. Each productivity measure is calculated and stored in logs. 


\section{F.3 Auxiliary Data}

In a separate directory (Auxiliary), further external information is stored which are used during the calculations:

- Conversion tables between NACE Rev 2 to NACE Rev 1.1

- Price indices and average labour costs (country*industry*year) from OECD STAN (see Section B)

- The industry-level ICOP PPP database (See Timmer et al., 2007)

- Employment (country*industry* ${ }^{*}$ sizeclass*year) from SDBS, and its filled-up version (see Section $2.4)$

- RegImpact variable (country*industry*year), provided by the Economics Department of the OECD 


\section{References}

Ackerberg, Daniel A., Kevin Caves, and Garth Frazer (2006) "Structural Identification of Production Functions," mimeo.

Andrews, Dan and Federico Cingano (2012) "Public Policy and Resource Allocation: Evidence from Firms in OECD Countries," OECD Economics Department Working Papers 996, OECD Publishing.

Andrews, Dan and Chiara Criscuolo (2013) "Knowledge-Based Capital, Innovation And Resource Allocation," ECO/CPE/WP1(2013)5/ANN3.

Andrews, Dan, Chiara Criscuolo, and Carlo Menon (2013) "Do Resources Flow To Innovative Firms? Cross-Country Evidence From Firm-Level Data," ECO/CPE/WP1(2013)5/ANN3.

Arnold, Jens Matthias, Giuseppe Nicoletti, and Stefano Scarpetta (2008) "Regulation, Allocative Efficiency and Productivity in OECD Countries: Industry and Firm-Level Evidence," OECD Economics Department Working Papers 616, OECD Publishing.

Bartelsman, Eric, Pieter Gautier, and Joris De Wind (2010) "Employment Protection, Technology Choice, and Worker Allocation," IZA Discussion Papers 4895, Institute for the Study of Labor (IZA).

Bartelsman, Eric, John Haltiwanger, and Stefano Scarpetta (2009) "Measuring and Analyzing Crosscountry Differences in Firm Dynamics," in Producer Dynamics: New Evidence from Micro Data: National Bureau of Economic Research, Inc, pp. 15-76.

Bartelsman, Eric J. and Mark Doms (2000) "Understanding Productivity: Lessons from Longitudinal Microdata," Journal of Economic Literature, Vol. 38, No. 3, pp. 569-594.

Bartelsman, Eric J., John C. Haltiwanger, and Stefano Scarpetta (2009) "Cross-Country Differences in Productivity: The Role of Allocation and Selection," Working Paper 15490, National Bureau of Economic Research.

Bartelsman, Eric J, Jonathan Haskel, and Ralf Martin (2008) "Distance to Which Frontier? Evidence on Productivity Convergence from International Firm-level Data," CEPR Discussion Papers 7032, C.E.P.R. Discussion Papers.

Bartelsman, Eric, Stefano Scarpetta, and Fabiano Schivardi (2003) "Comparative Analysis of Firm Demographics and Survival: Micro-Level Evidence for the OECD Countries," OECD Economics Department Working Papers 348, OECD Publishing.

(2005) "Comparative analysis of firm demographics and survival: evidence from micro-level sources in OECD countries," Industrial and Corporate Change, Vol. 14, No. 3, pp. 365-391.

Biesebroeck, Johannes Van (2007) "Robustness of Productivity Estimates," Journal of Industrial Economics, Vol. 55, No. 3, pp. 529-569.

Biosca, Bravo, Chiara Criscuolo, and Carlo Menon (2012) "What Drives the Dynamics of Business Growth?" Forthcoming OECD Working Paper DSTI/IND(2012)7, OECD.

Bourlès, Renaud, Gilbert Cette, Jimmy Lopez, Jacques Mairesse, and Giuseppe Nicoletti (2010) "Do Product Market Regulations in Upstream Sectors Curb Productivity Growth? Panel Data Evidence for OECD Countries," NBER Working Papers 16520, National Bureau of Economic Research, Inc. 
Brown, Charles and James Medoff (1989) "The Employer Size-Wage Effect," Journal of Political Economy, Vol. 97, No. 5, pp. 1027-59.

Caves, Douglas W, Laurits R Christensen, and W Erwin Diewert (1982) "The Economic Theory of Index Numbers and the Measurement of Input, Output, and Productivity," Econometrica, Vol. 50, No. 6, pp. 1393-1414.

Conway, Paul and Giuseppe Nicoletti (2006) "Product Market Regulation in the Non-Manufacturing Sectors of OECD Countries: Measurement and Highlights," OECD Economics Department Working Papers 530, OECD Publishing.

Foster, Lucia, John C. Haltiwanger, and C. J. Krizan (2001) "Aggregate Productivity Growth. Lessons from Microeconomic Evidence," in New Developments in Productivity Analysis: National Bureau of Economic Research, Inc, pp. 303-372.

Gabaix, Xavier (2011) "The Granular Origins of Aggregate Fluctuations," Econometrica, Vol. 79, No. 3, pp. $733-772$.

Gonnard, Eric and Alexandros Ragoussis (2013) "The OECD-ORBIS database treatment and benchmarking procedures," forthcoming oecd working paper, OECD.

Griffith, Rachel, Stephen Redding, and John Van Reenen (2004) "Mapping the Two Faces of R\&D: Productivity Growth in a Panel of OECD Industries," The Review of Economics and Statistics, Vol. 86, No. 4, pp. 883-895.

Griffith, Rachel, Stephen Redding, and Helen Simpson (2009) "Technological Catch-Up And Geographic Proximity," Journal of Regional Science, Vol. 49, No. 4, pp. 689-720.

Hamermesh, Daniel S. and Gerard A. Pfann (1996) "Adjustment Costs in Factor Demand," Journal of Economic Literature, Vol. 34, No. 3, pp. 1264-1292.

Hsieh, Chang-Tai and Peter J. Klenow (2009) "Misallocation and Manufacturing TFP in China and India," The Quarterly Journal of Economics, Vol. 124, No. 4, pp. 1403-1448.

Hulten, Charles R. (2001) "Total Factor Productivity. A Short Biography," in New Developments in Productivity Analysis: National Bureau of Economic Research, Inc, pp. 1-54.

Idson, Todd L. and Walter Y. Oi (1999) "Workers Are More Productive in Large Firms," American Economic Review, Vol. 89, No. 2, pp. 104-108.

Klapper, Leora, Luc Laeven, and Raghuram Rajan (2006) "Entry regulation as a barrier to entrepreneurship," Journal of Financial Economics, Vol. 82, No. 3, pp. 591-629.

Levinsohn, James and Amil Petrin (2003) "Estimating Production Functions Using Inputs to Control for Unobservables," Review of Economic Studies, Vol. 70, No. 2, pp. 317-341.

Nicoletti, Giuseppe and Stefano Scarpetta (2003) "Regulation, productivity and growth: OECD evidence," Economic Policy, Vol. 18, No. 36, pp. 9-72.

OECD (2001) "Measuring Productivity, OECD Manual,"Technical report, Paris: Organisation for Economic Co-operation and Development.

Oi, Walter Y. and Todd L. Idson (1999) "Firm size and wages," in O. Ashenfelter and D. Card eds. Handbook of Labor Economics, Vol. 3 of Handbook of Labor Economics: Elsevier, Chap. 33, pp. 21652214 . 
Olley, G. Steven and Ariel Pakes (1996) "The Dynamics of Productivity in the Telecommunications Equipment Industry," Econometrica, Vol. 64, No. 6, pp. pp. 1263-1297.

O'Mahony, Mary and Marcel P. Timmer (2009) "Output, Input and Productivity Measures at the Industry Level: The EU KLEMS Database," Economic Journal, Vol. 119, No. 538, pp. F374-F403.

Pilat, Dirk (1996) "Labour Productivity Levels in OECD Countries: Estimates for Manufacturing and Selected Service Sectors," OECD Economics Department Working Papers 169, OECD Publishing.

Schwellnus, Cyrille and Jens Arnold (2008) "Do Corporate Taxes Reduce Productivity and Investment at the Firm Level?: Cross-Country Evidence from the Amadeus Dataset," OECD Economics Department Working Papers 641, OECD Publishing.

Sivadasan, Jagadeesh (2009) "Barriers to Competition and Productivity: Evidence from India," The B.E. Journal of Economic Analysis \& Policy, Vol. 9, No. 1, p. 42.

Syverson, Chad (2004) "Product Substitutability and Productivity Dispersion," The Review of Economics and Statistics, Vol. 86, No. 2, pp. 534-550.

(2011) "What Determines Productivity?" Journal of Economic Literature, Vol. 49, No. 2, pp. 326-65.

Timmer, Marcel, Gerard Ypma, and Bart van van Ark (2007) "PPPs for Industry Output: A New Dataset for International Comparisons," GGDC Research Memorandum GD-82, Groningen Growth and Development Centre, University of Groningen.

Venn, Danielle (2009) "Legislation, Collective Bargaining and Enforcement: Updating the OECD Employment Protection Indicators," OECD Social, Employment and Migration Working Papers 89, OECD Publishing.

Wooldridge, Jeffrey M. (2009) "On estimating firm-level production functions using proxy variables to control for unobservables," Economics Letters, Vol. 104, No. 3, pp. 112-114. 


\section{WORKING PAPERS}

The full series of Economics Department Working Papers can be consulted at www.oecd.org/eco/workingpapers/

1048. A projection method for public health and long-term care expenditures by Christine de la Maisonneuve and Joaquim Oliveira Martins (forthcoming)

1047. R\&D, patenting and growth: the role of public policy (May 2013) by Ben Westmore

1046. Knowledge-based capital, innovation and resource allocation by Dan Andrews and Chiara Criscuolo (forthcoming)

1045. Reforms for a Cleaner, Healthier Environment in China (April 2013) by Sam Hill

1044. Making the tax system less distortive in Switzerland (April 2013) by Andrés Fuentes

1043. The determinants of informality in Mexico's states (April 2013) by Sean M. Dougherty and Octavio Escobar

1042. Legal reform, contract enforcement and firm size in Mexico (April 2013) by Sean M. Dougherty

1041. Improving the economic situation of young people in France (April 2013) by Hervé Boulhol Améliorer la situation économique des jeunes en France (avril 2013) par Hervé Boulhol

1040. Improving employment prospects for young workers in Spain (April 2013) by Anita Wölfl

1039. Youth labour market performance in Spain and its determinants - a micro-level perspective (April 2013) by Juan J. Dolado, Marcel Jansen, Florentino Felgueroso, Andres Fuentes and Anita Wölfl

1038. The efficiency and equity of the tax and transfer system in France (April 2013) by Balázs Égert Efficacité et équité du système de prélèvements et de transferts en France (avril 2013) par Balázs Égert

1037. Income inequality and poverty in Colombia. Part 2. The redistributive impact of taxes and transfers (April 2013) by Isabelle Joumard and Juliana Londoño Vélez

1036. Income inequality and poverty in Colombia. Part 1. The role of the labour market (April 2013) by Isabelle Joumard and Juliana Londoño Vélez

1035. Policy options to durably resolve euro area imbalances (March 2013) by Yvan Guillemette and Dave Turner 
1034. Labour market, welfare reform and inequality in the United Kingdom

(March 2013) by Christophe André, Clara Garcia, Giulia Giupponi and Jon Kristian Pareliussen

1033. Work incentives and Universal Credit - reform of the benefit system in the United Kingdom (March 2013) by Jon Kristian Pareliussen

1032. Strengthening social cohesion in Luxembourg: making efficiency and equity go hand in hand (March 2013) by Jean-Marc Fournier and Clara Garcia

1031. The price of oil - Will it start rising again?

(March 2013) by Jean-Marc Fournier, Isabell Koske, Isabelle Wanner and Vera Zipperer

1030. The system of revenue sharing and fiscal transfers in China

(February 2013) by Xiao Wang and Richard Herd

1029. The declining competitiveness of French firms reflects a generalised supply-side problem (February 2013) by Hervé Boulhol and Patrizio Sicari

1028. Do the overall level and dispersion of socio-economic background measures explain France's gap in PISA scores?

(February 2013 by Hervé Boulhol and Patrizio Sicari

1027. Labour market performance by age groups: a focus on France

(February 2013) by Hervé Boulhol and Patrizio Sicari

1026. Moving towards a single labour contract: pros, cons and mixed feelings

(February 2013) by Nicolas Lepage-Saucier, Juliette Schleich and Etienne Wasmer

1025. Boosting productivity in Australia

(January 2013) by Vassiliki Koutsogeorgopoulou and Omar Barbiero

1024. Housing, financial and capital taxation policies to ensure robust growth in Sweden (January 2013) by Müge Adalet McGowan

1023. Labour market and social policies to foster more inclusive growth in Sweden (January 2013) by Stéphanie Jamet, Thomas Chalaux and Vincent Koen

1022. Educational attainment and labour market outcomes in South Africa, 1994-2010 (January 2013) by Nicola Branson and Murray Leibbrandt

1021. Education quality and labour market outcomes in South Africa

(January 2013) by Nicola Branson and Murray Leibbrandt

1020. Do policies that reduce unemployment raise its volatility? Evidence from OECD countries (January 2013) by Alain de Serres and Fabrice Murtin

1019. Slovakia: A catching up euro area member in and out of the crisis (January 2013) by Jarko Fidrmuc, Caroline Klein, Robert Price and Andreas Wörgötter 